\title{
Biodiversity and Development Co-operation
}

Anna Drutschinin, Juan Casado-Asensio, Jan Corfee-Morlot, OECD Development Co-operation Directorate, and Dilys Roe, International Institute for Environment and Development (IIED)

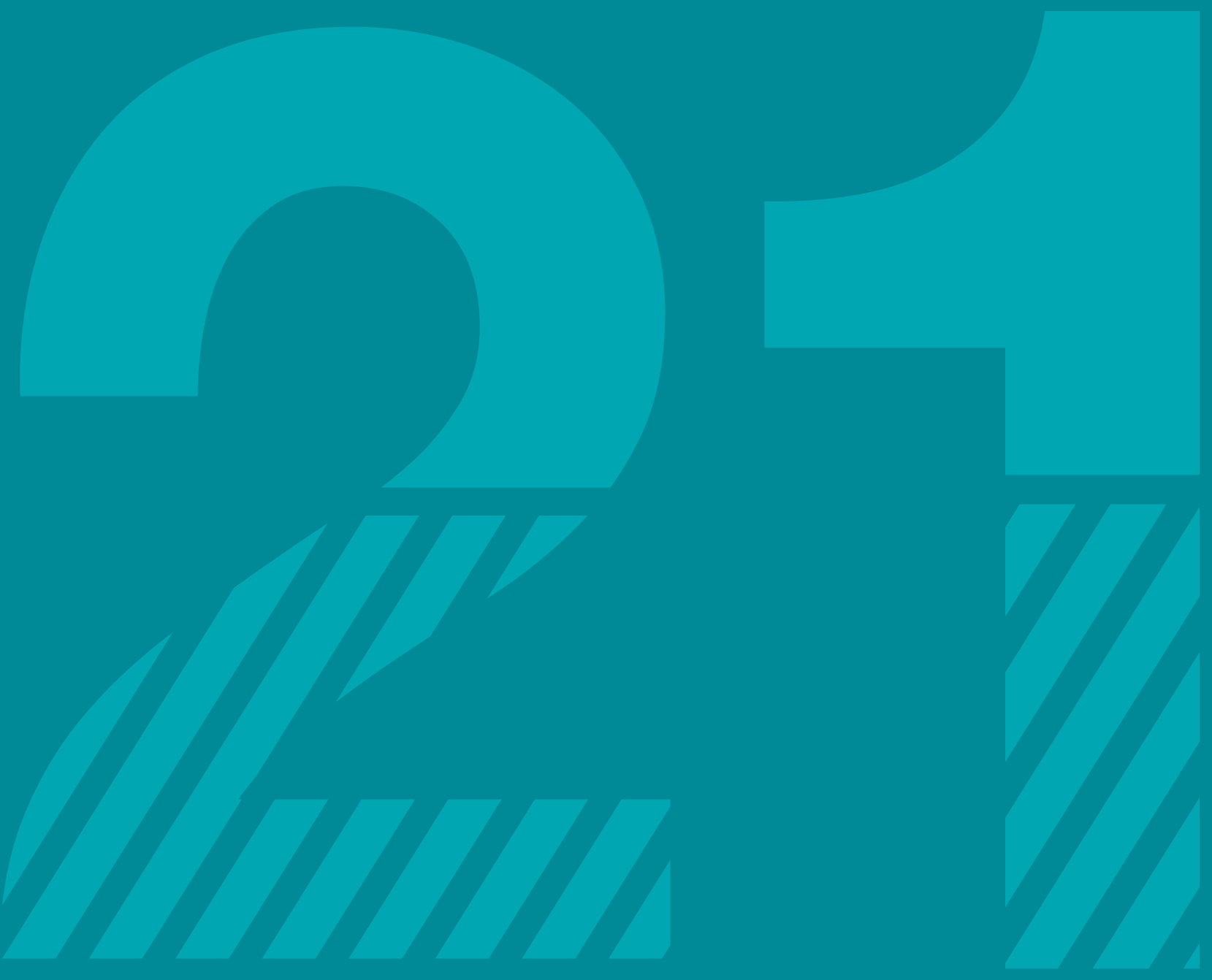

OECD DEVELOPMENT CO-OPERATION WORKING PAPER 21

Authorised for publication by Jon Lomoy, Director, Development Co-operation Directorate 


\section{OECD Development Co-operation Working Papers}

OECD Working Papers should not be reported as representing the official views of the OECD or of its member countries. The opinions expressed and arguments employed are those of the authors.

Working Papers describe preliminary results or research in progress by the author(s) and are published to stimulate discussion on a broad range of issues on which the OECD works. Comments on the present Working Paper are welcomed and may be sent to Jan.CorfeeMorlot@oecd.org - the Development Co-operation Directorate, OECD, 2 rue André-Pascal, 75775 Paris Cedex 16, France.

This document and any map included herein are without prejudice to the status of or sovereignty over any territory, to the delimitation of international frontiers and boundaries and to the name of any territory, city or area.

You can copy, download or print OECD content for your own use, and you can include excerpts from OECD publications, databases and multimedia products in your own documents, presentations, blogs, websites and teaching materials, provided that suitable acknowledgement of OECD as source and copyright owner is given. All requests for public or commercial use and translation rights should be submitted to rights@oecd.org.

COPYRIGHT @ OECD 2015 


\section{BIODIVERSITY AND DEVELOPMENT CO-OPERATION}

Anna Drutschinin, Juan Casado-Asensio, Jan Corfee-Morlot, Dilys Roe ${ }^{1}$

\section{ABSTRACT}

This paper considers how development co-operation is addressing the twin objectives of biodiversity conservation and sustainable use on the one hand, and development and poverty reduction on the other. It outlines how development co-operation can a) support mainstreaming biodiversity and ecosystem services into development; b) manage for results, particularly across trade-offs and synergies; c) incorporate monitoring and evaluating approaches into biodiversityrelated development co-operation activities; and d) better align and harmonise providers' activities with partner country priorities. The paper showcases examples of how development cooperation is supporting conservation and sustainable use of biodiversity and ecosystem services. It also identifies areas where more research is needed, such as sharing experience with the tools and good practices available for successful mainstreaming, and developing indicators to improve monitoring and evaluation to boost understanding of the effectiveness of biodiversity-related development interventions and of the relative performance of different mainstreaming approaches.

\section{ACKNOWLEDGEMENTS}

This working paper is a first product from a scoping phase of work on biodiversity and development policy carried out by the Development Assistance Committee (DAC) Environment and Development Network (ENVIRONET). It provides a starting point for future joint work on biodiversity and development by the OECD DAC and Environment Policy Committee. The paper has benefitted from discussion, guidance and oversight from ENVIRONET. In particular, it draws on the in-kind contributions and inputs received from the following "Friends of Biodiversity" ENVIRONET partners: Elisabeth Soetz (Austria), Luc Janssens de Bisthoven (Belgium), Arnold Jacques-De-Dixmude (European Union), Emmanuelle Swynghedauw (France), Anders Ekbom and Karin Isaksson (Sweden), Alice Ruhweza (United Nations Development Programme) and Ersin Esen (United Nations Environment Programme). Helpful comments were also received from the African Leadership Group on Mainstreaming Biodiversity and Development, including representatives from the governments of Botswana, Liberia, Malawi, Namibia, Seychelles, South Africa, Uganda, Zimbabwe; Renaud Lapeyre (Institute for Sustainable Development and International Relations); Steve Bass (International Institute for Environment and Development), Markus Lehmann and Nadine Saad (Secretariat of the Convention on Biological Diversity), and Jamison Ervin, David Meyers (United Nations Development Programme). Finally the authors would like to acknowledge review and comments received from OECD secretariat colleagues: Katia Karousakis and Christina Van Winkle (Environment Directorate) and Megan KennedyChouane (Development Co-operation Directorate).

1. Anna Drutschinin and Juan Casado-Asensio are Policy Analysts in the OECD Development Co-operation Directorate's Environment and Development team, and Jan Corfee-Morlot is the Team Leader and Senior Policy Analyst. Dilys Roe is Principal Researcher in the Natural Resources Group and Team Leader on Biodiversity at the International Institute for Environment and Development (IIED). 


\section{TABLE OF CONTENTS}

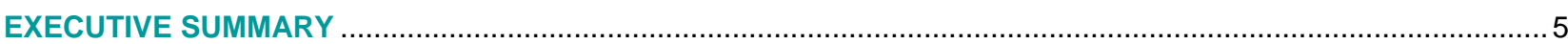

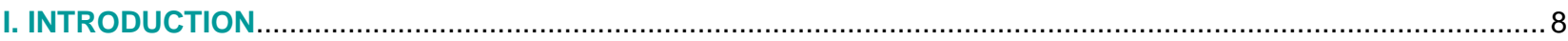

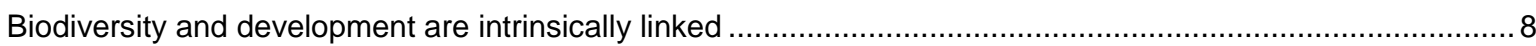

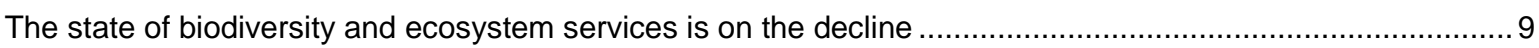

The CBD and the SDGs encourage countries to address biodiversity and development together .................... 11

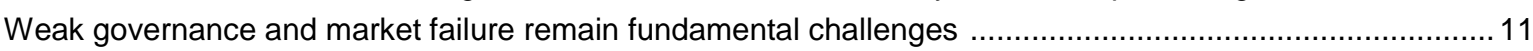

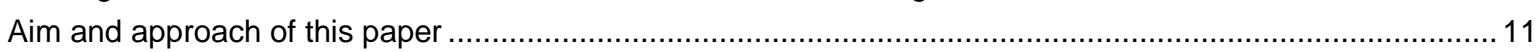

II. MAINSTREAMING BIODIVERSITY AND ECOSYSTEM SERVICES INTO DEVELOPMENT CO-OPERATION.....13

Mainstreaming is essential to maximise positive biodiversity and development outcomes .............................13

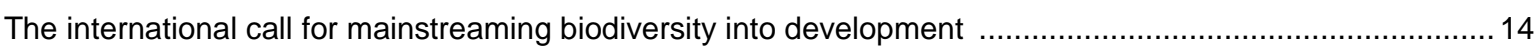

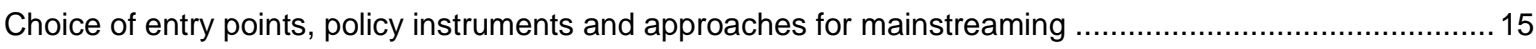

Despite progress, mainstreaming remains a challenge in partner countries ............................................... 19

Development co-operation provides essential financial and technical assistance in partner countries..............19

Good practice notions for supporting mainstreaming in partner countries .................................................. 20

Providers are mainstreaming biodiversity and ecosystem services into their own practices ............................21

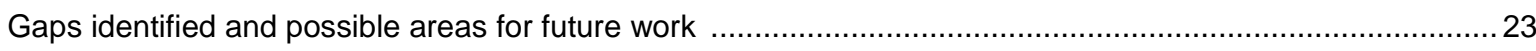

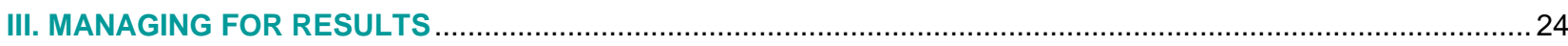

Setting clear, measurable objectives is essential to effectively manage for results ……...............................2

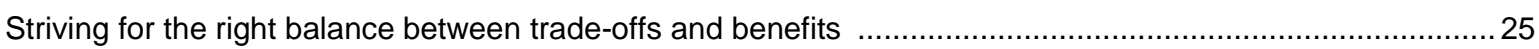

A wealth of tools exist to identify and manage trade-offs and synergies ................................................... 26

Good governance, engagement and management principles to address trade-offs and maximise benefits ....29

Build strong governance, institutions and legal frameworks ……............................................... 29

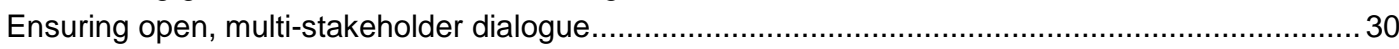

Compensating communities that are negatively affected .......................................................... 30

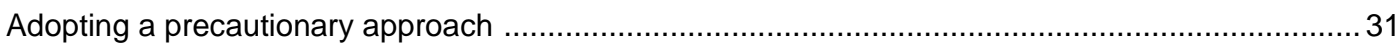

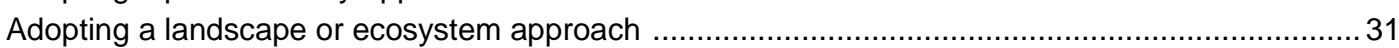

Policy coherence for development: biodiversity, ecosystem services and poverty reduction ............32

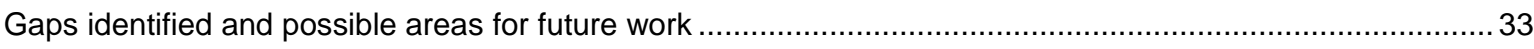

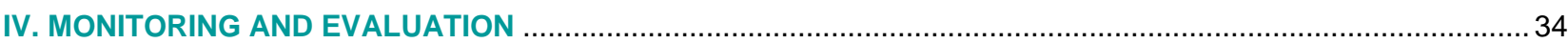

Monitoring and evaluation helps providers track progress and understand results .....................................34

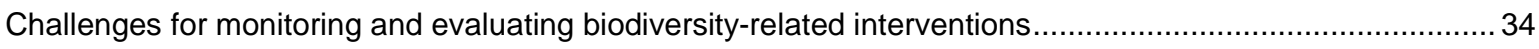

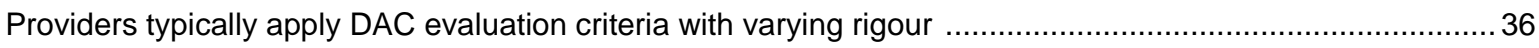

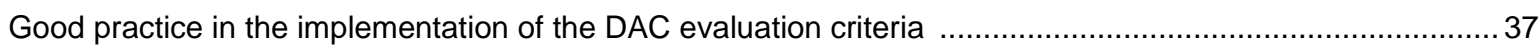

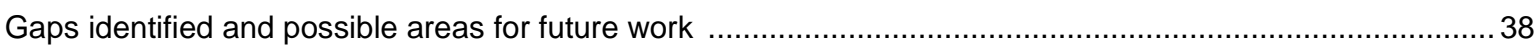

V. EFFECTIVE DEVELOPMENT CO-OPERATION: ALIGNMENT AND HARMONISATION ................................... 40

Principles of effective development co-operation apply to biodiversity-related interventions ..........................40

Development co-operation providers are partially aligning with partner countries' priorities ...........................41

Providers are co-ordinating through national and regional mechanisms, but with varying frequency and

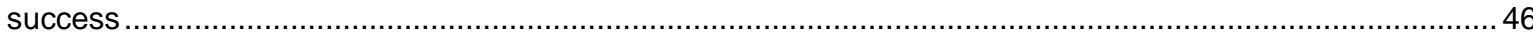

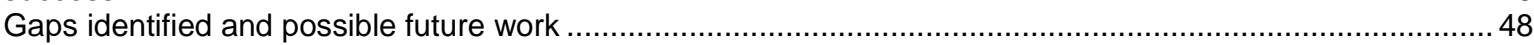

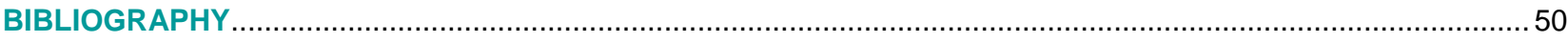

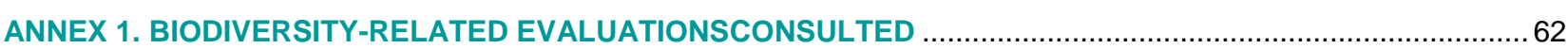


Table 2. Measurement and assessment tools for mainstreaming biodiversity and ecosystem services ......... 18

Table 3. Engagement approaches for mainstreaming biodiversity and ecosystem services ........................ 18

Table 4. Examples of support tools to identify and manage trade-offs and synergies...................................28

Table 5. Main sectoral priorities identified by partner countries in their NBSAPs, and targeted by development co-operation providers.

Figure 1. Millennium Ecosystem Assessment conceptual framework of interactions

Figure 2. Upstream and downstream outcomes of mainstreaming biodiversity and ecosystem services into development ........................................................................ 14

Figure 3. Entry points for mainstreaming biodiversity and development............................................... 16

\section{BOXES}

Box 1.

Box 2.

Box 3.

Keys concepts .9

Examples of international initiatives on mainstreaming biodiversity and development.

Mainstreaming biodiversity and the environment at the Swedish International

Development Cooperation Agency (Sida)

Box 4. Poverty-centric and nature-centric approaches ................................................................. 24

Box 5 .

Box 6.

The Wealth Accounting and the Valuation of Ecosystem Services (WAVES) programme

BUILD: An example of development co-operation support for biodiversity trade-offs and synergies assessment of infrastructure

Box 7.

Box 8.

The importance of strong governance, institutions and legal frameworks

Supporting sustainable parks management in Chad ............................................................... 31

Box 9. International principles of effective development co-operation

Box 10. Key points emerging from Third Annual Workshop on the NBSAPs 2.0 on alignment and harmonisation 
Biodiversity conservation and sustainable use, ecosystem services and development are intrinsically linked. While biodiversity issues have garnered much attention from the environmental policy community, less evidence and knowledge-sharing exist on how development co-operation providers are addressing the twin objectives of biodiversity conservation and sustainable use on the one hand, and development and poverty reduction on the other. Development co-operation providers are however important actors in the area of biodiversity, as they provide a major source of funding for action. Some estimate that official development assistance is the most significant source of biodiversity finance today in many low and lower middle income developing countries (Waldron et al., 2013).

This paper explores how development co-operation providers are supporting biodiversity-related interventions in partner countries, and how they are integrating biodiversity considerations into their own practices. Drawing on academic and grey literature, providers' policy documents, conversations with provider and partner countries and a wealth of examples, the paper aims to illustrate emerging good practices as well as ongoing challenges, particularly related to mainstreaming in partner countries and monitoring and evaluation.

\section{Development co-operation practice in mainstreaming biodiversity and ecosystem services}

Development co-operation providers are increasingly integrating biodiversity concerns into their operations by automatically screening every activity for potential harmful impacts upon biodiversity and ecosystem services. In addition, a number of providers have recently produced biodiversity strategies that target the mainstreaming of biodiversity and ecosystem services across all of their agency operations. This includes technical training on integrating biodiversity into development co-operation activities and raising awareness on the importance of biodiversity and ecosystem services.

Development co-operation providers are also supporting mainstreaming in partner countries, targeting their interventions at the national, sector, local or project-level entry point(s) prioritised by partner countries. Interventions target a range of policy instruments such as legislation and regulation, environmental taxes and other fiscal instruments; measurement and assessment tools such as ecosystem valuation and eco-labelling; and approaches such as education campaigns and voluntary standards for business.

Information gaps, awareness and capacity challenges remain and hinder progress to conserve and sustainably use biodiversity in development policy and planning. Development co-operation provides important financial and technical support to build partner country capacity to overcome these challenges and build the evidence base for decision-makers on the benefits of mainstreaming biodiversity. Feedback from partner country experience underlines that how support for mainstreaming is provided is also important, and could be improved. For example:

- At least 10-15 years of sustained support is needed for measurable results, both in the state of biodiversity and ecosystem services, and in inter-stakeholder relationships and institutional practices;

- All stakeholders must be involved in a transparent, inclusive manner from the beginning of the process, to build trust and ownership of actions taken;

- The process by which partner countries apply for interventions to support mainstreaming needs to be simplified, and the flexibility of this support to adapt to changing circumstances increased;

- Methods to monitor and take stock of what is working well and what is not need to be developed and implemented, along with approaches to allow learning from these experiences and modifications to occur based on these learnings in an interactive manner. 


\section{A wealth of tools and practices exist to minimise trade-offs and maximise benefits}

Focusing on results is crucial to ensure that interventions have a lasting positive impact on biodiversity and on development, and that trade-offs are kept to a minimum. A number of ex ante assessment tools exist to identify the interface and interaction between different objectives, such as the mapping tool InVEST and the planning tool Marxan. Decision support techniques include cost-benefit analysis, multi-criteria analysis, targeted scenario analysis and economic valuation. This review highlights a number of overarching good practices for minimising tradeoffs and maximising benefits, including:

- Ensuring open, multi-stakeholder dialogue;

- Adopting an ecosystem approach for integrated management of land, water and living resources;

- Adopting a precautionary approach when an activity may have serious negative consequences for biodiversity and ecosystem services;

- Identifying, involving and compensating local and indigenous communities that may be negatively affected by biodiversity conservation activities;

- Building strong governance, institutions and legal frameworks;

- Pursuing policy coherence for biodiversity, ecosystem services and poverty reduction.

\section{Challenges abound in monitoring and evaluation}

Development cooperation providers face a number of methodological and practical challenges in monitoring and evaluating biodiversity-related interventions. These are not exclusive to the field of biodiversity conservation and sustainable use, but their scale and interaction is relatively unique. Some of these challenges include:

- Ambiguous definitions that are not commonly understood of biodiversity and ecosystem services;

- A limited knowledge base of what works and why to create theories of change for achieving both biodiversity and development outcomes in biodiversity-related interventions ;

- A lack of suitable and simple standardised indicators to monitor biodiversityrelated activities;

- The problem of attribution for biodiversity and development outcomes of biodiversity-related interventions;

- Difficulties setting baselines and targets given uncertain operating contexts in developing countries;

- The large geographic spread of biodiversity and ecosystem services and the scale programmes required to manage these;

- The long timeframes required to observe results, extending beyond the lifespan of most development co-operation interventions.

This review draws on "five DAC evaluation criteria" (OECD, 2009b) -- relevance, effectiveness, efficiency, impact and sustainability -- to consider performance across development cooperation interventions targeting biodiversity. It reviews nine different providers and finds that while there are examples of good practice in meeting each of these criteria, none of the providers met all five in any particular intervention. This probably reflects the practical and methodological challenges noted above.

\section{Development co-operation providers are partially aligning with partner country priorities}

A preliminary look at how providers are applying the principles of aid effectiveness and development co-operation in the area of biodiversity gave mixed results. To explore the degree 
to which providers are aligning their activities with partner countries' needs and priorities, the paper compares the national priorities put forward by five partner countries (Azerbaijan, Guyana, Lao People's Democratic Republic, Kiribati and Malawi) in their National Biodiversity Strategies and Action Plans (NBSAPs) with external development finance flows targeting biodiversity. Although a certain degree of alignment with partner countries' priorities can be observed, the extent and the reason why this is occurring are unclear. Reviewing the literature on how providers co-ordinate, simplify procedures and share information to avoid duplication, the paper also finds that that in some countries, providers are increasingly co-ordinating biodiversityrelated interventions through the use of "sector-wide approaches" and "joint assistance strategies" (e.g. in Kenya and Zambia). Providers sometimes co-ordinate at the regional level too, for example, in Southeast Asia through the Informal Donor Meeting of the Mekong River Commission. However these co-ordination mechanisms are not present in all countries or regions, and where they are present they have come under a certain amount of criticism. The criticism stems from not adequately involving partner country governments or from being "talk shops" without adequate resources to achieve concrete results. There is evidence that providers and partner countries are learning from these experiences to improve alignment and targeting of biodiversity-relevant development co-operation interventions, however there is a need to strengthen review and adjust practices over time. 


\section{INTRODUCTION}

\section{Biodiversity and development are intrinsically linked}

1. Biodiversity is the scientific term to describe the totality of Earth's living natural resources - their abundance, variety and richness. Biodiversity underpins ecosystem functioning, which in turn supports the provision of a range of ecosystem services; these services are directly or indirectly essential for all human well-being. ${ }^{2}$ Biodiversity and ecosystem services provide, inter alia, food security, fuel, and clean air and water, and contribute to human health, local livelihoods and economic development (Figure 1). The rural poor are disproportionately dependent on biodiversity and ecosystem services for their subsistence, income, health and risk management needs. This is partly due to their close proximity to and daily interaction with natural resources and also due to their limited ability to purchase substitutes. As such, poor people are particularly vulnerable to the loss and degradation of these goods and services (CBD, 2009a; Billé et al., 2012; Roe, 2010a; Roe et al., 2011; Turner et al., 2012; OECD, 2008a). The Economics of Ecosystems and Biodiversity (TEEB) study (2009) highlights the disproportionate contribution that biodiversity and ecosystem services make to the income of poor people; for example, it estimates that in India, these make up 47\% of the "GDP of the Poor", 75\% in Indonesia, and 89\% in Brazil (TEEB, 2009). Biodiversity and ecosystem services are also "environmental assets" that provide the inputs and enabling environment for production and consumption activities, which development and economic growth depend upon (MA, 2005; GIZ, 2012a; Smith, 2013; World Bank, 2006). This may particularly be the case in sectors such as agriculture, forestry, fishing and tourism. Biodiversity and ecosystem services are essential for resilient and lasting development outcomes, including poverty reduction (MA, 2005; CBD, 2010b; UNGA, 2012; OECD, 2013c). (See Box 1 for definitions of key concepts.)

2. The poor are both victims to the loss and degradation of biodiversity and ecosystem services as well as part of the solution. This may particularly be the case for indigenous and local communities, whose traditional knowledge, innovations and practices have been used to conserve and sustainably use biodiversity and ecosystem services for millennia (UNGA, 2014; Sobrevila, 2008; CBD, 1992, Article 8j and Article 10;). Traditional indigenous territories coincide with about $80 \%$ of the planet's biodiversity (Sobrevila, 2008). This makes indigenous peoples natural partners in efforts to conserve and sustainably use biodiversity and ecosystem services in ways that also support poverty reduction and development. 


\section{Box 1. Key concepts}

The concepts of biodiversity, ecosystem services, conservation and sustainable use and poverty frame the key issues explored in this paper. They impact where and how mainstreaming biodiversity occurs (Section 2) how trade-offs and synergies are understood between the conservation and sustainable use of biodiversity and ecosystem services and poverty reduction (Section 3), and how policies, programmes and projects related to biodiversity, ecosystem services and poverty reduction are monitored and evaluated (Section 4). The definitions used in this paper are outlined below.

Biodiversity: The Convention on Biological Diversity (CBD) defines biodiversity as "the variability among living organisms from all sources including, terrestrial, marine and other aquatic ecosystems and the ecological complexes of which they are part; this includes diversity within species, between species and of ecosystems" (Article 2, CBD, 1992). This is the definition used in this paper. Measuring the multiple facets of biodiversity is complex. Biodiversity has often been measured narrowly, in terms of species richness in a defined area (Davies et al., 2013). However, progress is being made in increasing the variety and availability of information on the state of and trends in biodiversity, such as through the Biodiversity Indicators Partnership (BIP) and the Intergovernmental Panel on Biodiversity and Ecosystem Services (IPBES).

Ecosystem services: Ecosystem services are defined as the benefits that people obtain from ecosystems (Mace et al., 2012). The Millennium Ecosystem Assessment (MA, 2005) has categorised these into supporting services, regulating services, provisioning services and cultural services. Although research is ongoing regarding the link between biodiversity and ecosystem services (Mace et al., 2012), biodiversity has been shown to be key for the delivery of a large number of ecosystem services (Elmqvist et al., 2010; Cardinale et al., 2012). This paper therefore considers biodiversity and ecosystem services as going hand-in-hand, and addresses both together.

Biodiversity conservation: In this paper, biodiversity conservation is taken to mean the protection and maintenance of living natural resources (encompassing biodiversity and ecosystem services) to ensure their survival over the long term (see Roe et al., 2011). This can refer to a species or natural habitat for example. Nevertheless, biodiversity conservation is interpreted and applied in a variety of ways. A narrow interpretation of biodiversity conservation implies protection, i.e. protected areas with limited human intervention or use (Roe et al., 2011). Others view biodiversity conservation in a broader sense, which allows some level of human intervention or use, such as the extraction of non-timber forest products for local use, or visiting national parks for recreation (see Roe, 2010a).

Sustainable use: refers here to the use of biodiversity and ecosystem services (e.g. forests and timber, fish, soil) at a rate that allows the environment to renew itself, thereby maintaining their potential to meet current and future human needs and aspirations and preventing their long term decline (CBD COP 7 Decision VII/12).

Poverty: In this paper, poverty is understood as being multidimensional, encompassing not only economic wealth but also deprivation of basic needs (e.g. education, work, health, nutrition), lack of political voice and empowerment, lack of social dignity, and vulnerability to risk (OECD, 2013a; Roe, 2010a OECD, 2001). Measuring the multiple dimensions of poverty is difficult. New indicators are being developed (OECD, 2013a), yet studies - including those on the biodiversity-poverty nexus often only measure changes in the economic dimension of poverty in terms of income per capita (Roe, 2010a).

Poverty reduction and development: In this paper we use the term poverty reduction to refer to the goal of lifting people above the poverty line. ${ }^{3}$ This is recognised as one important element of development. Development is generally understood as the effort to improve human well-being (OECD, 2007). Other ways of measuring the impact of development include whether it aims to alleviate poverty (improve the living conditions of the poor, but not necessarily to lifting them above the poverty line) and/or prevent poverty (prevent vulnerable populations from falling below the poverty line). Discussions of alleviating and reducing poverty are frequent in the literature, and the terms are often used interchangeably. "Poverty eradication" is also used, particularly by the CBD. While poverty eradication, reduction and alleviation remain paramount, more recent literature has pointed to the need to prevent poverty (Roe, 2010a; OECD, 2013a), and reduce inequality (OECD, 2013a; Billé et al., 2012).

Sources: OECD (2013a), Development Co-operation Report 2013: Ending Poverty, OECD Publishing, Paris; Elmqvist et al. (2010) 'Biodiversity, Ecosystems and Ecosystem Services', in Kumar, P. (ed.) (2010) The Economics of Ecosystems and Biodiversity Ecological and Economic Foundations. London/Washington, D. C.: Earthscan; Cardinale et al. (2012), "Biodiversity loss and its impact on humanity", Nature, vol. 486 no. 59; Billé, R., Lapeyre, R., and Pirard, R. (2012), "Biodiversity conservation and poverty alleviation: a way out of the deadlock?", S.A.P.I.E.N.S, Vol.5, No.1; Mace, G.M., Norris, K. and Fitter, A.H. (2012), "Biodiversity and ecosystem services: a multi-layered relationship", Trends in Ecology and Evolution, January 2012, Vol. 27 No. 1; MA (Millennium Ecosystem Assessment) (2005), Millennium Ecosystem Assessment - Ecosystems and Human Well-being: Synthesis, World Resources Institute, Washington, DC; Roe, D. (2010a). "Linking Biodiversity Conservation and Poverty Alleviation: A State of Knowledge Review", CBD Technical Series 55, Secretariat of the CBD, Montreal. OECD (2007), Promoting Pro-Poor Growth: Policy Guidance for Donors, OECD, Paris; OECD (2001) The DAC Guidelines: Poverty Reduction, OECD, Paris; Roe, D., et al. (2011), "Biodiversity and Poverty: Ten Frequently Asked Questions - Ten Policy Implications", Gatekeeper 150, IIED, London; CBD (Convention on Biological Diversity) (1992), 'Text of Convention'; Davies, T.E. et al. (2013), "Missing the trees for the wood: Why we are failing to see success in pro-poor conservation", Animal Conservation, 21 November 2013.

\section{The state of biodiversity and ecosystem services is on the decline}

3. Scientific evidence shows a decline in the global state of biodiversity and ecosystem services (Butchart et al., 2010; CBD, 2010a; UN, 2014), and the Convention on Biological Diversity (CBD)'s Global Biodiversity Outlook stresses that current efforts to reverse this global decline are insufficient (CBD, 2014a). These trends are not new; a sharp acceleration in the absolute loss of biodiversity and the damage of ecosystems has been observed since mid-last century (Steffen et al., 2011). ${ }^{4}$ It is estimated that the level of biodiversity loss has exceeded the 
safety threshold by one to two orders of magnitude, and is coming dangerously close to a "tipping point" beyond which abrupt, irreversible changes to biodiversity and ecosystems could occur, with dire consequences for human well-being and development (Rockström et al., 2009; CBD, 2010a).

4. The Millennium Ecosystem Assessment (2005) highlights the drivers of the rapid decline in biodiversity and ecosystem services (Figure 1). Recent analysis underscores that the scale and pace of change in these drivers is either constant or intensifying, in turn leading to further loss and degradation of biodiversity and ecosystem services (Butchart et al., 2010; CBD, 2010a; OECD, 2012a). The OECD Environmental Outlook to 2050 projects that, under a business-asusual scenario, biodiversity will continue to decline by a further 10\% between 2010 and 2050 (OECD, 2012a). The key direct drivers of loss and degradation are land-use change and unsustainable land management, habitat encroachment and fragmentation, infrastructure development, over-exploitation of resources, chemical and organic pollution, invasive alien species, and climate change (CBD, 2010a; OECD, 2012a). Changes in these drivers in turn stem from broader, indirect forces including demographic change, macro-economic policy, global consumption and production patterns and technology developments (MA, 2005).

Figure 1. Millennium Ecosystem Assessment conceptual framework of interactions between biodiversity, ecosystem services, human well-being, and drivers of change

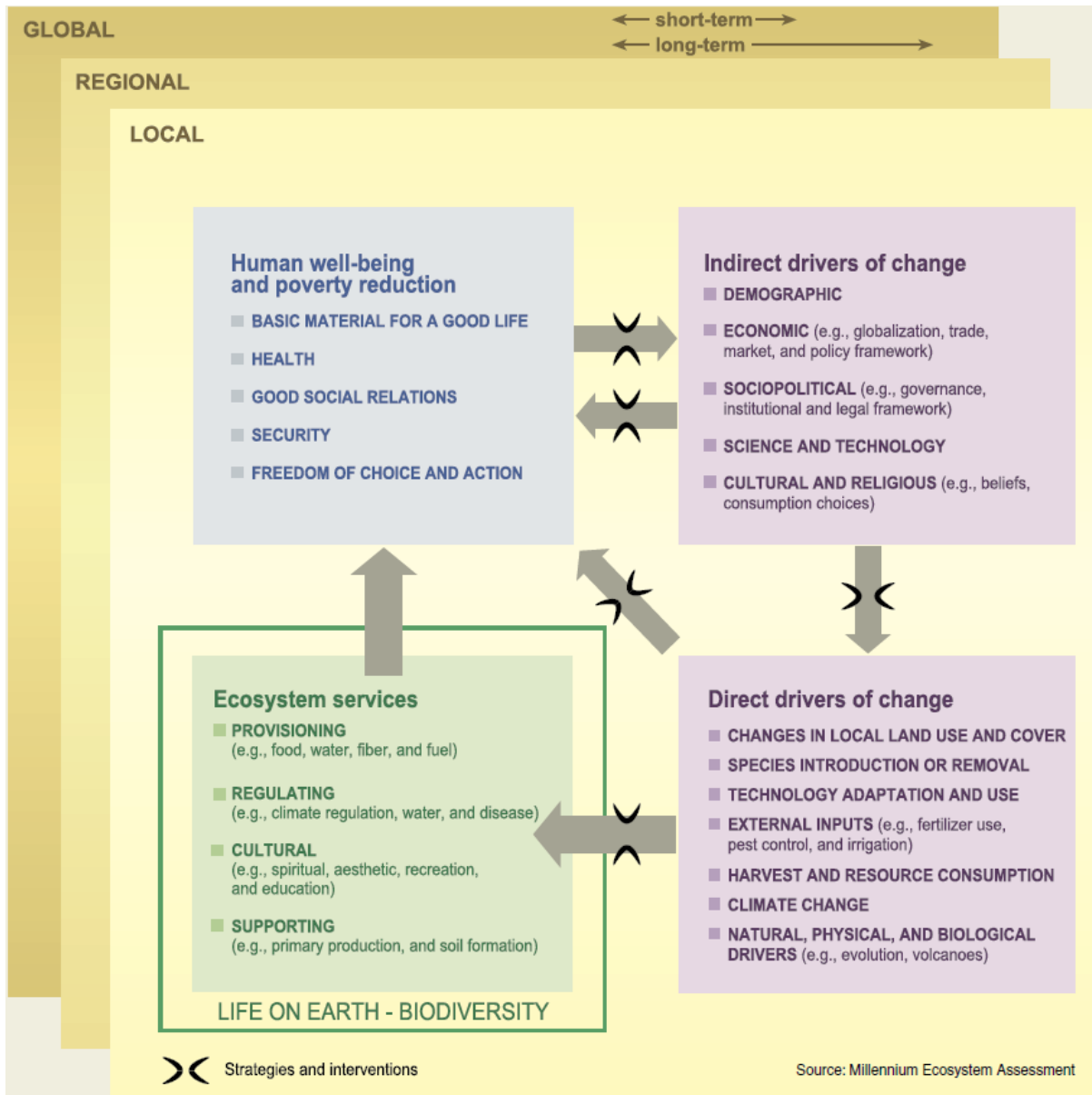

Source: Millennium Ecosystem Assessment (2005), Millennium Ecosystem Assessment - Ecosystems and Human Wellbeing: Synthesis, World Resources Institute, Washington, DC 
The CBD and the SDGs encourage countries to address biodiversity and development together

5. The Convention on Biological Diversity (CBD) and the Sustainable Development Goals (SDGs) international policy frameworks both encourage countries to address biodiversity and development together, including through development co-operation activities. At the 12th Conference of the Parties to the CBD, this was reaffirmed in Decision XII/5 on Biodiversity for poverty eradication and sustainable development and by the Gangwon Declaration on Biodiversity for Sustainable Development (2014). In the SDGs, this is reflected both through two biodiversity-related stand-alone goals (on marine and terrestrial biodiversity), and through the integration biodiversity and ecosystem services into the targets under a number of the other proposed goals (e.g. water). ${ }^{5}$ Although the academic literature is divided as to whether (and how) biodiversity conservation and sustainable use and poverty reduction can actually be achieved simultaneously, practitioner opinions suggest an emerging consensus of positive synergies (Roe et al., 2013). While there are examples of synergies being achieved on the ground (Munang et al., 2014), combining these objectives in development planning, policy and co-operation still presents a number of challenges, many of which are explored in this paper.

\section{Weak governance and market failure remain fundamental challenges}

6. Weak governance and market failures are two fundamental challenges to achieving synergies between biodiversity and development outcomes. Weak governance is repeatedly identified as a key barrier in this respect (Sayer et al., 2013; Manzoor Rashid et al., 2013; Gardner et al., 2013; Vaz and Agama, 2013; Armah et al., 2013; Sandker et al., 2012; Billé et al., 2012; UNDP, 2012; Roe et al., 2011; Roe, 2010a). Governance challenges relate to ineffective or non-existent government institutions and rule of law, engendering other problems including a lack of clearly defined, secure and enforceable property rights/land tenure; a lack of clearly defined roles and responsibilities and of accountability; and elite capture and corruption (see Box 6 in Section 3 on some of these governance challenges).

7. Market failure is a second central factor hindering the achievement of synergies and contributing to the decline in the state of biodiversity and ecosystem services. Their values are not reflected in market prices, and when considered they are often undervalued. As a result, integrating biodiversity-related considerations into decision- and policy-making processes has proven difficult (UNDP, 2012; TEEB, 2010a).

\section{Aim and approach of this paper}

8. This scoping paper provides an overview of the state of play of how development cooperation is addressing the twin objectives of biodiversity conservation and sustainable use on the one hand, and development and poverty reduction on the other. While biodiversity issues have garnered much research and policy attention in the last decade from the environmental policy community, less attention has been given to a development co-operation perspective despite providers being key actors. The analysis takes the dependence of the poor upon biodiversity and ecosystem services and the serious and declining state of biodiversity as a starting point. It is based on a literature review of academic, primary and secondary sources from OECD DAC providers, ${ }^{6}$ developing country partners and other stakeholders (e.g. international organisations and civil society organisations). The paper draws on examples provided by development co-operation practitioners based on their experience in the field. The OECD Secretariat also participated in a workshop with eight African countries on mainstreaming biodiversity and development, from which the Secretariat gathered feedback on providers' practices from partner countries. ${ }^{7}$ On the topic of monitoring and evaluation the paper illustrates emerging notions of good practice by reviewing experience drawing from the OECD DAC Evaluation Resource Centre (DEReC) database and by comparing results described there against OECD DAC evaluation performance criteria.

9. Following the general literature review in this introduction, the paper is organised into four sections to address a range of policy challenges for biodiversity and ecosystem services in 
development co-operation. Section 2 looks at mainstreaming biodiversity into development cooperation. Section 3 looks at managing for results, with a particular focus on identifying and assessing trade-offs and synergies encountered in biodiversity and poverty reduction projects. Governance and market failure challenges are handled as cross-cutting issues in Sections 2 and 3. Section 4 looks at the monitoring and evaluation frameworks for development cooperation activities targeting biodiversity. Finally, Section 5 looks at alignment and co-ordination of development co-operation provider activities with partner country priorities.

\section{Endnotes Section I}

2. Although research is ongoing regarding the link between biodiversity and ecosystem services (Mace et al., 2012), biodiversity has been shown to be key for the delivery of a large number of ecosystem services (Elmqvist et al., 2010; Cardinale et al., 2012). This paper therefore considers biodiversity and ecosystem services as going hand-in-hand, and addresses both together. For more information see Box 1.

3. The poverty line is the minimum level of income required to meet the basic needs in a particular country. At the time of publication, The World Bank defines the international poverty line as USD 1.25 per day.

4. There are some local system-specific exceptions - for example, the Water Quality Index in Asia has improved $7.4 \%$ since 1970, and a number of species have had their categories of extinction risk downgraded on the IUCN Red List following successful conservation action - indicating that with political will and financial and human resources, biodiversity loss can be reduced or reversed (Butchart et. al., 2010).

5. Proposal available here: http://sustainabledevelopment.un.org/sdgsproposal.html

6. "Providers" refers to DAC donors.

7. See here for more information on the workshop: http://pubs.iied.org/G03827.html 


\section{Mainstreaming biodiversity and ecosystem services into development co-operation}

10. Mainstreaming can be understood as including or incorporating an issue or practice that is typically dealt with in a separate and marginalised form into another, often more dominant or prevailing institution or system (Huntley and Redford, 2014). Mainstreaming is often used interchangeably with policy integration, which implies the integration of a given issue into policyand decision-making processes, outputs and outcomes. In the biodiversity and development context, mainstreaming refers to "the recognition and integration of biodiversity and ecosystem services and development considerations across different levels of governance and entry points (e.g. national, sectoral, local)" (IIED and UNEP-WCMC, 2013a; OECD, 2013c).

11. This section focuses on the role of development co-operation to mainstream biodiversity and ecosystem services into policy, planning and projects, first, in partner countries and second, in provider strategies and policies. It reviews the rationale and international mandate for mainstreaming biodiversity and ecosystem services into development policy and planning, presents some of the entry points, policy instruments, tools and approaches available for mainstreaming, and provides examples of how development co-operation providers have been supporting mainstreaming. It also identifies areas where further research would be of value.

\section{Mainstreaming is essential to maximise positive biodiversity and development outcomes}

12. The potential for synergistic linkages, or trade-offs, between biodiversity and ecosystem services on the one hand and poverty reduction and development on the other means that it is important to address them together. Biodiversity and ecosystem services are often invisible in markets and to policy makers, yet they are essential for human well-being, particularly that of the poor, and for economic growth, income generation (e.g. through export or selling biodiversity-related assets in global or local markets), the long-term productivity of sectors, and development. The importance of biodiversity and ecosystem services for poverty reduction and for the economy, combined with the fact that they are often overlooked by markets and policy makers, provides the rationale for mainstreaming.

13. Mainstreaming biodiversity and ecosystem services into development planning, policies and projects can help decision-makers assess interconnections and identify how best to steer investments to maximise positive biodiversity and development outcomes. It is equally important to reciprocally mainstream development considerations into biodiversity policies (e.g. see CBD COP12 Decision XII/5), such as into National Biodiversity Strategies and Action Plans (NBSAPs); however analysis of this reverse process goes beyond the scope of this paper. ${ }^{8}$ The $^{2}$ type of biodiversity, ecosystem services and development outcomes that are likely to arise from mainstreaming biodiversity and ecosystem services into development will range from "upstream" effects (governance, policy, plans, budget or related policy decisions), to "downstream" effects (behavioural change to deliver progress "on-the ground"; see Dalal-Clayton and Bass, 2009 and Figure 2 for further details). 
Figure 2. Upstream and downstream outcomes of mainstreaming biodiversity and ecosystem services into development

\begin{tabular}{|c|c|c|}
\hline & Outcome & \\
\hline \multirow[t]{8}{*}{ UPSTREAM } & Governance outcomes & $\begin{array}{l}\text { e.g. Improved involvement of directly biodiversity-dependent } \\
\text { (sometimes vulnerable) stakeholders }\end{array}$ \\
\hline & Policy and political outcomes & $\begin{array}{l}\text { e.g. High-level sector, fiscal, development and social policies, } \\
\text { constitutions and statements of national vision, include biodiversity } \\
\text { considerations, and vice versa }\end{array}$ \\
\hline & Plan outcomes: & $\begin{array}{l}\text { e.g. Inclusion of biodiversity-poverty linkages in development and } \\
\text { poverty reduction strategies and in biodiversity strategies }\end{array}$ \\
\hline & Budget outcomes & $\begin{array}{l}\text { e.g. evidence of public-private sector resource mobilisation, } \\
\text { inclusion of development-biodiversity linkages in national public } \\
\text { and sector budgets }\end{array}$ \\
\hline & $\begin{array}{l}\text { Institutional and capacity } \\
\text { outcomes }\end{array}$ & $\begin{array}{l}\text { e.g. strengthened capacity within biodiversity-related institutions to } \\
\text { understand development and economic processes and interact in } \\
\text { a constructive manner }\end{array}$ \\
\hline & Investment outcomes & $\begin{array}{l}\text { e.g. improved domestic resource mobilization for poverty- } \\
\text { biodiversity investments or recognition of potential trade-offs in } \\
\text { sector investments such as mining }\end{array}$ \\
\hline & Behavioural outcomes & $\begin{array}{l}\text { e.g. key patterns and processes of production, consumption and } \\
\text { waste treatment in sectors and localities are informed by } \\
\text { biodiversity and poverty considerations. }\end{array}$ \\
\hline & $\begin{array}{l}\text { Pro-poor biodiversity and } \\
\text { ecosystem management } \\
\text { outcomes }\end{array}$ & $\begin{array}{l}\text { e.g. maintenance/restoration/enhancement of pro-poor ecosystem } \\
\text { services, such as medicinal, cosmetic or edible plants; healthcare, } \\
\text { wild foods, soil fertility; traditional breeds and crop varieties; water } \\
\text { purification }\end{array}$ \\
\hline DOWNSTREAM & $\begin{array}{l}\text { Ultimate (biodiversity and } \\
\text { developmental) impacts of } \\
\text { these outcomes }\end{array}$ & $\begin{array}{l}\text { e.g. improved productivity and sustainability of use of biodiversity } \\
\text { assets and ecosystem services on which the poor depend; } \\
\text { protection and management of targeted species populations }\end{array}$ \\
\hline
\end{tabular}

Source: Source: IIED (Internal Institute for Environment and Development) and UNEP-WCMC (United Nations Environment Programmes World Conservation Monitoring Centre) (2012), Biodiversity mainstreaming: A rapid diagnostic tool, IIED and UNEP-WCMC, London and Cambridge

\section{The international call for mainstreaming biodiversity into development}

14. The importance of mainstreaming biodiversity into development is enshrined in the Convention and subsequent decisions of the CBD, and in the OECD Development Assistance Committee (DAC)'s Policy Statement on Integrating Biodiversity and Associated Ecosystem Services into Development Co-operation (OECD, 2010b). Articles 6(b) and 10(a) of the Convention call for the mainstreaming of biodiversity and ecosystem services; the former into "relevant cross-sectoral plans, programmes and policies", and the latter "into national decisionmaking" (CBD, 1992). The current mandate is found in the Strategic Plan for Biodiversity 20112020 (Aichi Target 2) and Goal 5 of the CBD Strategy for Resource Mobilization 2008-2015. The DAC Policy Statement emphasises the importance of development co-operation agencies supporting partner countries to "integrate biodiversity and ecosystem services into development policies, sector plans and budget processes" and to support the development of tools, practices, capacity, awareness and governance frameworks necessary for mainstreaming processes to succeed.

15. A number of other actors in the international development co-operation arena also support the mainstreaming of biodiversity and ecosystem services into development. These include international governmental organisations, such as the United Nations Environment Programme (UNEP), the United Nations Development Programme (UNDP), the International Union for the Conservation of Nature (IUCN), the Global Environment Facility (GEF) and a number of development non-governmental organisations, institutes and partnerships such as BirdLife International, International Institute for Environment and Development (IIED), The Nature Conservancy or World Resources Institute (WRI). Box 2 below provides examples of the support that these actors are providing. 


\section{Box 2. Examples of international initiatives on mainstreaming biodiversity and development}

The NBSAPs 2.0 Mainstreaming Biodiversity and Development project: Co-ordinated by the International Institute for Environment and Development (IIED) and the UNEP World Conservation Monitoring Centre (WCMC), the NBSAP 2.0 initiative is building African leadership and sharing experience and good practice in mainstreaming biodiversity and development in four pilot countries as they revise their NBSAPs: Botswana, Uganda, Namibia and the Seychelles. Project partners are successfully implementing a reciprocal mainstreaming approach and fostering wider ownership of biodiversity and development priorities through the process. This encourages development priorities to be reflected in national biodiversity plans and biodiversity to be reflected in development and sectoral plans.

Project for Ecosystem Services (Proecoserv): Co-ordinated by UNEP and funded by GEF, Proecoserv aims to better integrate ecosystem assessment, scenario development and economic valuation of ecosystem services into national sustainable development planning at the national, regional and local levels. The three pillars of Proecoserv are i) providing support tools for policy making, ii) providing assistance for policy implementation, and iii) bridging the gap between science and policy. Proecoserv is currently operating in 5 pilot countries: Chile, South Africa and Lesotho, Trinidad and Tobago, and Viet Nam (UNEP, 2014b).

Mainstreaming biodiversity: What does success look like? A series of fact sheets: Following a call from countries at the Global Workshop on Reviewing Progress and Capacity for NBSAP Revision (Nairobi, 11-15 November 2013) for more evidence of how biodiversity mainstreaming works on the ground, and to complement existing yet mostly theoretical guidance on mainstreaming, IUCN and BirdLife International initiated a project with seed funding from the French Government to document successful mainstreaming cases through a series of practical fact sheets to inspire further biodiversity mainstreaming efforts and contribute to the achievement of Aichi Target 17 by 2015 and beyond.

The Global Environment Facility (GEF) biodiversity mainstreaming programme: The $6^{\text {th }}$ cycle of the GEF (GEF-6) has allocated USD 1.4 billion to the biodiversity focal area (out of a total resource envelope of USD 4.9 billion). The programming directions for the biodiversity focal area define a specific programme (Programme 10) to integrate biodiversity and ecosystem services into development and finance planning. This programme will pilot national-level interventions that link biodiversity valuation and economic analysis with development policy and finance planning. The outcome from these projects will be valuation of ecosystem services that informs policy instruments and fiscal reforms designed to mitigate perverse incentives leading to losses in natural capital and biodiversity.

Sources: Inputs provided by John Tayleur, UNEP-WCMC, correspondence 9 March 2015; Maximillian Mueller, IUCN, correspondence 6 November 2014; Ersin Esen, UNEP, correspondence 19 November 2014. Input for Proecoserv from UNEP (2014b), Project for Ecosystem Services (ProEcoServ), http://www.proecoserv.org/, last accessed 16 July 2014.

\section{Choice of entry points, policy instruments and approaches for mainstreaming}

16. For biodiversity mainstreaming to be effective, it should occur across all levels of government and include all relevant stakeholders (IIED and UNEP-WCMC, 2013a). This means there are several entry points to mainstream biodiversity and ecosystem services into development policy and planning (see Figure 3). These include:

1. Overarching development strategies, plans, policies and budgets, in order to consider the opportunities that biodiversity and ecosystem services provide in contributing to broad development objectives, the potential impacts that development might have on key biodiversity-related resources, and to allocate resources to mainstreaming;

2. Sectoral plans and policies that are intended to realise the over-arching national plan, particularly those where the links between biodiversity, the traditional economic sector and human well-being are clearest and most easily communicated (e.g. agriculture);

3. Sub-national strategies, plans and policies;

4. Development co-operation programmes or projects that support national, sectoral and sub-national strategies, plans and policies.

17. Entry points interact and are located at different levels of governance (Figure 3). For example, including attention to biodiversity and ecosystem services within the narrative of a national or sectoral development plan is a key step in the mainstreaming process but will not result in changed outcomes on the ground if there is no budget allocated to implement the plan. 
Similarly, doing so will be insufficient if sub-national and sectoral level activities are not coordinated and aligned with the national vision and strategy.

18. Development co-operation providers can support mainstreaming and promote cohesion by targeting their interventions at the entry point(s) that are prioritised by partner countries and are most timely, e.g. targeting the mainstreaming of biodiversity into a law, strategy or policy when it is being drafted or revised, or targeting the mainstreaming of biodiversity into the budget when it is being prepared (CBD, 2011). Development co-operation can also support the processes that link the different entry points, e.g. enabling conditions implementing sectorial and local interventions; environmental fiscal reform that inter alia helps allocate budget to sectorial mainstreaming, and monitoring and evaluation of interventions.

Figure 3. Entry points for mainstreaming biodiversity, ecosystem services and development

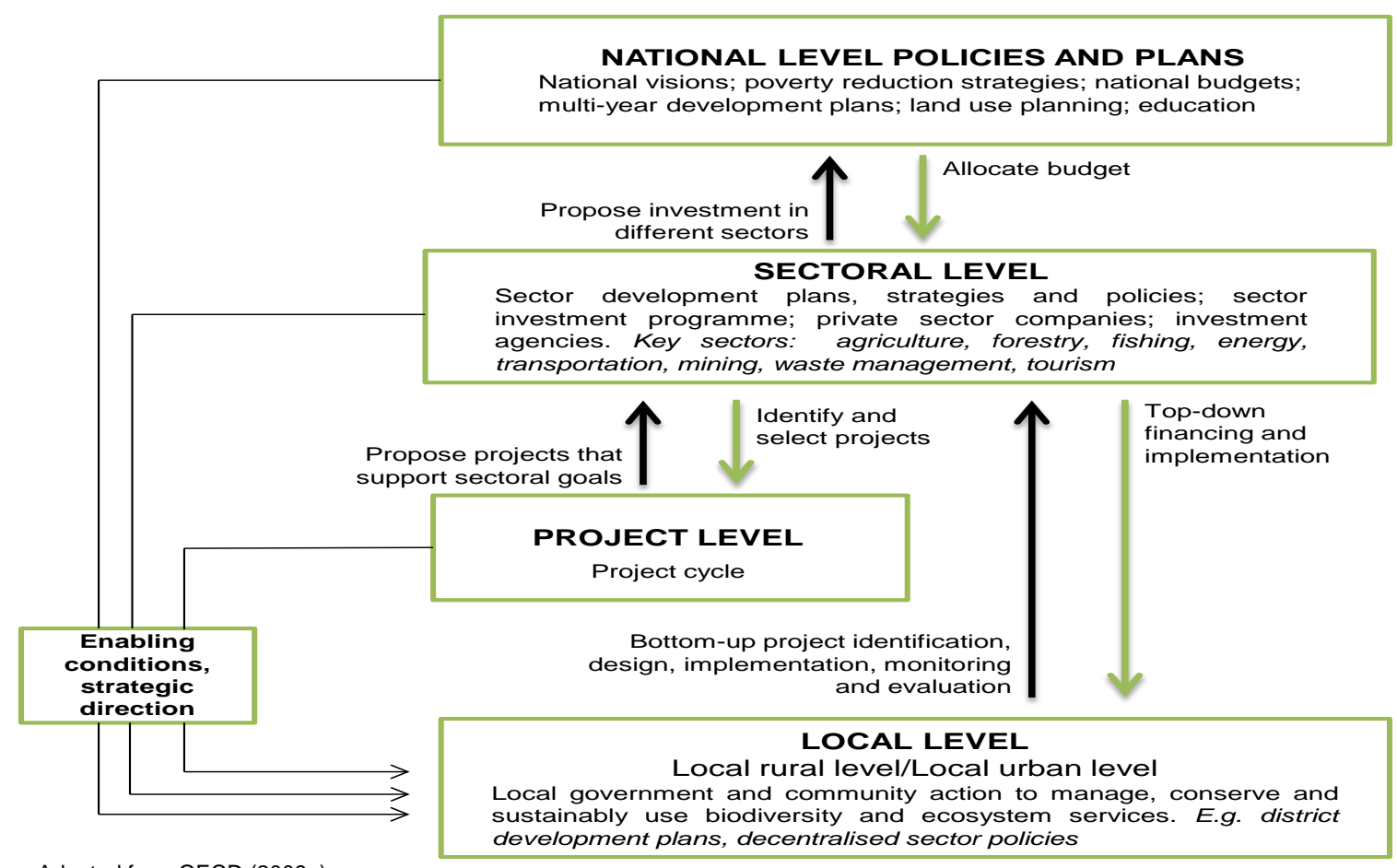

Source: Adapted from OECD (2009a)

19. Intervening at any of these entry points may require use of a wide variety of policy instruments. Relevant instruments range from environmental fiscal reform to information and awareness raising policies. Table 1 below gives an overview of the policy instruments available and a number of illustrations for each of them. 
Table 1. Policy instruments to mainstream biodiversity and development

\begin{tabular}{|c|c|}
\hline Policy Instrument & Examples \\
\hline \multicolumn{2}{|c|}{ Legal/regulatory approaches } \\
\hline Regulations governing use & $\begin{array}{l}\text { Nature protection and conservation such as the establishment of } \\
\text { protected areas; forest management; prohibitions and restrictions on } \\
\text { use; permits and quotas such as for logging and fishing }\end{array}$ \\
\hline Laws governing access & $\begin{array}{l}\text { Ensuring that the poor and traditional and indigenous communities have } \\
\text { clear and enforceable property rights over the land, resources and } \\
\text { ecosystem services upon which they live and depend }\end{array}$ \\
\hline Spatial planning & $\begin{array}{l}\text { Integrated land, water and living resources management (such as the } \\
\text { ecosystem approach) }\end{array}$ \\
\hline Planning requirements & $\begin{array}{l}\text { Making the use of environmental impact assessments (EIA) and strategic } \\
\text { environmental assessments (SEA) compulsory (see Table } 3 \text { for more } \\
\text { details) }\end{array}$ \\
\hline \multicolumn{2}{|r|}{ Economic instruments } \\
\hline Price-based instruments & $\begin{array}{l}\text { Environmental Fiscal Reform e.g. Taxes, fees and charges such as } \\
\text { taxes on pesticide use, fees for natural resource use and access to } \\
\text { national parks, reform of environmentally harmful subsidies }\end{array}$ \\
\hline Biodiversity offsets & $\begin{array}{l}\text { Last step in the environmental impact mitigation hierarchy to offset } \\
\text { residual negative environmental impacts of activities in e.g. mining, } \\
\text { energy, pulp and paper sectors. }\end{array}$ \\
\hline \multicolumn{2}{|c|}{ Information/education and other instruments } \\
\hline Voluntary agreements & $\begin{array}{l}\text { Between businesses, civil society and government for nature protection } \\
\text { and conservation, voluntary offset schemes }\end{array}$ \\
\hline Eco-labelling and certification & Forest Stewardship Council; Rainforest Alliance \\
\hline Green public procurement & $\begin{array}{l}\text { Using certificated products to guide procurement, e.g., of sustainably } \\
\text { harvested timber }\end{array}$ \\
\hline
\end{tabular}

Source: adapted from OECD (2012a), OECD Environmental Outlook to 2050: The Consequences of Inaction, OECD Publishing, Paris, doi: 10.1787/9789264111318-en.

20. Additionally, a number of measurement and assessment tools ${ }^{9}$ are available to assist with the selection of policy instruments and with identification of priorities and targets for the mainstreaming process. Table 2 outlines key types of measurement and assessment tools as well as examples of each. 
Table 2. Measurement and assessment tools for mainstreaming biodiversity and ecosystem services

\begin{tabular}{|l|l|}
\hline \multicolumn{1}{|c|}{ Tool } & \multicolumn{1}{c|}{ Examples } \\
\hline Ecosystem accounting & $\begin{array}{l}\text { Use of System of Environmental-Economic Accounting (SEEA) - Experimental Ecosystem } \\
\text { Accounting in national statistical systems (European Commission et al., 2013) can help to } \\
\text { integrate the value of biodiversity and ecosystem services into traditional accounting frameworks }\end{array}$ \\
\hline Biodiversity indicators & $\begin{array}{l}\text { Indicators can help assess the health of biodiversity and ecosystem services and whether this is } \\
\text { improving or declining. Examples of indicators include marine fish stocks, forest cover, threatened } \\
\text { species and species abundance (see OECD, 2012a and the Biodiversity Indicators Partnership) }\end{array}$ \\
\hline Economic valuation & $\begin{array}{l}\text { The Wealth Accounting and the Valuation of Ecosystems (WAVES) programme, co-ordinated by } \\
\text { the World Bank, is an example of a programme supporting partner countries to economically } \\
\text { value ecosystems, e.g. in terms of services such as protection against natural disasters, jobs }\end{array}$ \\
\hline $\begin{array}{l}\text { Planning and project } \\
\text { assessment }\end{array}$ & $\begin{array}{l}\text { The following tools can be used to assess the possible impact that a plan or a project could have } \\
\text { upon biodiversity, and how these may be managed: } \\
\text { - Strategic Environmental Assessment (TEEB, 2010b; OECD, 2010c, UNEP, 2014a) } \\
\text { Environmental Impact Assessment (TEEB, 2010b) } \\
\text { A manual developed by GIZ called Integrating Ecosystem Services into Development } \\
\text { Planning (GIZ, 2012a) }\end{array}$ \\
\hline Sector assessment & $\begin{array}{l}\text { Targeted Scenario Analysis can be used for mainstreaming biodiversity and ecosystem services } \\
\text { into production sectors (Aplizar \& Bovarnick, 2013) }\end{array}$ \\
\hline Budget assessment & \begin{tabular}{l} 
Public Environmental Expenditure Review (IIED, 2008; OECD 2012b) \\
\hline Source: Authors
\end{tabular}
\end{tabular}

Source: Authors

21. Finally, a number of different approaches may be adopted to engage different stakeholder communities to assist the mainstreaming process. Some of these governance or engagement approaches, as well as examples relevant to biodiversity, are outlined in Table 3.

Table 3. Engagement approaches for mainstreaming biodiversity and ecosystem services

\begin{tabular}{|c|c|}
\hline Approach & Examples \\
\hline $\begin{array}{l}\text { Knowledge sharing and } \\
\text { education campaigns }\end{array}$ & $\begin{array}{l}\text { Increasing awareness of the importance of biodiversity through national Clearing House } \\
\text { Mechanisms and information campaigns in local communities. The central Clearing House } \\
\text { Mechanism is a biodiversity knowledge sharing network to facilitate scientific and technical co- } \\
\text { operation, established by the CBD in order to contribute to the implementation of the Strategic } \\
\text { Plan for Biodiversity. National clearing house mechanisms facilitate effective information services } \\
\text { to support implementation of national biodiversity strategies and action plans. }{ }^{10} \text { The } \\
\text { Communication, Education and Public Awareness (CEPA) programme under the CBD is another } \\
\text { important example.11 Germany undertakes a range of CEPA-related activities both domestically } \\
\text { and in partner countries. For example, in the Philippines, Germany supported a "pride campaign" } \\
\text { in Cortes, Mindanao, Philippines to inspire the local community to take pride in their local species } \\
\text { and habitats, thereby encouraging them to take up alternatives to environmentally destructive } \\
\text { practices (BMU and BMZ, 2014). }\end{array}$ \\
\hline $\begin{array}{l}\text { Community } \\
\text { strengthening and } \\
\text { engagement } \\
\text { approaches }\end{array}$ & $\begin{array}{l}\text { Engagement and consultation of local and indigenous communities directly using and depending } \\
\text { on biodiversity and ecosystem services. For example, this includes inclusive mapping of } \\
\text { biodiversity and ecosystem services, mapping of timing and location of different economic } \\
\text { activities (such as mining, agriculture) (TEEB, 2010b). Community strengthening can include } \\
\text { improving communities' negotiating skills to convince local authorities and businesses to integrate } \\
\text { biodiversity considerations into laws, policies and practices (e.g. OECD, 2013b). }\end{array}$ \\
\hline Regional co-operation & $\begin{array}{l}\text { Regional co-operation and the creation of appropriate institutional structures may be useful to help } \\
\text { to integrate biodiversity and ecosystem services considerations into the management of } \\
\text { transboundary natural resources such as watersheds, marine areas and forests, e.g. the Mekong } \\
\text { River Commission. }{ }^{12}\end{array}$ \\
\hline $\begin{array}{l}\text { Voluntary standards for } \\
\text { business, led by } \\
\text { business }\end{array}$ & $\begin{array}{l}\text { The Equator Principles are a voluntary framework adopted by } 78 \text { banks to apply the International } \\
\text { Finance Corporation Standards, which includes Performance Standard } 6 \text { on Biodiversity } \\
\text { Conservation and Sustainable Management of Living Natural Resources, to all projects over USD } \\
10 \text { million (IFC, 2012). Another example is the Climate, Community and Biodiversity (CCB) } \\
\text { Standards, which are designed to be applied to land management projects, from the early stages } \\
\text { of development through to implementation, to ensure net positive benefits for climate change } \\
\text { mitigation, for local communities and for biodiversity.13 }\end{array}$ \\
\hline
\end{tabular}


22. A combination of policy instruments, tools and engagement approaches may be relevant and used by partner country governments and development co-operation providers to support the mainstreaming of biodiversity and ecosystem services into development; inevitably the mix of approaches and instruments will be tailored to individual country contexts (OECD, 2012a; IIED and UNEP-WCMC, 2013a).

\section{Despite progress, mainstreaming remains a challenge in partner countries}

23. In both developed and developing countries, there is evidence of biodiversity mainstreaming, but this needs to be scaled up, institutionalised and budgeted for. A review of NBSAPs from both developed and developing countries (Prip et al., 2010) found biodiversity and ecosystem services mainstreaming to be well integrated into forestry and tourism sectors, partly integrated into agriculture, and poorly integrated into the fishing, extractive and energy sectors. Mainstreaming of biodiversity and ecosystem services was also found to be not widespread in National Development Plans, Poverty Reduction Strategy Papers (PRSPs) or in development co-operation agencies' policies (Prip et. al., 2010; Roe, 2010b). More recent reporting to the CBD revealed that $85 \%$ of Parties to the Convention (both developed and developing countries) have considered biodiversity in their national priorities or development plans (CBD, 2014d). However, the Secretariat found that some of this integration appears to be incidental or random, often with no institutionalisation or planned process involved. This is reflected by the fact that the explicit integration of biodiversity into national budgetary processes is currently limited to a dozen countries (Burundi, Chile, Comoros, Ecuador, France, Kyrgyz Republic, Mexico, Mozambique, Netherlands, Norway, Tunisia, Vietnam) (CBD, 2014d). Interestingly the countries where national budgetary mainstreaming is occurring do not follow a particular pattern of wealth, spanning low-income and high-income nations.

24. The limited mainstreaming of biodiversity and ecosystem services at national budgetary or development planning level may be due to a lack of awareness, recognition or understanding of the importance of biodiversity and ecosystem services themselves, low awareness of biodiversity-poverty linkages or of biodiversity-economy linkages (Dalal-Clayton and Bass, 2009; Prip et al., 2010; OECD, 2013a). This low level of awareness and understanding is exacerbated by (IIED and UNEP-WCMC, 2013a):

- The complexity and the multidimensional nature of these links;

- Lack of economic valuation of biodiversity and ecosystem services;

- Insufficient evidence in the form of case studies and success stories on the advantages of mainstreaming.

25. As the preamble of the Convention recognises, "economic and social development and poverty eradication are the first and overriding priorities of developing countries" (CBD, 1992). Developing country governments will not prioritise biodiversity and ecosystem services if they cannot be shown to influence high-priority economic and social issues for development such as poverty reduction, food security, health, job creation and economic growth ${ }^{14}$. However, a lack of sufficient data, information, skills and capacity raises makes it difficult to make a convincing case for biodiversity (Dalal-Clayton and Bass, 2009). This is part of a broader capacity challenge faced by developing countries (e.g. OECD, 2013a; OECD, 2012b). Even where there is interest from developing country government actors, limited resources and structures for communicating and co-ordinating between multiple ministries, sectors, stakeholders, and levels of governance can present a challenge to mainstreaming (Dalal-Clayton and Bass, 2009).

\section{Development co-operation provides essential financial and technical assistance in partner countries}

26. Development co-operation providers are using a full range of policy instruments, assessment tools and approaches to support biodiversity mainstreaming in different partner country contexts:

- Education and information campaigns: Since 2010, Belgium has integrated communication, education and public awareness into national biodiversity strategies and policies of its development co-operation practice and has called for the CBD or national Clearing House Mechanism ( $\mathrm{CHM}$ ) focal points to propose projects to 
establish indicators and baseline studies for Aichi Target $1 .^{15}$ In Benin, Belgium supported a year-long campaign through the $\mathrm{CHM}$ to raise public awareness about everyday actions to conserve biodiversity and water (Centre d'échange d'informations du Bénin, 2014). In Niger, Belgium provided capacity-building training for rural development and environment advisors to the Prime Minister's Cabinet and members of the Technical Commission on Biodiversity so that they could better use the $\mathrm{CHM}$ as a communication and education tool on biodiversity and development (Centre d'échange d'informations du Niger, 2014).

- Land use plans: Japan provides technical support to assist with the data collection, conceptualisation and capacity to develop sustainable management plans of areas that balance socio-economic considerations and environmental considerations, in particular biodiversity. For example, Japan is working on the "Sikkim Biodiversity Conservation and Forest Management Project" in India that is, inter alia, helping the local community develop ecotourism so as to continue to benefit from the growing number of tourists visiting Sikkim without increasing the negative impacts on local ecosystems (JICA, 2010a).

- Certification schemes: France's Fonds Français pour L'Environnement Mondial (FFEM) supports certification schemes as a way to integrate biodiversity and ecosystem service considerations into production systems in partner countries. For example, FFEM is working with Fair Trade Africa in Western African countries to build the capacity to put in place 15 organisations of certified producers, of which at least three will be specifically in the domain of biodiversity protection (FFEM, 2014).

- Legislation, Strategic Environmental Assessment: Germany is providing technical support to countries to help implement legislation and Strategic Environmental Assessments (SEA) (GIZ, 2010; BMU and BMZ, 2012). Namibia offers one success story, where Germany has been working with the government since 1994 to support development of a policy and legal framework that strikes a balance between economic development and conserving the environment. In 2007, the Namibian Parliament passed the Environmental Management Act (EMA). Germany is supporting the implementation of the EMA through technical and financial assistance for local experts in developing the regulatory and institutional framework, for drafting regulations and procedures, and for efforts to raise public awareness and networking. Additionally, experts from Namibia and Germany have worked together to develop an SEA training course and to facilitate the use of this instrument. Germany is supporting the use of this tool in the mining sector and in biofuel production (GIZ, 2010).

- Regional co-operation: Sweden has a long history of supporting the Mekong River Commission, comprised of representatives from Cambodia, Lao PDR, Thailand and Viet Nam, in order to promote regional co-operation for the mainstreaming of biodiversity and ecosystem service objectives into regional decision-making processes. The Mekong River is an important livelihood source for over 60 million people, with the fish, rice and vegetables harvested in the watershed providing both food and income for the local population. Regional co-operation is therefore necessary to ensure that the Mekong River continues to provide essential ecosystem services to the poor in all four countries (Karin Isaksson, Swedish International Development Co-operation Agency (Sida), personal communication, 15 September 2014).

\section{Good practice notions for supporting mainstreaming in partner countries}

27. The literature identifies a number of emerging and overarching good practices in development co-operation's support of in-country mainstreaming biodiversity and development (Huntley and Redford, 2014 and OECD, 2010a). Lessons learned through development cooperation were further reinforced by feedback received from eight leading African countries (Botswana, Liberia, Malawi, Namibia, Seychelles, South Africa, Uganda, Zimbabwe) working to mainstream biodiversity in development planning and policy. ${ }^{16}$ Namely, providers may: 
- Offer technical support and institutional capacity building for the formulation and implementation of plans, policies, programmes, or projects that are developed and owned by the partner country according to their needs and priorities to secure alignment, ownership and sustainability after providers' interventions have ceased;

- Allocate sufficient time to see change in biodiversity and in institutions, recognising that mainstreaming is an organic and long-term process requiring at least 10-15 years of sustained support;

- Identify and involve all relevant stakeholders in a transparent and inclusive manner; create a learning and listening process whereby all stakeholders can voice their views and develop solutions together;

- Develop and implement the means to monitor and reflect on the mainstreaming process; this should allow for learning from past experience, and for modifications to be made based on these learnings;

- Ensure that efforts to integrate biodiversity and development are evidence-based, using scientific findings, biophysical and socio-economic data collection and economic assessments, and support partner countries to develop the capacity to collect these data and perform these calculations themselves (e.g. biodiversity and ecosystem valuation);

- Support the development of transparent and accountable frameworks and processes, which are a pre-requisite to successful mainstreaming;

- Streamline and simplify the process by which partner countries can apply for support for mainstreaming projects; biodiversity-related development finance has declined in some countries simply because partner country governments lack the time, technical knowledge and skills to develop proposals that meet the sometimes elaborate requirements set out by providers;

- Support partner countries to make the case for biodiversity. This may involve helping to identify the right target audience and tailoring the messages to that audience, and providing support to develop the evidence that might support the case such as the economic valuation of biodiversity and ecosystem services.

\section{Providers are mainstreaming biodiversity and ecosystem services into their own practices}

28. Development co-operation providers take a range of approaches to mainstreaming biodiversity and ecosystem services into their own policies and programmes, to ensure that biodiversity is taken into account in all activities. While some providers have environmental policies that do not explicitly treat biodiversity as a cross-cutting theme across their programmes (e.g. Denmark, ${ }^{17}$ New Zealand, Portugal, Spain, Sweden), others have a specific environmental policy where biodiversity and ecosystem services are recognised as key a component (e.g. Austria, Finland, Ireland, Japan, Norway). Several providers now have a stand-alone strategy or policy for biodiversity and ecosystem services (e.g. Austria in addition to its environmental policy, Belgium, European Union, France, Germany, United States) (CBD, 2014d).

29. A comprehensive overview of mainstreaming biodiversity into development co-operation in 2010 found that while about half of OECD DAC members' development co-operation agencies paid significant attention to biodiversity, ${ }^{18}$ climate change remained a more prominent focus (Roe, 2010b). However, a number of providers have been developed more stand-alone biodiversity policies to guide actions of their development co-operation agencies since $2010 .^{19}$ Stand-alone policies for biodiversity indicate a heightened awareness within agencies, which may translate to biodiversity and ecosystem services being taken into account more broadly and explicitly in development co-operation activities. These stand-alone biodiversity policies also contain mechanisms to integrate biodiversity into all activities of the development co-operation agency, including dedicated financial means. Agency policies on climate change can also provide an entry point for biodiversity mainstreaming, given the numerous linkages and cobenefits between them (see CBD, 2009b). 
30. A number of OECD DAC members have a compulsory biodiversity screening system in place, which means that every development co-operation activity must be screened for potential harmful impacts upon biodiversity and ecosystem services. Where activities are found to have potentially significant negative impacts on biodiversity and ecosystem services, a Strategic Environmental Assessment (SEA), Environmental Impact Assessment (EIA) and/or Environment Management Plan (EMP) must be carried out. Members with this policy include Australia, Austria, the European Commission, France, Germany, Japan, Sweden (see Box 3) and the United States (AFD, 2013; AusAID, 2012; European Commission, 2011; GIZ, 2010; JICA, 2010b; Sida, 2014; USAID, 2013).

\section{Box 3. Mainstreaming biodiversity and the environment at the Swedish International Development Cooperation Agency (Sida)}

Sida's Environmental Management System aims to avoid supporting environmentally unsustainable activities, including those that would harm biodiversity. Programmes that are screened and found to have a significant environmental impact require an extensive, detailed and formal environmental assessment. For activities that are expected to have a small environmental impact, the environmental assessment can be brief. The main purpose of Sida's environmental assessment and review procedures is to identify, in a systematic manner, the environmental risks and opportunities of every proposed development co-operation activity. An assessment early on in the programme cycle can improve development results by limiting or eliminating negative impacts, and by ensuring that opportunities for positive outcomes are seized. The assessment process itself, including the necessary dialogue between Sida and the partner country, can also help improve development results by building the capacity of partner country to analyse and address the environmental and social aspects of development and, in the longer term, strengthen their ownership of environmental issues. Finally, an environmental assessment early in the planning cycle may also save costs later on, thereby helping to make Swedish international development cooperation more efficient.

Source : Example provided by Karin Isaksson, Swedish International Development Cooperation Agency (Sida), 15 September 2014.

31. A number of development co-operation providers have processes in place to train and raise the awareness of staff working across their development agencies, and even in other governmental administrations, about how to take biodiversity considerations into account in their work:

- Belgium has the objective of "[improving] the mainstreaming of biodiversity and ecosystem services in policy sectors that have high relevance for development" enshrined in its Building capacities for biodiversity for sustainable development and poverty reduction strategy 2014-2023. The Royal Belgian Institute of Natural Sciences (RBINS) and Directorate General for Development Co-operation (DGD) have organised a series of nine-hour training sessions on biodiversity and ecosystem services that have been delivered to programme and project managers of DGD and staff in other federal administrations. Feedback from these sessions is being used to design more specialised training for staff working across Belgian Development Co-operation, e.g. on options for the sustainable management of ecosystems (RBINS, 2013).

- Sweden's Sida established a Helpdesk function for Environment and Climate Change in 2011, to help Sida staff integrate environmental considerations (including biodiversity) into Swedish development co-operation. The Helpdesk gives support, on demand, by providing advice and strategic guidance on environmental integration at the policy, programme and project level. The Helpdesk also develops tools and methods for environmental mainstreaming and facilitates dialogue concerning environmental issues (Karin Isaksson, Sida, personal communication, 15 September 2014).

- USAID's Biodiversity Policy, released in July 2014, has "integrating biodiversity as an essential component of human development" as one of its two goals with the other being to "conserve biodiversity in priority places". The policy states that USAID will promote the integration of biodiversity into priority sectors including: agriculture, food security, climate change, health, democracy and governance, economic growth, and trade. Implementation of the policy is primarily focused on improving the 
evidence base for biodiversity integration, increasing internal capacity of staff to effectively integrate, and improving existing processes in USAID to promote biodiversity mainstreaming. For example, this may include integrating biodiversity values and externalities into USAID's Cost-Benefit Analysis and Growth Diagnostic models, integrating biodiversity conservation approaches into existing sectoral trainings, and refining development practices and tools to support the achievement of biodiversity conservation outcomes (USAID, 2014).

- France's Agence Française de Développement (AFD) has developed a Biodiversity Cross-Sectoral Intervention Framework 2013-2016 that has, as one of three pillars, the obligation that all actions, projects and programmes financed by AFD "integrate the conservation of ecosystems and the services that depend on them into development policies and all their sectoral dimensions". This is done, inter alia, by ensuring that biodiversity and ecosystems are integrated into strategic documents during the drafting or updating of Sectoral Intervention Frameworks or Regional and Country Intervention Frameworks; ensuring that no projects funded by AFD cause a net loss in the biodiversity of critical habitats; ensuring that a "Sustainable Development Second Option" outlining the contribution of potential projects to sustainable development, including preservation of biodiversity, is included as an annex during the appraisal of projects funded by AFD (AFD, 2013).

\section{Gaps identified and possible areas for future work}

32. This section gives an initial overview of how different policy instruments, measurement and assessment tools, and engagement approaches to mainstreaming are being used. The documentation of experience however remains limited as does systematic assessment of which approaches have proven to be more or less successful or efficient in different contexts, and why. Further work could be useful to develop more case examples to compare performance of these in different country contexts and circumstances. With respect to mainstreaming in development co-operation organisations, the increasing existence and use of screening tools is positive. However, further work would be necessary to understand whether these tools are having the intended positive impact, including with regard to biodiversity and ecosystem services. Furthermore, additional work would be needed to gain a more comprehensive understanding of how mainstreaming biodiversity and ecosystem services is performed across all development co-operation organisations. Finally, it would also be interesting to review current good practice (e.g. in Belgium, France or the United States) to assess if and how providers have increased the mainstreaming of biodiversity and ecosystem services across their organisation.

\section{Endnotes Section II}

8. But see http://www.iied.org/nbsaps-20-mainstreaming-biodiversity-development for a wide range of tools and guidance.

9. These are called policy support tools by the work under the Intergovernmental Panel on Biodiversity and Ecosystem Services (IPBES).

10. For more information see www.cbd.int/chm/.

11. For more information see www.cbd.int/cepa/.

12. For more information see www.mrcmekong.org/.

13. For more information see www.climate-standards.org/.

14. This has implications for development co-operation, which should be driven by priorities determined by partner countries (Paris Declaration on Aid Effectiveness, 2005; Accra Agenda for Action, 2008; Busan Partnership for Effective Development Co-operation, 2011; CBD COP11 Decision XI/4; Roe, 2010b).

15. Aichi Target 1: By 2020, at the latest, people are aware of the values of biodiversity and the steps they can take to conserve and use it sustainably.

16. This feedback was received at the third workshop of the NBSAP 2.0 Mainstreaming Biodiversity and Development project, held in Namibia on $23-25$ July 2014. A summary of the workshop (Thomas, 2014) is available online at http://pubs.iied.org/G03827.html.

17. For example, Denmark's Strategic Framework for Natural Resources, Energy and Climate Change (2012) addresses biodiversity within the broader context of sustainable agriculture and food production, and the sustainable management of natural resources, water and land.

18. The development co-operation provider either has a stand-alone strategy or policy for biodiversity or biodiversity is explicitly integrated into its environmental strategy/policy.

19. E.g. Belgium, the European Union, France, United States. 


\section{MANAGING FOR RESULTS}

\section{Setting clear, measurable objectives is essential to effectively manage for results}

33. Focusing on results is a crucial element of development co-operation, as emphasised in the Busan Declaration on Effective Development Co-operation (OECD, 2011). This means ensuring that development co-operation investments and efforts have a lasting impact on reducing poverty and inequality and on achieving sustainable development, which encompasses the conservation and sustainable use of biodiversity and ecosystem services. This should be done through enhancing developing countries' capacities, aligned with the priorities and policies set out by developing countries themselves (Busan Declaration, 2011) (see Section 5 and Box 8 for more details).

34. The first step to managing for results is to clearly identify the objectives of the development co-operation activity from the very beginning. This is important for the design of any development co-operation activity and is also a pre-requisite for neutral evaluation during and after the activity (OECD, 1991; see Section 4 for more details). In the context of biodiversity and development, there are likely to be objectives focusing on poverty reduction and on the conservation and sustainable use of biodiversity and ecosystem services. Practice to date shows that while it is possible to achieve benefits in both areas, (Munang et al., 2014; Kareiva et al., 2008), trade-offs are likely to remain (Hirsch et al., 2010; Barrett et al., 2011; McShane et al., 2011; Roe et al., 2011; Salafsky, 2011; Redpath et al., 2013). Clarifying whether there are priorities among the different objectives, i.e. more poverty-centric or nature-centric (see Box 4), is important to guide the design of the activity and help manage any possible trade-offs. Doing so requires participation and full engagement from both development co-operation providers and partner countries (Barret et al., 2011; Salafsky, 2011).

\section{Box 4. Poverty-centric and nature-centric approaches}

Identifying and prioritizing the objectives of a biodiversity-related development co-operation activity from the start is essential. There are a number of lenses through which to view the objectives and priorities of such an intervention. A poverty-centric approach prioritises how biodiversity and ecosystem services can be instrumental in reducing poverty, and will often target areas outside of biodiversity hotspots and critical habitats. In contrast, a nature-centric approach to biodiversity mainstreaming will prioritise areas of particular biodiversity significance, such as biodiversity hotspots and critical habitats, to deliver the greatest biodiversity benefits. "Biodiversity hotspots" are those areas containing exceptional concentrations of endemic species that are undergoing exceptional loss of habitat (Myers et al., 2000). The International Finance Corporation defines "critical habitats" as areas with high biodiversity value, including (i) habitat of significant importance to Critically Endangered and/or Endangered species (as determined by the IUCN Red List).; (ii) habitat of significant importance to endemic and/or restricted-range species; (iii) habitat supporting globally significant concentrations of migratory species and/or congregatory species; (iv) highly threatened and/or unique ecosystems; and/or (v) areas associated with key evolutionary processes. Poverty- and nature-centric approaches are not mutually contradictory but prioritise different aspects of an intervention (for further information see Miller, 2014).

Sources : Miller, D. (2014), "Explaining Global Patterns of International Aid for Linked Biodiversity Conservation and Development”, World Development, Vol. 59, pp. 341-359; Myers, N. et al. (2000), "Biodiversity hotspots for conservation priorities", Nature, Vol. 403, pp. 853-858.

35. The next step is to develop indicators to measure progress towards the objectives. This is important for the design of the activity, to monitor progress and to evaluate results, and will require clarity in how key concepts are understood and operationalised (see Box 1). Several frameworks can help in this respect. The Biodiversity Indicators Partnership (BIP), for example, can help assess the state, pressures and changes related to biodiversity and ecosystem services. The BIP was established in 2007 to promote and co-ordinate the development and delivery of biodiversity-related indicators, thereby supporting countries to evaluate progress towards meeting the twenty global Aichi Biodiversity Targets and national biodiversity goals. To date, 39 indicators cover trends in the extent, condition and vulnerability of ecosystems, biomes and habitats, trends in pressures from unsustainable agriculture, forestry, fisheries and aquaculture, and trends in coverage, condition, representativeness and effectiveness of protected areas and other area-based approaches. The BIP "National Indicator Development Toolkit" provides guidance, training materials and examples of how to develop national and subnational level indicators for biodiversity and ecosystem services. 
36. The System for Economic and Environmental Accounting (SEEA) ${ }^{20}$ is another useful framework to support decision-making, notably through its module on Experimental Ecosystem Accounting (EEA) (European Commission et al., 2013). SEEA is an internationally agreed methodology, based on the System of National Accounts, which is the backbone of internationally-agreed national economic statistical systems. SEEA integrates information on the environment, such as the raw data and the indicators developed through the BIP, into national economic accounting frameworks, thereby reflecting biodiversity, ecosystem services and all other elements of the environment as assets ("natural capital"). It helps track the use and depletion of natural capital and can generate data to develop biodiversity-relevant indicators, e.g. state, pressure, response indicators. SEEA can help answer questions such as: who benefits from the use of biodiversity and ecosystem services, how their depletion affects the real income of the country, and whether production and consumption trends impacting upon biodiversity and ecosystem services are sustainable (SEEA, n.d.). The Wealth Accounting and the Valuation of Ecosystem Services (WAVES) programme, run by the World Bank, is an example of putting SEEA into action (see Box 5).

\section{Box 5. The Wealth Accounting and the Valuation of Ecosystem Services (WAVES) programme}

The Wealth Accounting and the Valuation of Ecosystem Services (WAVES) programme, run by the World Bank, is supporting eight developing countries (Botswana, Colombia, Costa Rica, Guatemala, Indonesia, Madagascar, the Philippines and Rwanda) to compile accounts of their natural resources, such as water, forests and mangroves. These natural resource statistics are used to build the evidence base and inform decision makers about the contribution of this natural capital to the country's economy. For example, accounting in the Philippines is being used to assess the current state of mangroves, to evaluate the success of existing mangrove reforestation programmes, show the contribution of mangroves to local income (e.g. how many people are employed and what the revenue is from fishing, timber and non-timber products, and tourism associated with mangroves), and show the contribution of mangroves to climate change resilience. WAVES aims to help governments understand and determine the most sustainable uses of key natural resources (WAVES, 2014).

Source: Wealth Accounting and the Valuation of Ecosystem Services (WAVES) (2014), Philippines, https://www.wavespartnership.org/en/philippines, last accessed 24 October 2014.

\section{Striving for the right balance between trade-offs and benefits}

37. In the context of biodiversity and development, trade-offs may exist where there are management choices concerning competing uses of land, water and living resources (Sayer et al., 2013). These trade-offs relate to the distribution of costs and benefits (Roe et al., 2011; McShane et al., 2011):

- $\quad$ over space (some benefits in one place, some costs in another - either between local, national and international levels, or between different local areas),

- over time (some benefits now, some costs later, or vice versa) or

- across beneficiaries (some actors win, others lose).

Since the economic value of biodiversity and ecosystem services is most often not reflected in market prices, these services are generally undervalued or not considered in decisions concerning land, water and/or resource use options (OECD, 2002; TEEB, 2010b; UNDP, 2012). These decisions present inherent trade-offs as they change the type, magnitude and relative mix of biodiversity and ecosystem services, entailing long term ecological, economic and social consequences (Redpath et al, 2013; GIZ, 2012a; McShane et al, 2011).

38. Synergies and co-benefits between biodiversity, ecosystem services and poverty reduction are also possible, and policy and project design can aim to maximise these. For example, conserving and sustainably using biodiversity and ecosystem services can provide health benefits (e.g. via clean air, water and nutrition), food security, jobs, resilience against natural disasters, gender and adaptation benefits to local communities, as well as supporting global efforts in climate change mitigation (Munang et al., 2014; Harvey et al., 2013; CBD, 2009b). Additionally, biodiversity and ecosystem services provide traditional medicines used by an estimated $60 \%$ of the world's population (WHO, 2014) and can reduce the spread of infectious diseases (Stem et al., 2014; WHO, 2014; Roe, 2010b). Another example where synergies exist is ecosystem-based adaptation, which is the use of biodiversity and ecosystem 
services to help people and communities adapt to climate change (Munang et al., 2014). For example, in Togo, ecosystem-based adaptation was used to rehabilitate water reservoirs to boost water security and quality, and to increase the capacity of women and youth to work in irrigation and crop-related employment, leading to greater agricultural production, greater crop diversity (and therefore greater food security), and greater social inclusion (Munang et al., 2014). Another example is the work of "Mangroves for the Future," which supports local communities across 12 Asian countries to restore and sustainably manage coastal ecosystems, to increase resilience against natural disasters and to improve livelihoods for local communities (Mangroves for the Future, 2014).

\section{A wealth of tools exist to identify and manage trade-offs and synergies}

39. Trade-offs and synergies between biodiversity, ecosystem services and development, in particular poverty reduction, can be highly complex and multidimensional, making them difficult to identify and to manage. Cost-benefit analysis (CBA), multi-criteria analysis (MCA), and targeted scenario analysis (TSA) provide useful frameworks to do so (for technical details see: Aplizar and Bovarnick, 2013; TEEB, 2010b; and OECD, 2006b). An important step for each is putting a comparable value on the outcomes of different interventions and comparing these to a baseline. Some but not all frameworks require monetising the costs and benefits of the activity (e.g. CBA requires this, MCA does not). Attaching a monetary value to biodiversity and ecosystem services can ensure that it is properly integrated into decision-making processes (UNDP, 2012; TEEB, 2010b; OECD, 2002). While the economic valuation of biodiversity and ecosystem services is essential in CBA, it can also be partial (due to lack of data), judgemental and sometimes controversial (e.g. some services may be irreplaceable by physical or manmade capital). Multi-criteria analysis and targeted scenario analysis, or other complementary approaches based on a variety of non-monetary metrics, may also support decision making.

40. CBA, MCA, TSA, and economic valuation of biodiversity and ecosystem services are technical, data intensive exercises that require expertise, time and a commitment of funding over what may be an extended period of time. Where valuation or economic analysis occurs, it is possible to use simple methods so as to limit the time and resources required for assessment (Drakenberg, et al. 2008).

41. Building on these frameworks, several tools are available today to assist with identification and management of trade-offs and synergies in the design of biodiversity-related development co-operation activities or other similar public interventions (see Table 4). These include spatial mapping tools that can be used to improve the spatial understanding of where land and water use conflicts and synergies, and biodiversity-poverty-development tensions and synergies, are most likely to occur. Dramatic improvement in Geographic Information Systems (GIS) has led to the development of a number of free online tools that can be used to this effect, such as InVEST and Vital Signs. Mapping can be used in any location ${ }^{21}$ A variety of other software tools exist to estimate and map the impacts of specific public activities designed to deliver biodiversity, ecosystem service and development benefits as a support for managing trade-offs and synergies in decision-making. These include the Landscape Outcomes Assessment Methodology (LOAM); the Open Source Impacts of REDD+ Incentives Spreadsheet (OSIRIS); the Carbon Biodiversity Calculator; and Marxan (see Table 4 for more details).

42. Another example of a relevant tool is Reducing Emissions from Deforestation and Forest Degradation Social and Environmental Safeguards (REDD+ SES). REDD+ SES consist of principles, criteria and indicators around policy, process and outcomes. These define issues of concern and conditions to be met to achieve high social and environmental performance, and lay out a process for assessment (REDD+ SES, 2012). REDD+ SES can be used to structure country-led assessment and dialogue around REDD+ programme design, implementation and outcomes such that they respect the rights of indigenous peoples and local communities and generate both social and biodiversity-relate benefits.

43. Though costly to carry out, such formal assessments provide an important foundation of knowledge upon which to base decisions (e.g. James, 2013) and a means to manage trade-offs and maximise synergies. Formal ex ante assessments can also be used as an input to support ex-post evaluation as a means to manage performance over time (see Section 4). 
44. Aligning the assessment with policymakers' and stakeholders' priorities (e.g. economic growth, poverty reduction, fiscal balance and public health) will increase the influence on policy decisions. In addition to using software tools to understand trade-offs, it is also important to directly engage with the relevant stakeholders to understand how these trade-offs are perceived. Participatory appraisal is an approach that involves asking stakeholders how the biodiversity and ecosystem services in question affect them, how they affect the biodiversity and ecosystem services, how they perceive and value biodiversity and ecosystem services, and how each scenario elaborated would impact them. Participatory appraisal should be a collective, transparent process, generally run by a facilitator who is not a part of any of the stakeholder groups. To assist this process, a variety of techniques can be used, such as participatory maps (e.g. on which stakeholders can map resource boundaries, health and education services, places where cultural and spiritual activities take place etc.), Venn diagrams (to reflect how issues are interconnected), seasonal calendars (to reflect annual schedules of activity and variation) and trend analysis (to see how ecosystem services have changed over years, and the impact that that has had on stakeholders). Participatory appraisal can help to conceptualise not only the costs and benefits of each policy, programme, plan, project option, but also of the distribution of these costs and benefits. Successfully managing such engagement with affected stakeholders also requires a commitment of time and resources (TEEB, 2010b). 
Table 4. Examples of support tools to identify and manage trade-offs and synergies

\begin{tabular}{|c|c|c|}
\hline \multicolumn{2}{|r|}{ Name of tool } & Description \\
\hline \multirow{2}{*}{$\begin{array}{l}\frac{0}{0} \\
\frac{0}{0} \\
\frac{.}{2} \\
\frac{0}{2} \\
\frac{\pi}{2}\end{array}$} & $\begin{array}{l}\text { InVEST (Integrated } \\
\text { Valuation of } \\
\text { Environmental } \\
\text { Services and Trade- } \\
\text { Offs) }\end{array}$ & $\begin{array}{l}\text { InVEST is a software tool developed by the Natural Capital Project that models biodiversity } \\
\text { and ecosystem services over different spatial and time scales, under different scenarios. } \\
\text { InVEST can be used to support spatial planning, SEAs, EIAs, Payments for Ecosystem } \\
\text { Services (PES), permits and mitigation, and climate adaptation strategies. This tool is } \\
\text { already used widely; for example, in China, Colombia, or Indonesia (TEEB, 2010b). } \\
\text { InVEST can be applied to any country, provided that there is the data to feed into the } \\
\text { model. }\end{array}$ \\
\hline & Vital Signs² & $\begin{array}{l}\text { Vital Signs is a risk management tool designed specifically for designing and monitoring } \\
\text { policies, plans, programmes and projects targeting agricultural development. It provides } \\
\text { near real-time integrated data on agricultural management and productivity, ecosystems } \\
\text { and human well-being. To date, Vital Signs is in use in Ghana and Tanzania and it will } \\
\text { soon be used in Uganda, Ethiopia, Mozambique. }\end{array}$ \\
\hline \multicolumn{2}{|c|}{$\begin{array}{l}\text { Landscape Outcomes } \\
\text { Assessment } \\
\text { Methodology (LOAM) }\end{array}$} & $\begin{array}{l}\text { LOAM is a process and a methodology developed by the World Wildlife Fund (WWF) to } \\
\text { measure, monitor and communicate the nature and extent to which a landscape is } \\
\text { changing over time with respect to a small number of agreed conservation and livelihood } \\
\text { outcomes. It can be used as a tool to facilitate dialogue and understanding between } \\
\text { different stakeholders using the landscape, to understand landscape change, and to } \\
\text { determine priorities for the use of a landscape. }\end{array}$ \\
\hline \multicolumn{2}{|c|}{$\begin{array}{l}\text { The Open Source } \\
\text { Impacts of REDD+ } \\
\text { Incentives Spreadsheet } \\
\text { (OSIRIS) }\end{array}$} & $\begin{array}{l}\text { OSIRIS is a suite of free, transparent, open-source, spreadsheet-based decision support } \\
\text { tools specifically for estimating and mapping the climate, forest and revenue benefits of } \\
\text { alternative policy decisions for reducing emissions from deforestation and forest } \\
\text { degradation (REDD+). Although originally designed from a climate change mitigation } \\
\text { perspective, it can be a useful tool for assessing potential synergies between biodiversity } \\
\text { and climate change involved in different policy decisions. }\end{array}$ \\
\hline \multicolumn{2}{|c|}{$\begin{array}{l}\text { Carbon Biodiversity } \\
\text { Calculator }^{5}\end{array}$} & $\begin{array}{l}\text { This tool is useful for understanding the synergies between biodiversity conservation and } \\
\text { restoration on the one hand, and climate change mitigation on the other. The calculator } \\
\text { allows the user to define a particular area of interest on the map, and to calculate an } \\
\text { estimated contribution of this area to climate change mitigation, while simultaneously } \\
\text { providing information on the area's conservation values, protected areas, forest status and } \\
\text { opportunities for forest and landscape restoration. }\end{array}$ \\
\hline \multicolumn{2}{|c|}{ Marxan 6} & $\begin{array}{l}\text { Marxan is a free conservation planning toolset that supports design and decision making } \\
\text { by, among other functions, producing a number of different options that meet both welfare } \\
\text { and conservation objectives. Marxan has also been used to support multiple-use zoning } \\
\text { plans that balance the different interests of a wide range of stakeholders. For an example } \\
\text { of Marxan in use by the Africa Biodiversity Collaborative Group, see wa Mutu, 2014. }\end{array}$ \\
\hline \multicolumn{2}{|c|}{$\begin{array}{l}\text { tes: } \\
\text { InVEST: http://www.naturalcapitalproject.org }\end{array}$} & Vital Signs: $h$ http://vitalsigns.org/ \\
\hline
\end{tabular}

45. Providers can help partner countries with technical expertise, training and capacity building to perform CBA, MCA, TSA and economic valuations and update them as necessary (see Box 6). 


\section{Box 6. BUILD: An example of development co-operation support for biodiversity trade-offs and synergies assessment of infrastructure}

Biodiversity Understanding in Infrastructure and Landscape Development (BUILD), funded by USAID with support from the Gordon and Betty Moore Foundation and implemented by the Conservation Strategy Fund (CSF), aims to create lasting human capacity for energy and transport infrastructure analysis in partner countries that assesses the ecological and economic trade-offs involved in infrastructure investment decisions. It does this through a series of training courses (e.g. covering economic tools such as environmental valuation methods and cost-benefit analysis, plus communication and negotiation techniques), regional forums, and in-depth analyses of specific infrastructure projects with partner governments and other organisations. To date, BUILD has been applied in activities in the Andes-Amazon region (Peru, Bolivia, Brazil), in the Albertine Rift (Uganda, Rwanda, Kenya, Tanzania, Democratic Republic of Congo), and in the Himalayan region (CFS, 2014).

Source: Conservation Strategy Fund (CSF) (2014), Biodiversity Understanding in Infrastructure and Landscape Development (BUILD), http://conservationstrategy.org/en/node/1031\#.U-EilPmSxHV, last accessed 5 August 2014.

\section{Good governance, engagement and management principles to address trade-offs and maximise benefits}

46. The literature points to a number of overarching management approaches and principles to help achieve mutually reinforcing biodiversity and development outcomes and safeguard against unintended negative outcomes. These may be used and supported by providers of development co-operation. ${ }^{22}$ They apply to all stages of decision- and policy-making, and include the necessity to build strong governance, institutions and legal frameworks to support good decision-making. They also include approaches to ensure open, multi-stakeholder dialogue as well as those to compensate negatively affected local communities. Finally, adopting a landscape or other ecosystem approach, use of a precautionary approach and more broadly pursuing policy coherence can help to address trade-offs and maximise benefits.

\section{Build strong governance, institutions and legal frameworks}

47. Strong governance, institutions and legal frameworks are crucial to ensure that the biodiversity-related intervention is implemented and has the intended impacts (Armah et al., 2013; Gardner et al., 2013; Manzoor Rashid et al., 2013; Sayer et al., 2013; Vaz and Agama, 2013; Sandker et al., 2012; Billé et al., 2012; UNDP, 2012; Roe et al., 2011; Roe, 2010a). Key elements in this respect include: clear, enforceable property rights and land tenure; clearly defined roles and responsibilities; combatting elite capture and corruption; building local customs into national legislation; and implementing robust monitoring and enforcement mechanisms (see Box 7). 


\section{Box 7. The importance of strong governance, institutions and legal frameworks}

Land tenure and property rights are important for determining who has the right to use what land and natural resources, and consequently who reaps the benefits from their use. The poor often have low social capital and a weaker voice in the political process (which are two of the multiple dimensions of poverty), and therefore are often the worst off in any land dispute or are unable to participate in processes determining land-related laws, resulting in a restriction in their access to and benefits from natural resources (OECD, 2013b; Armah et al., 2013; Roe, 2010a).

When the roles and responsibilities of governments and resource management institutions are not clearly defined, conflicts are more likely to arise. Additionally, when accountability mechanisms are not in place, corruption is likely to be higher. Once again, as the poor often have the weakest social capital and political voice, they are the most likely to lose from these conflicts and this corruption (Armah et al., 2013; Manzoor Rashid et al., 2013).

Elite capture is the phenomenon whereby the elite - those with more assets, power and a higher social status - capture the bulk of the benefits from the exploitation of biodiversity and natural resources, without distributing the benefits to the poor communities living in these areas. If laws intended to govern the sustainable use of natural resources, or other relevant laws such as property rights, are violated without sanction due to a lack of compliance and enforcement permitted by corrupt practices, this can lead to negative outcomes for biodiversity and for the poor (Mohammed and Inoue, 2014; Manzoor Rashid et al., 2013; Sandker et al., 2012; Roe, 2010a; OECD, 2008a).

Sources: Armah, F.A. et al. (2013), "Management of natural resources in a conflicting environment in Ghana: unmasking a messy policy problem", Journal of Environmental Planning and Management, http://dx.doi.org/10.1080/09640568.2013.834247; Manzoor Rashid, A.Z.M. et al. (2013), "A journey towards shared governance: Status and prospects for collaborative management in the protected areas of Bangladesh", Journal of Forestry Research, Vol. 24, Issue 3, pp.599-506; Mohammed, A.J. and Inoue, M. (2014), "Linking outputs and outcomes from devolved forest governance using a Modified Actor-PowerAccountability Framework: Case Study from Chilimo forest, Ethiopia", Forest Policy and Economics, Vol. 39, Issue C, pp.21-31; OECD (2013b), Scaling-up Finance Mechanisms for Biodiversity, OECD Publishing, Paris, doi: 10.1787/9789264193833-en; OECD (2008a), Natural Resources and Pro-Poor Growth: The Economics and Politics, DAC Guidelines and Reference Series, OECD Publishing, Paris; Roe, D. (2010a). "Linking Biodiversity Conservation and Poverty Alleviation: A State of Knowledge Review", CBD Technical Series 55, Secretariat of the CBD, Montreal. Available at www.cbd.int/doc/publications/cbd-ts-55-en.pdf

\section{Ensuring open, multi-stakeholder dialogue}

48. An essential ingredient for strong biodiversity and development planning and policy is a multi-stakeholder approach that is inclusive, transparent and built on trust (Roe et al., 2011; Redpath et al., 2013; Sayer et al., 2013). Such an approach acknowledges that trade-offs are possible, and that different stakeholders perceive them differently; engagement will ensure that stakeholder needs and concerns are considered, fostering joint ownership of the plan, programme, policy or project. A multi-stakeholder approach can deliver a compromise that is more acceptable to most people, and can dvelop a clearer picture of the broader context within which the intervention is operating (McShane et al., 2011; Hirsch et al., 2010; Redpath et al., 2013; Sayer et al., 2013).

49. One principle guiding open, transparent stakeholder dialogue with indigenous and local communities is Free Prior and Informed Consent (FPIC). This was first laid out in the 1989 International Labour Organisation's Convention on Indigenous and Tribal Peoples in Independent Countries (ILO 169), and was subsequently reinforced by the 2007 United Nations Declaration on the Rights of Indigenous Peoples (UNDIRP). FPIC is now considered to be best practice for negotiations between indigenous peoples and any other entity regarding land, culture, property, resources and conservation (First Peoples Worldwide, 2013; UNDIRP, 2007).

\section{Compensating communities that are negatively affected}

50. If an area is chosen for an intervention, e.g. creation of a protected area, the affected local communities can be assisted so that their welfare is not harmed. Financial transfers can avoid perverse incentives (e.g. illegally exploiting the land or water resources). However, avoiding or minimising impacts on local communities should be priorities before compensation. Assistance can include:

- The establishment of Payment for Ecosystem Services (PES), so that local communities are compensated for maintaining the ecosystem service instead of exploiting the land, water or living resources for alternative purposes (e.g. see "compensation for opportunities skipped (COS), van Noordwijk and Leimona, 2010). In the use of PES, it is important that the payment is at least as high as the income that the community would earn from the highest paying alternative use of the land. It is also essential that the local community supports and believes in the programme. 
This second step would require the local community to be fully involved in the design of the PES programme from the beginning, and education and training in the value and importance of biodiversity and ecosystem services (Sandker et al., 2012).

- The development of appropriate alternative options for local communities to subsist and raise revenue: if a biodiversity-related intervention limits the ability of the local population to use land, water and living resources for income in a particular way, assistance could aim to provide an alternative means to raise revenue (Gardner et al., 2013; Sandker et al., 2012). While alternative livelihood projects have a dubious track record, they can be effective if developed in close consultation with the affected community. One example comes from the Anjozorobe-Angavo and LokyManabato protected areas in Madagascar. These are co-managed by the Malagasy NGO Fanamby and local community institutions, which together have worked to build partnerships between local communities and the private sector to develop income alternatives. These include the establishment of a tourist lodge and a market garden, providing local employment and opportunities for organic and fair trade certification (Gardner et al., 2013).

- Provision of training and upfront capital for the adoption of sustainable management practices of land, water and living resources (Gardner et al., 2013). Related approaches include "asset building PES" (Pirard, Billé and Sembrés, 2010) and "coinvestment in environmental stewardship PES" (van Noordwijk and Leimona, 2010). See Box 8 for a practical example.

\section{Box 8. Supporting sustainable parks management in Chad}

One example of the creation of a protected area that ensures benefits flow to local communities is the EU-funded project for Zakouma National Park in Chad (2011-2015). This project aims to support the conservation and good governance of natural resources and ecosystems for the benefit of local development, thereby exploiting biodiversity and development synergies. The project involves the African Parks Network (APN), the Chad Ministry of Agriculture and Environment, the Wildlife Conservation Society (WCS), the Network of Protected Areas of Central Africa (RAPAC) and UNESCO, which are establishing the Zakouma National Park foundation. Besides considerable investments in strengthening the management capacity of the park itself (e.g. equipment, organisation, communication and transport network and infrastructure, wildlife monitoring, marketing), a key element of this project is to strengthen relations between the park and local communities. This has been successful: to date thirteen agreements have been signed with local communities, security forces and the national parks agency. The project has also supported two local health care initiatives, supplying medicine and providing accommodation for the health centre manager. The project has also improved the provision of schooling in three villages through building a school and providing six teachers, teaching materials and school books. To help local communities benefit from park tourism, women in one village have created three typical dwellings, and tourists can purchase local products at the park entrance in an improved visitors centre. Other tourism infrastructure is also being upgraded: the park maintains $655 \mathrm{~km}$ of tracks each year, has improved picnic areas and is offering tourists the option to visit villages and sleep beneath the stars in mobile 'fly camps'.

Source: Example provided by the European Commission. For more details see African Parks (2014), "Zakouma National Park, Chad", http://www.africanparks.org/Park 6 Zakouma+National+Park\%2C+Chad.html, last accessed 27 October 2014.

\section{Adopting a precautionary approach}

51. The precautionary approach states that "In order to protect the environment...where there are threats of serious or irreversible damage, lack of full scientific certainty shall not be used as a reason for postponing cost-effective measures to prevent environmental degradation" (Principle 15, Rio Declaration on Environment and Development, 1992). In other words, if an activity risks having a large negative or irreversible effect upon the environment, decision makers should err on the side of caution. A precautionary approach is recommended with interventions that may negatively affect biodiversity and ecosystem services because the interactions between different ecosystems and with climate change -- their thresholds and their tipping points -- are still not well understood (Rockström et al., 2009).

\section{Adopting a landscape or ecosystem approach}

52. The landscape or ecosystem approach is a strategy for the integrated and multidisciplinary management of land, water and living resources that promotes livelihoods and the conservation and sustainable use in an equitable way (CBD, 2006; FAO, 2012). It is widely 
recommended as the best way to explicitly seek synergies between biodiversity and ecosystem services, poverty reduction and other development goals, as well as climate change mitigation and adaptation goals (CBD COP12 Decision XII/5; Harvey et al., 2013; Sayer et al., 2013; Vaz and Agama, 2013; Sandker et al., 2012; Roe et al., 2011; CBD, 2006). It is achieved through multi-stakeholder dialogue, and requires the consideration of both spatial and sectoral integration within the landscape (FAO, 2012). Adopting this approach can be challenging as it requires a shift from project- to a process-oriented way of thinking, without a clear starting or end point, and it requires long-term engagement of all relevant stakeholders (Sayer et al., 2013). Some providers of development co-operation, such as the Netherlands, are already moving towards this approach. The CBD has developed 12 principles to guide practitioners in the application of the ecosystem approach (see CBD, 2006).

\section{Policy coherence for development: biodiversity, ecosystem services and poverty} reduction

53. Development co-operation that supports biodiversity and ecosystem services does not operate in a policy vacuum. These activities may be undermined by other aid or non-aid policies, both in OECD countries and by OECD countries in partner countries. The interaction between non-aid or development policies and development outcomes is the main concern in the notion of "policy coherence for development" (PCD). PCD aims to minimise the adverse impacts that public policies can have in developing countries, and therefore "entails the systematic application of mutually reinforcing policies and integration of development concerns across government departments to achieve development goals along with national policy objectives" (OECD, 2012c). In the case of biodiversity, particular areas where policy coherence for development issues may occur are: fisheries access agreements, which may lead to overexploitation; regulation and promotion of trade concerning food products whose production harms biodiversity, such as palm oil, sugar and cocoa; importation of timber, which leads to the overexploitation of forestry resources; regulations concerning the use and export of chemicals and pesticides; regulations concerning the exploitation of genetic resources in partner countries; support for biofuel production in partner countries; trade in endangered species; and mining in partner countries (King, 2013; OECD, 2012c; Smith, Bass and Craeynest, 2008).

54. A whole-of government approach is recommended to achieve PCD. This includes making a high-level commitment to PCD, then establishing working practices and co-ordination mechanisms to work between ministries on the elaboration and implementation of policies, and finally improving the monitoring, analysis and reporting on the outcomes of these policies (King, 2013; OECD, 2012c). Specific recommendations to take biodiversity and ecosystem services into account in OECD policies that affect development include (King, 2013; OECD, 2012c; Smith, Bass and Craeynest, 2008):

- ensuring that biodiversity concerns are integrated into trade agreements, such as Economic Partnership Agreements between the European Union and Africa, Caribbean and Pacific regions;

- taking measures to limit trade in endangered species, e.g. by making it nonlucrative;

- reassessing biofuel policies to consider their potential impact on biodiversity and ecosystem services;

- supporting sustainable fisheries and forestry management, certification schemes and policies to avoid excess fishing and overexploitation of forestry resources in partner countries;

- recognising the authority of partner countries (particularly local and traditional communities) to determine access to genetic resources; and

- legislating the increased transparency and sustainability of extractive industries operating in partner countries. 


\section{Gaps identified and possible areas for future work}

55. This section has laid out the importance of clarifying and prioritising the objectives of a biodiversity-related development co-operation activity, of mainstreaming and measurement approaches, and of identifying, assessing and managing trade-offs and synergies in order to achieve the intended results of an activity. One area for further work could be to do a deeper study of the trade-offs and synergies with poverty reduction that can be achieved through biodiversity-related interventions. Another area could be to gather more examples to illustrate how available tools, principles and practices to manage for results, listed above, have been implemented in the field and to understand their comparative effectiveness to deliver lasting results. This would help to develop and strengthen the evidence base for how to best use these tools and practices to minimise trade-offs and maximise benefits across biodiversity and development objectives.

\section{Endnotes Section III}

20. This may be known more generally as natural capital accounting or environmental accounting.

21. For an example of spatial mapping to support decision making on biodiversity and development, see WRI et al., 2007.

22. Many of these principles and practices are applicable to the management of trade-offs and synergies and general. Here their explanation has been adapted to be specific to biodiversity, ecosystem services, poverty reduction and development 


\section{MONITORING AND EVALUATION}

\section{Monitoring and evaluation helps providers track progress and understand results}

56. Monitoring for development refers to the systematic collection of data along specific indicators to provide information and manage an on-going intervention (OECD, 2009a). Monitoring informs progress in the use of allocated funds and achievement of stated objectives. Importantly, this exercise is underpinned by a theory of change that explains how long-term goals are achieved - and which maps backward the expected causal chains and necessary preconditions for success (White, 2009). Effective monitoring also depends upon clearly defining the intended results of an intervention, as well as identifying the factors that can affect how those results are achieved - and depends on the knowledge base available and how this knowledge is used to inform how the intervention is designed. In turn, this will determine what can be achieved and what is to be measured (see Section 3).

57. While monitoring can help policy-makers keep track of an intervention, evaluation provides in-depth insights into whether and how results are attained. Development evaluation is the systematic and objective assessment of an on-going or completed intervention, including its design, implementation and results (OECD, 2009b). The evaluation process aims to: (a) adjust and improve on-going and future interventions and policy by providing credible, independent analysis and recommendations, and by linking past and future activities through feedback mechanisms; and (b) provide a basis for transparency and accountability on the policy process. Concretely, development evaluations assess the relevance, effectiveness, efficiency, impact and sustainability of an intervention (the five DAC evaluation criteria; see OECD, 2011a), including those related to biodiversity.

58. This section explores the frameworks used by development co-operation providers to monitor and evaluate their biodiversity and ecosystem service interventions in partner countries. It looks at specific features of and challenges posed by biodiversity and ecosystem service interventions to monitoring and evaluation, and at how the five OECD DAC evaluation criteria have been applied. This is illustrated with a number of good practice cases. The analysis draws primarily from academic and grey literature, and the development co-operation agency evaluations posted on the DAC Evaluation Resource Centre (DEReC). ${ }^{23}$ The evaluations analysed were selected on the basis of their relevance to biodiversity and ecosystem services, the quality of the explanation of methodologies used to evaluate an intervention and the clarity of the results presented.

\section{Challenges for monitoring and evaluating biodiversity-related interventions}

59. Monitoring and evaluation for biodiversity and ecosystem services and development has typically been constrained by a shortfall in resources allocated to this task due, for example, to reluctance from managers to divert resources from implementation or hesitancy to expose shortcomings of an intervention (Davies et al. 2013). Since the 1990s, however, monitoring and evaluation has been common in the field (see Joppa et al. 2008; Bottrill et al. 2011), reflecting a growing desire to increase learning and accountability from biodiversity-related interventions, as well as to ensure that tight budgets stretch as far as possible (and possibly increase) by demonstrating effectiveness in achieving desired outcomes.

60. When monitoring and evaluating biodiversity-related interventions in the context of development, understanding causal impacts across a number of relevant variables and foster learning and accountability are common difficulties (e.g., Davies et al. 2013; Roe et al. 2013). On the one hand, this is because the available knowledge base underlying what is causing biodiversity loss (see Figure 1) is not always informing the types of interventions designed, which in turn thwarts the effectiveness of monitoring and evaluation as an exercise that can help improve on-going and future interventions (see White, 2009). On the other hand, this may be the result of specific biodiversity-related features that make monitoring and evaluation more difficult than in other fields of development evaluation, such as (e.g. Ferraro and Pattanayak, 2006):

- Definitions of biodiversity and ecosystem services, and agreement on how to measure these over time, are often ambiguous, as are definitions of other concepts 
typically targeted in biodiversity-related interventions (see Box 1). This "cascades to vague objectives and difficulty in developing targets and indicators to gauge performance" (Davies et al. 2013; also see Section 3 of the paper on managing for results);

- The outcomes targeted by interventions related to biodiversity and ecosystem services tend to be local in nature. Yet strong and complex spill-over and leakage effects over a broader geographic area are common and these are difficult to capture through routine monitoring of individual programmes;

- Compliance or "cheating" (e.g. in conservation or certification schemes) can be hard to verify. This may be compounded by weak governance structures and unclear property rights in many developing countries, thus making it difficult to find counterfactuals against which monitoring and evaluation could be performed from a cross-section perspective and over time (Honey-Rosés et al. 2011);

- Outcomes related to biodiversity and ecosystem services often respond slowly to interventions (e.g. forest or wildlife stocks change over many years). Measuring progress is relatively difficult because the time required to demonstrate positive change to social and ecological systems is lengthy and often extends well beyond the lifespan of most interventions (Hildén 2009). Moreover, long time horizons reduce the incentives to learn from an evaluation for the staff involved in the exercise (e.g. due to staff promotion policy);

- Relevant data and information related to biodiversity and ecosystem services is often poor or lacking, especially at the community or local level in many developing countries (Roe et al. 2013b). Data collection, validity and reliability would need to improve if they were to guide further analysis on the impacts of biodiversity-related interventions;

- Monitoring and evaluation is further complicated by a lack of understanding of social science research by natural scientists implementing biodiversity-related interventions, and vice-versa (Davies et al. 2013). Few multi-disciplinary methodological approaches are readily available to conduct development evaluation in the field of biodiversity and ecosystem services.

61. These features result in three specific methodological challenges that affect monitoring and evaluation of interventions related to biodiversity and ecosystem services and development, namely: (a) the problem of outcome attribution of biodiversity and ecosystem service interventions; (b) difficulties setting baselines and targets given relatively uncertain operating contexts in developing countries; and (c) the challenge of monitoring and evaluating biodiversity and ecosystem services over time (Dinshaw et al., forthcoming). While this is not a comprehensive list and these challenges are not unique to biodiversity and ecosystem services, their combined scope and scale are.

62. Depending upon the assumptions and methods used, these challenges can bias monitoring and evaluation results. The time frame and spatial scale chosen for an intervention may provide a first explanation on why this is the case, for these determine which activity options are socially and environmentally optimal or desirable (WRI, 2008; Perrings and Halkos, 2012). In general, the longer the time frame and the broader the spatial scale, the more likely it is that biodiversity and ecosystem services interventions will have socially optimal outcomes. Alternatively, a second explanation may relate to how objectives (what the intervention is trying to achieve and for whom) are defined in an intervention, e.g. by taking poverty-centric and/or cost- and nature-centric approaches (see Section 3).

63. Providers can draw from the work of the Biodiversity Indicators Partnership (BIP) ${ }^{24}$ and the Intergovernmental Platform on Biodiversity and Ecosystem Services (IPBES) ${ }^{25}$ to prioritise, plan, monitor and evaluate biodiversity-related interventions. The BIP (see Section 3) helps to evaluate progress towards meeting the global Aichi Biodiversity Targets, and may also be adapted to help track progress towards national biodiversity goals as expressed, for example, in NBSAPs. The widespread adoption of the BIP approach could help to harmonise the measurement of changes in biodiversity and ecosystem services initiated by development interventions across providers. 
64. The IPBES is an independent inter-governmental learning body established in 2012 to assess the state of biodiversity, ecosystems and the essential services they provide to society. IPBES provides a mechanism recognised by both the scientific and policy communities to synthesise, review, assess and critically evaluate relevant information and knowledge generated worldwide by governments, academia, scientific organisations, non-governmental organisations and indigenous communities. IPBES also aims to strengthen capacity for the effective use of science in decision-making on biodiversity and ecosystem services at all levels. By doing so, it can support existing processes ensuring synergies and complementarities in all stakeholders' work. This practice would facilitate the improved targeting of funding and investments to the most vital needs and ensure better harmonisation among providers (see also Section 5).

\section{Providers typically apply DAC evaluation criteria with varying rigour}

65. The OECD DAC's Network on Development Evaluation ${ }^{26}$ has developed common Principles for Evaluation of Development Assistance (OECD, 1991; reviewed in 1998) to guide the management and institutional arrangements of the evaluation system within development co-operation agencies. These principles are at the heart of on-going efforts to make development co-operation more effective, while helping to demonstrate results from development activities (OECD, 2013f). These principles pertain to the need to communicate evaluation findings in a clear, accessible and easily understood manner to the relevant stakeholders shaping the domestic policy agenda, and to dedicate sufficient resources to monitoring and evaluation. These principles also apply to interventions in the area of biodiversity and ecosystem services and underpin the findings presented in this section.

66. A preliminary study of nine evaluations from Austria, Denmark, Finland, France, Norway, Spain, Switzerland, the United States, and the World Bank, available at the OECD DAC DEReC database (see Annex 1 for list of evaluations), illustrates that providers typically follow OECD DAC principles and criteria, although the extent to which this is done varies. The tools used to identify causal chains and assumptions, and the selection of indicators to monitor progress, vary across cases. By way of illustration, the preliminary review conducted here shows that in the United States, funding was tied to clear, evidence-based justifications for the programme design, while in Spain it was not. In Finland, the evaluation provided lengthy background documentation, while Austria and Switzerland provided a more targeted evaluation of a project or programme respectively. France, Spain and the United States conducted their evaluations internally, while Austria and Finland relied on external consultants. The interventions monitored and evaluated in this sample of studies concern supporting the development of protected areas, payments for ecosystem services, certification schemes, integrating biodiversity into development plans and policies, and helping with the decentralisation of natural resource management to the local and community level. Some target more than one of these elements.

67. The background review provided in this paper confirms that providers do not always gather relevant ecological and social data systematically over time to conduct monitoring (e.g. on conservation, Kapos et al., 2008). Without appropriate baseline information, using alternative highly-aggregated or descriptive data and indicators to measure progress (even if these are already collected and used on a regular basis) may be unfit for purpose: they may be too narrow, broad or partial to capture the multidimensional impact of many biodiversity-related interventions (Axford et al., 2008; Pullin and Knight, 2009). From the sample of evaluations analysed here, only four (Finland, France, US, World Bank) specified indicators to measure progress.

68. Evaluations in the field of development are generally weaker at looking at interventions over long periods of time, a critical element for biodiversity and ecosystem services. However, comprehensive evaluations of biodiversity-related programmes stretching over many years and covering many interventions were identified in the cases of Finland, France, the United States and the World Bank. Yet in the majority of evaluations reviewed, case-study narratives from individual field initiatives were included, raising questions on their rigour, e.g., they lack explicit theories of change linking interventions to impacts and outcomes (White, 2009). Methodologically, this approach prevents providers from further exploring the use of counterfactuals, or from better demonstrating causality and attribution in complex contexts (see 
Ferraro and Pattanayak, 2006; Margoluis et al. 2009; Gaarder and Annan, 2013; Roe et. 2013b).

69. Finally, the evaluations analysed consider the political economy and context in which interventions take place (see also Kennedy et al. 2009; Miteva et al. 2012), but this generally reflects an ex post consideration. This limits the effectiveness of many interventions because factors such as uncertain property rights, corruption or the lack of strong institutions can impact how biodiversity and ecosystem services interventions are carried out, but they are not considered from the outset (Vincent, 2010). Moreover, evaluations are typically performed shortly after completion of an intervention, which usually happens before the full impact of the intervention can become apparent. Examples of long-term evaluations (e.g. over 10-15 years after completion) are rare.

\section{Good practice in the implementation of the DAC evaluation criteria}

70. The OECD DAC has developed a set of evaluation criteria to support evaluation activities based on relevance, effectiveness, efficiency, impact and sustainability (OECD, 2011a). The extent to which these evaluation criteria have been adapted to biodiversity-related interventions is explored here, illustrating each criterion with good practice based on the evaluations selected.

71. Relevance refers to the extent to which an activity is suited to the priorities and policies of the target group, partner country and provider of development co-operation (OECD, 2011a). The Mesoamerican Green Corridor (MBC) initiated by the World Bank in 1997 provides a good illustration of how this criterion is approached. The project's evaluation, performed by the World Bank's Independent Evaluation Group, found the MBC to be "highly relevant" (IEG, 2011). This was based on a comprehensive analysis of irreversible biodiversity loss in the Mesoamerican area, using quantitative and qualitative criteria (e.g. number of unique species, land mass to be covered, community engagement) and a concrete theory of change based on the creation of core, buffer, multiple use and corridor zones in the region to protect biodiversity. To ensure community participation, support was provided to market an array of environmental goods and products growing in the area to the Central American and global society. The result was the creation of a few large areas of intact natural habitat connected by strips of sustainably managed habitat.

72. Effectiveness is a measure of the extent to which a development co-operation activity achieves (or is likely to achieve) its objectives (OECD, 2011a). Norway's International Climate and Forest Initiative (NICFI) provides a good example of an effective programme. NICFI aimed to contribute to the development of an international regime to Reduce Emissions from Deforestation and forest Degradation (REDD+) and biodiversity loss by influencing climate negotiations; supporting relevant bilateral and multilateral initiatives and related institutional frameworks; and funding research and policy advocacy to develop a relevant body of practice and methods. Progress towards these policy goals was assessed using indicators relating to policy and institutional requirements needed to deliver a working REDD+ regime. The results of a 2010 "real time" evaluation of NICFI show that Norway has been effective in: (a) injecting overall momentum into UN climate negotiations through the strategic direction and financial commitments provided by NICFI; (b) contributing to an agreement on a phased approach towards a fully functioning, results based financing system; (c) supporting institutional capacity building through the UNREDD programme, the Forest Carbon Partnership Facility, and the Congo Basin Forest Fund; and (d) contributing to the development of the Interim REDD+ Partnership (Norad, 2010). These objectives remain relevant given the underlying, broader objective of halting biodiversity loss (but could have been even more relevant if evaluated by taking trade-offs into consideration).

73. Efficiency is an economic term used to assess the extent to which development finance uses the least costly resources possible to achieve the desired results (OECD, 2011a). This is not only limited to the efficiency of reaching an output, but also concerns the relationship of this output with the driving factors identified in the intervention's theory of change. This is probably one of the most challenging principles and from the sample of evaluations analysed here, the Austrian project on "Sustainable coffee production and processing coupled with income diversification in Mbeya and Mbozi District in Tanzania" provides a good illustration of the first part of the efficiency criterion. The project aimed to increase farm income through sustainable 
coffee farming and promotion of other promising crops in a cost-effective manner. The evaluation of the project concluded that the management was professional and the resources disbursed were used efficiently, a conclusion arrived at after analysing alternative staffing and other cost configurations. The project was implemented through a number of partner organisations and NGOs, which provided highly specialised knowledge in a relatively lean manner (GPPI, 2009). Concerning the second part of the criterion, however, no evaluation surveyed for this paper considered the scale of their intervention to achieve broader results (e.g. in the case of the Austrian project, there was no consideration of how the project could halt and/or reverse biodiversity loss and the benefits of avoiding this loss more generally).

74. Impact is the positive and negative change(s) and effect(s) produced by a development intervention, directly or indirectly, intended or unintended, along local, social, economic, environmental and other development-relevant dimensions (OECD, 2011a). The USAID LIFE Project assisted the Namibia National Community Based Natural Resources Management (CBNRM) programme for 15 years (Jones, 2004), thus providing for a comprehensive analysis of immediate and long-term impacts of intended and unintended effects of the intervention. The evaluation determined that the project provided an additional 59\% of landmass compatible with Namibia's existing protected area network (Jones, 2004), which is particularly significant to the biodiversity health of Namibia's park system, where low and sporadic rainfall frequently requires extensive movements of wildlife between parks and adjacent communal lands. Moreover, the project was adapted to ensure conservation areas could be accessed and used by local communities, promoting new opportunities for wildlife and tourism. This has reduced poaching, wildlife recoveries and innovative land-use planning processes that are widespread across Namibia. Other studies also provide robust evaluations of this project on poverty reduction outcomes in Namibia (World Bank, 2004; Bandyopadhyay et al., 2009).

75. Sustainability measures whether the benefits of an activity are likely to continue after provider funding has ceased, and includes environmental and financial sustainability (OECD, 2011a). A good example of this criterion is the evaluation of Finnish Support to Forestry and Biological Resources that reviewed the portfolio of forestry programme interventions in Kenya, Lao PDR, Mozambique, Nicaragua, Tanzania, Viet Nam and Zambia, as well as regional interventions in Central America and the Western Balkans (Ministry of Foreign Affairs of Finland, 2010). A central requirement for sustainability identified by the evaluation is having the institutional capacity to carry out sustainable forest management and take it forward after the original intervention, as well as policy reforms and political commitment, and supportive legislation and regulations that are also endorsed and applied. The evaluation found that the institutional capacity in Viet Nam, Western Balkans and Central America looked positive based on achievements reached and the level of investments made by the partner country institutions. Also, regarding policy reforms and political commitments in Kenya, the evaluation found that the government was carrying key forest sector reforms forward. Other possible intervening factors, however, such as the trade-offs with market forces or economic growth were not analysed.

\section{Gaps identified and possible areas for future work}

76. There are a number of research streams where potential future work could be fruitful to strengthen monitoring and evaluation and hence understanding of biodiversity-related development activities. These include:

- better testing and refining of theories of change that underpin biodiversity-related interventions, especially the most common ones (e.g. on payments for ecosystem services);

- the expansion of case studies to examine a broader range of country experiences, e.g. countries where monitoring and evaluation is more advanced compared to those countries where it is not;

- the identification and application of methods and approaches from other scientifically complex (non-biodiversity) development co-operation areas, in particular with respect to including broad spatial scales and long time frames; and

- a meta-analysis of monitoring and evaluation findings from a broad sample of case studies. 
77. These research streams could strengthen the current practice of monitoring and evaluation, the results of which could inform better biodiversity-related interventions.

particular, this information in hand, providers could then determine what types of interventions work well (or not) to deliver the biodiversity, ecosystem services and poverty reduction results, and to scale-up and transfer their successful interventions to other settings. Such work would help fill the practical gaps identified in the literature regarding how monitoring and evaluating biodiversity-related interventions are typically performed.

\section{Endnotes Section IV}

23. For further information see: http://www.oecd.org/derec.

24. http://www.unep-wcmc.org/featured-projects/a-partnership-to-monitor-biodiversity

25. http://ipbes.net/about-ipbes.html

26. The Network on Development Evaluation is a subsidiary body of the OECD DAC. Its purpose is to increase the effectiveness of international development programmes by supporting robust, informed and independent evaluation (see: http://www.oecd.org/development/evaluation). 


\section{EFFECTIVE DEVELOPMENT CO-OPERATION: ALIGNMENT AND HARMONISATION}

\section{Principles of effective development co-operation apply to biodiversity-related interventions}

78. Current understanding of what is "effective development co-operation" has its roots in the early-2000s and the formulation of the Millennium Development Goals. By 2005, various initiatives to improve the impact of aid were brought together under the Paris Declaration on Aid Effectiveness, which sets out five principles for aid effectiveness: country ownership, alignment, harmonisation, managing for results and mutual accountability. In 2008, the Accra Agenda for Action reiterated these principles and set out three further pillars around which to concentrate efforts, including the support of country ownership through greater use of country systems and provision of "demand driven" capacity development. The subsequent Busan Declaration on Effective Development Co-operation (2011) further refined these (see Box 9), adding the need for inclusive development partnerships and for transparency.

\section{Box 9. International principles of effective development co-operation}

The Paris Declaration on Aid Effectiveness (2005) outlines five fundamental principles for making aid more effective, born out of decades of experience of what works and what does not work for development (country ownership, alignment, harmonisation, managing for results and mutual accountability). These principles are further elaborated by the Busan Declaration (2011), which fleshed out some of these principles to form the foundation of effective development co-operation, namely:

- Ownership of development priorities by developing countries: Partnerships for development can only succeed if they are led by developing countries, implementing approaches that are tailored to country-specific situations and needs.

- $\quad$ Focus on results: Investments and efforts must have a lasting impact on eradicating poverty and reducing inequality, on sustainable development, and on enhancing developing countries' capacities, aligned with the priorities and policies set out by developing countries themselves.

- Inclusive development partnerships: Openness, trust, and mutual respect and learning lie at the core of effective partnerships in support of development goals, recognising the different and complementary roles of all actors.

- Transparency and accountability to each other: Mutual accountability and accountability to the intended beneficiaries of co-operation efforts, as well as to respective citizens, organisations, constituents and shareholders, is critical to delivering results. Transparent practices form the basis for enhanced accountability.

Source: Paris Declaration on Aid Effectiveness, 2005; Busan Declaration on Effective Development Co-operation, 2011.

79. All members of the OECD Development Assistance Committee (DAC) have endorsed these principles, which are applicable to all development co-operation activities, including those related to biodiversity and ecosystem services. In fact, the OECD DAC Policy Statement on Integrating Biodiversity and Associated Ecosystem Services into Development Co-operation (OECD, 2010b) reiterates the principles of the Paris Declaration and Accra Agenda for Action.

80. Implementation of these principles and commitments to integrate them into development co-operation activities of DAC members is well under way and the OECD has been monitoring progress since 2006 (OECD, 2007, 2008, 2012, 2014). To this end, a number of indicators have been developed and adapted over time, a number of which will be elaborated upon below.

81. This section explores how providers of development co-operation have applied the principles of alignment ${ }^{27}$ and harmonisation ${ }^{28}$ (see Box 10 on key points emerging from the Third Annual Workshop on the NBSAPs 2.0 on these two principles). This is based on preliminary desk research that draws on grey and academic literature, on a quantitative analysis of 
biodiversity-related finance at the sector level in selected countries using the OECD DAC Creditor Reporting System database, and on discussions with stakeholders. Illustrations of good practice, key challenges encountered and gaps for future work are highlighted.

\section{Box 10. Key points emerging from Third Annual Workshop on the NBSAPs 2.0 on alignment and harmonisation}

During the meeting of the Third Annual Workshop on the NBSAPs 2.0: Mainstreaming Biodiversity and Development Project: "Mainstreaming Biodiversity and Development - What does success look like?", 23-25 July 2014, Okahandja, Namibia (see Section 2) a session was devoted to looking at partner country experiences of development co-operation related to biodiversity and ecosystem services. The key points emerging from the discussion with participants relating to alignment and harmonisation, and which could be explored in future work included:

- $\quad$ Ownership by partner countries can be supported by building common accountability mechanisms and by waiting to harmonise positions across providers around partner country priorities, as opposed to the development cooperation providers imposing their priorities.

- $\quad$ There is a need to support processes of implementation of strategies and plans that the partner country has developed, instead of supporting isolated projects. Implementation processes require sustained support over long periods of time, i.e. at least 10 years.

- $\quad$ There is a need to build local capacity, including at the technical and policy levels, and to build and strengthen institutions in partner countries to deal with biodiversity instead of delivering related projects that do not empower the country.

- $\quad$ There is a need to support local communities to manage biodiversity, and to ensure that funds provided through budget support are ear-marked for biodiversity (otherwise they might end up financing infrastructure unrelated to the topic).

- $\quad$ Often providers work through civil society and do not consult with the governments - making it difficult for the partner country government to own the activity.

- Partners need to target provider's local offices and embassies - they have to become "biodiversity champions", especially because these officials are often sitting in provider co-ordination bodies (such as the Joint Assistance Strategies of Kenya or Zambia).

- Co-ordination bodies were criticised by these partner countries as being "talking shops" lacking effectiveness, due to a lack of resources and no Secretariat to carry out work.

- $\quad$ Project proposal templates are cumbersome for partner countries - and in some cases positive discussions with the provider do not lead to the project being adopted.

- $\quad$ Countries are aware of activities being funded and implemented by the GEF, World Bank and UNDP, but they rarely mentioned bilateral providers; it appears that bilateral providers do not have a high profile in these countries, or at least are not well known to partner country officials working in the Ministry of Environment.

\section{Development co-operation providers are partially aligning with partner countries' priorities}

82. Alignment means that providers base their support on partner countries' national development strategies, institutions and processes. For example, providers commit to use country systems as the default option for programmes managed by the public sector. In return, partner countries improve the quality and transparency of their public financial management systems. A lack of alignment leads to unsustainable outcomes, as well as undermining national institutions and processes; and reflects efforts to build the institutional strength of partner countries (Birdsall and Kharas, 2014). By supporting this dimension, providers signal their willingness to make a long-term investment in the ability of partner countries to develop and implement their own strategies.

83. Given the multi-dimensionality of the principle, measuring alignment relies on a variety of indicators. Until 2011, monitoring progress towards more effective development co-operation by increasing alignment has been monitored by the OECD by looking at: the extent to which reliable country systems are being built (indicator 2), the degree of alignment of aid flows with national priorities (indicator 3), co-ordination of support to strengthen capacity technical cooperation (indicator 4), using strengthened country systems (indicator 5), avoiding parallel 
implementation structures (indicator 6), providing more predictable aid (indicator 7), and untying aid (indicator 8) (OECD, 2007). With the Global Partnership for Effective Development Cooperation (2011), alignment is monitored through a related and reduced set of indicators, namely (a) meeting developing countries' priorities, (b) ODA is on budgets which are subject to parliamentary scrutiny, (c) developing countries' systems are strengthened and used, and (d) aid is untied (OECD, 2014). A number of alternative indicators to measure alignment have also been proposed by academia, civil society and think tanks, such as coverage of forward spending plans, aid predictability, and the share of aid to partners with good operational strategies (see Birdsall and Kharas, 2014 for an overview).

84. There is relatively little work on the issue of alignment in the field of biodiversity and ecosystem services. Some studies have shown that providers tend to prioritise particular kinds of objectives, which may not always reflect those put forward by partner countries in this space. For example, biodiversity-related interventions do not always target poverty reduction objectives, and as a result these tend to be unstated or poorly articulated (Pullin et al., 2013). Also, biodiversity-related interventions need to be based on long-term commitments that reflect the time needed for impact (Blom et al. 2010), but providers tend not to focus on long-term and flexible funding, and do not or cannot accept trial-error type of ventures (Bottrill et al. 2011). Finally, substantial work has been performed on Sector-Wide Approaches (SWAps), which emerged in the 1990s out of a growing dissatisfaction with the traditional project approach which has often been viewed as "fragmented [and] donor-driven" and as entailing high transaction costs for aid recipient countries (AfDB, 2004). SWAps emphasize greater reliance on government institutions, common implementation procedures and stronger and closer country partnership with providers of development co-operation.

85. Progress on alignment can be considered by looking at the share of ODA flowing to partners' top biodiversity-related priorities through reviewing a sample of how SWAps operate in practice. First, developing country priorities are identified through National Biodiversity Strategy and Action Plans (NBSAPs) and are compared to the main sectors targeted by bilateral ODA. Analysing ODA data is a good starting point for this analysis given that ODA is likely to remain a key source of funding for biodiversity for many developing countries in the near future (Development Initiatives, 2013). However, providers may have a major impediment to enhance funding for biodiversity and ecosystem services if a partner country fails to identify biodiversity and ecosystem services as priorities in its national development plan (see WWF 2008 on the European Institutions). Providers may sponsor activities that raise awareness among key stakeholders in partner countries on the importance of addressing biodiversity and the value of ecosystem services.

86. The selected partner countries for this exploratory analysis are Azerbaijan, Guyana, Kiribati, Lao People's Democratic Republic (Lao PDR) and Malawi. These provide a geographical range, their NBSAPs are relatively recent (2004-10), and the proportion of total ODA committed to the country that targets biodiversity and ecosystem services is above the global average. It is noteworthy that the more recent NBSAPs (i.e. after 2010) are relatively clearer on what the priorities and capacity needs of countries are (e.g., Botswana). However, not all countries have developed a second generation NBSAP, and those that have are often too recent for this analysis; the DAC CRS database extends until 2012 (at the time of the analysis), thus making it difficult to compare flows with recently-set country priorities. Table 5 provides an overview of the five main sectoral priorities identified by these countries in their NBSAPs and the top five sectors targeted by providers in their biodiversity-related interventions there. The sectoral distribution of ODA is presented both in terms of US dollars and in terms of number of activities, as large projects can heavily influence the distribution in terms of US dollars. 
Table 5. Main sector priorities identified by partner countries in their NBSAPs, and targeted by development co-operation providers

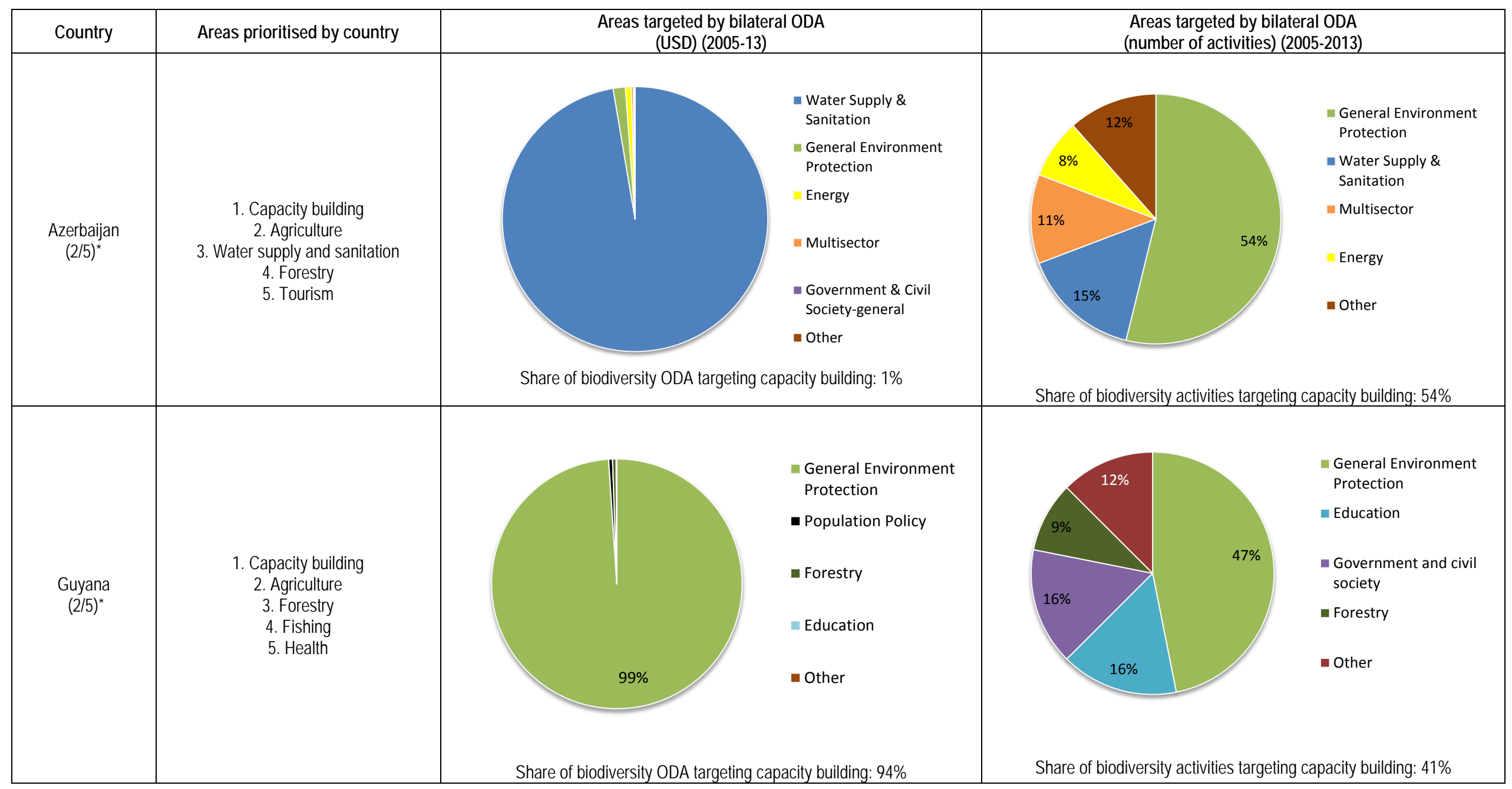




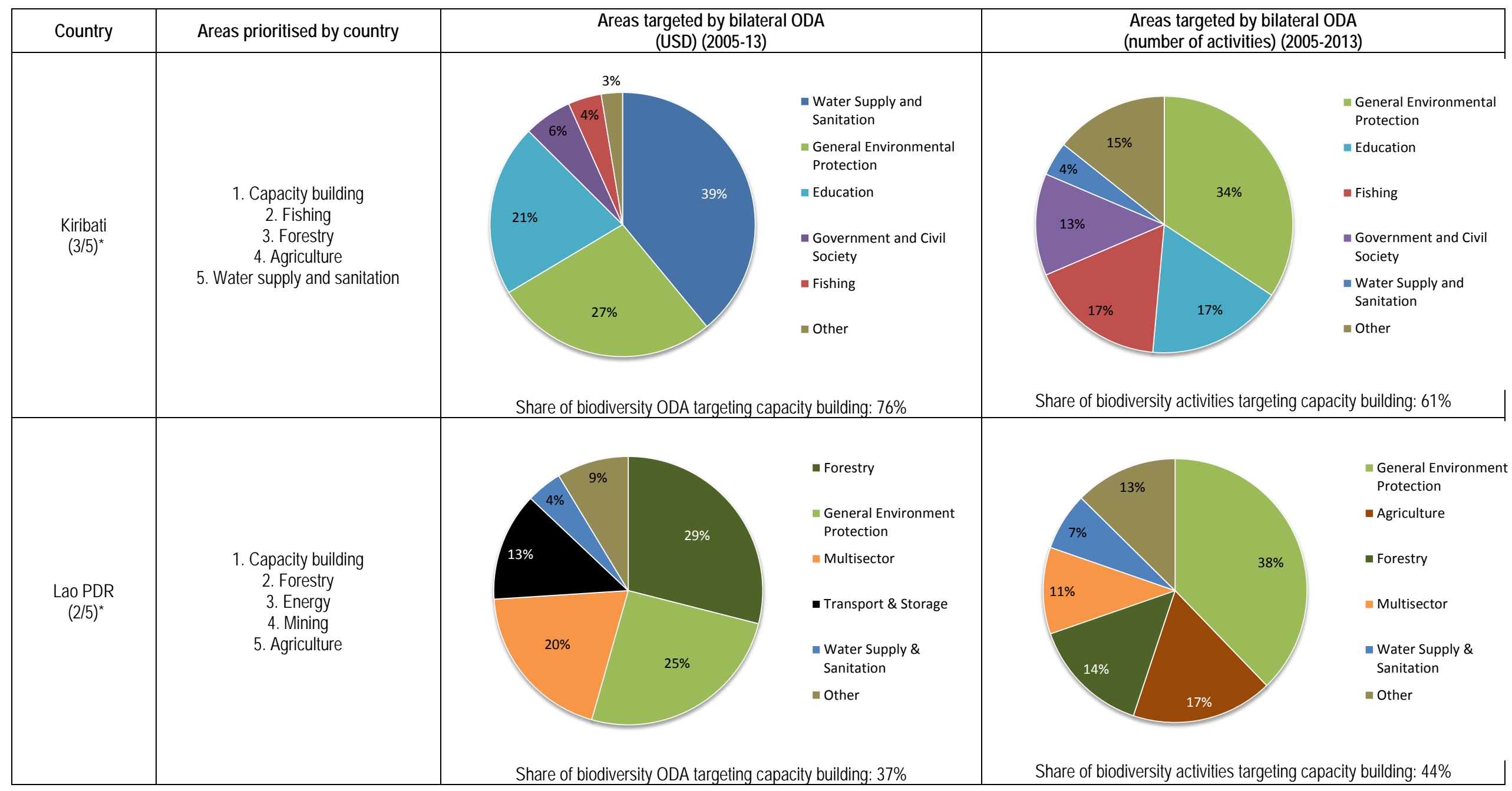




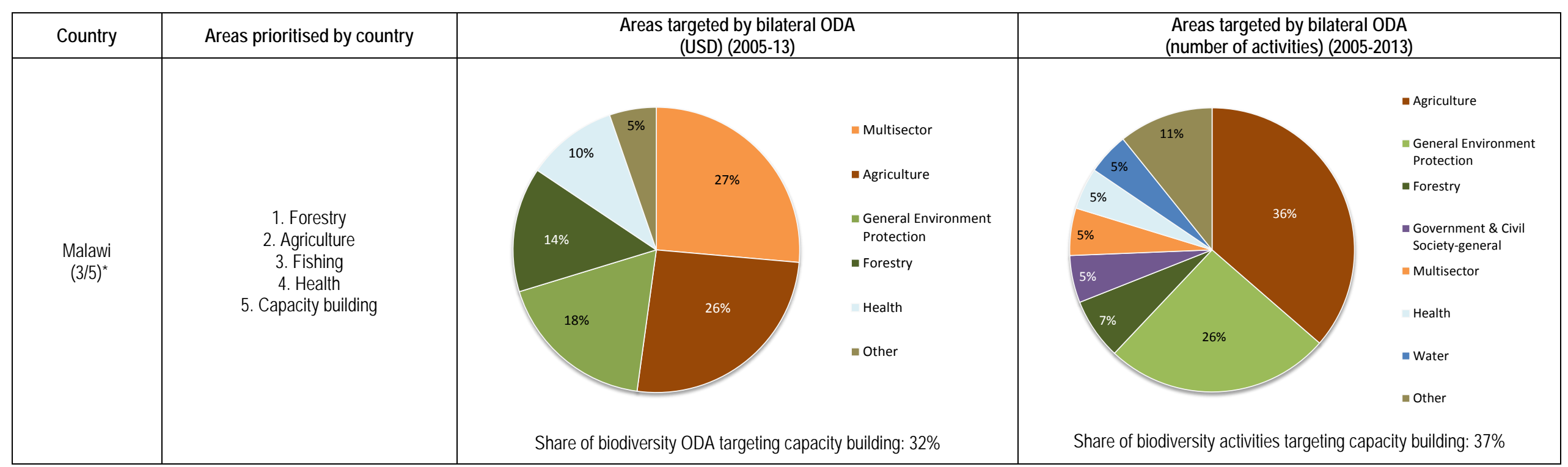

* Numbers in brackets indicate the number of sectors in the top five priority list of partner countries are targeted as top five sectors for biodiversity-related bilateral ODA to the partner country.

Source: NBSAPs for Azerbaijan (2008), Guyana (2000), Kiribati (2005), Lao PDR (2006) and Malawi (2008), Available online at www.cbd.int/nbsap/search/default.shtml; OECD DAC CRS database, March 2015.

Notes:

(1) Although "capacity-building" is not a sector in the OECD DAC CRS database, it can be calculated by looking at the sub-categories within each of the sectors in the CRS. In this paper, "capacity building" was calculated by pulling out all sub-categories that included the following words: research, education, training, policy and administration management, capacity, institutions and finance. Upon closer inspection, agricultural extension was also added.

(2) General Environment Protection" covers activities concerned with conservation, protection or amelioration of the physical environment without sector allocation. The category comprises aid to: environmental policy and administrative management (capacity building); biosphere protection; site preservation; flood prevention/control; environmental education/training; environmental research; and a specifically-coded "biodiversity" sub-sector which specifically covers the conservation, protection or amelioration of natural reserves and actions in the surrounding areas, and other measures to protect endangered or vulnerable species and their habitats, such as wetlands preservation.

(3) For activities cutting across several sectors, the "Other Multisector" category is applied. 
87. This preliminary analysis shows that all five selected NBSAPs highlight the need for capacity building, and in all five cases, biodiversity-related capacity building interventions account for at least a quarter of biodiversity-related activities from bilateral providers. More generally, if "General Environmental Protection" is broadly equated with capacity building, for each of the five selected countries, two to three of the top five sector priorities for biodiversity identified by these countries are within the top five sectors targeted by biodiversity-related bilateral ODA to these countries. This suggests that there is a certain degree of alignment of providers with these partner countries' priorities and needs. However, in other cases, less alignment is displayed. For example, in Azerbaijan, providers heavily focus their biodiversity-related ODA on water supply and sanitation, which is only the fifth priority in this country's NBSAP, and Lao PDR receives 13\% of its biodiversity-related ODA in the transport and storage sector, which is not mentioned in its NBSAP. It should be borne in mind, however, that bilateral ODA is not the only form of finance used to meet biodiversity-related needs in these countries; other biodiversity-related financial flows may be targeting other sectors.

88. A number of Sector Wide Approaches (SWAps) were also reviewed to understand the extent of alignment in biodiversity-related development activities. An increasing number of providers are adopting SWAps as a process for facilitating sustainable development and enhancing the impact of development finance (AfDB, 2004). Among the key defining imperatives for an effective SWAps process are: the existence of a government-led and co-ordinated comprehensive sector development programme; the existence of a conducive policy environment or policy reform agenda leading to it; and the commitment and availability of provider resources in the form of sector investment loans and grants for institutional capacity building and studies to underpin sector development issues (AfDB, 2014). SWAps also require the existence of a strong and co-ordinated approach by providers to the relevant sector's challenges as well as the presence of an effective consultation mechanism between the partner country and its development co-operation providers. The approach generally envisages the pooling of providers' financial resources in support of government budget, the use of a common government-led implementation and co-ordination mechanism and a streamlined or harmonised set of disbursement and procurement procedures.

89. Several recent reviews of SWAps have concerned interventions that include biodiversityrelated ODA. For example, Denmark has worked with Uganda to prepare a Joint Water and Environment Sector Support Programme (Government of Uganda, 2013), which has contributed to policy development, strategic planning and budgeting, implementation of monitoring and evaluation frameworks for sector reforms, and had a strong co-ordination focus, including on financial management, performance review, joint decision-making and technical support. Similarly, the Netherlands has been active in Colombia (ODI, 2008), Senegal and Vietnam (Meta Management et al., 2007); here the SWAps are shown to be helping to align their contribution as much as possible with policy and management frameworks of the country in question and, in particular, to consider how biodiversity and ecosystem services can help reduce poverty.

\section{Providers are co-ordinating through national and regional mechanisms, but with varying frequency and success}

90. Harmonisation responds to concerns that providers' practices do not fit well with national development priorities and systems such as budget, programme and project planning cycles. The demands on partner countries to meet with different providers' objectives, reporting processes and procedures, along with unco-ordinated country analytical work and missions may create excessive transaction costs and reduce the effectiveness of the assistance provided. Providers and partner countries therefore have recognised that urgent, co-ordinated and sustained action is required to reduce overlap, waste and fragmentation among them and to reduce the burden placed upon partner countries (Birdsall and Kharas, 2014).

91. As with the concept of alignment, harmonisation is a multi-dimensional principle. Illustrative examples include harmonising efforts in research, decentralising governance to the sub-national level in partner countries or extension efforts with other sectors, and developing functional 
linkages between site-based activities run by different development co-operation providers. The Paris Declaration called for monitoring progress on harmonisation, and a number of indicators were developed, namely using common arrangements (indicator 9), and conducting joint missions and sharing analysis (indicator 10) (OECD, 2007). ${ }^{29}$ Other possible indicators found in the literature include the significance of aid relationships (in terms of volume of aid flows) or the total fragmentation across donor agencies (Birdsall and Kharas, 2014).

92. This sub-section provides a preliminary snapshot of some of the harmonisation activities in the biodiversity and ecosystem services area, in particular by focusing on the existence and effectiveness of using common arrangements to harmonise approaches across providers in a given country. Recent studies show little progress in reducing the burden placed on partner countries (Birdsall and Kharas, 2014), and no academic literature was found on monitoring progress in the area of biodiversity and ecosystem services. However, development co-operation agency documents show that at least some providers are considering harmonisation in their development co-operation activities related to biodiversity and ecosystem services.

93. Harmonisation of provider approaches is first considered at the strategy level and identified as a priority for action at the project level. For example, at the strategy level, the German Strategy on Biological Diversity, which serves as a guideline for country and regional programmes on biodiversity and for the priority strategies of German development co-operation and its positioning in the international debate, has a chapter on in-country target groups and partners. The chapter calls for co-ordination with other development co-operation providers at the national, regional and international level (BMZ, 2008).

94. Development co-operation providers are also encouraged to pursue harmonisation with other providers on the ground. For example, the USAID Fisheries Integration of Society and Habitats (FISH) project aims to consult with the broad community of actors involved with biodiversity conservation of fisheries in Malawi. FISH's objectives are to improve sustainable fisheries co-management and to achieve resilience to climate change. To do so it asks for the integration of FISH activities with other environment-related development efforts in Malawi to leverage mutual benefits (in particular with Norway, the UK, the EU, UNDP, Iceland, the World Bank and Japan). Illustrative examples of co-ordination efforts under $\mathrm{FISH}$ are harmonising efforts in research, decentralisation of governance or extension efforts with other sectors, developing functional linkages between site-based activities.

95. Once formulated and identified as a priority of action, harmonisation tends to be operationalised in the form of Joint Assistance Strategies, which are comprehensive frameworks to manage development co-operation in-country. A number of these have been formulated and evaluated, and include environment- and biodiversity-related chapters, depending on the focus placed on these topics by partners and providers (e.g. the Gambia, Kenya, Tanzania, or Zambia). A preliminary study of the Joint Assistance Strategies of Kenya and Zambia is illustrated below.

96. The Kenya Joint Assistance Strategy (KJAS, 2007-12) provides the basis for the implementation of the government's development strategy, including the country's 2030 Vision. It groups 17 DAC and multilateral providers and serves as a forum to discuss and if necessary formalise the bilateral programmes and agreements with the government. The Strategy recognises that sustained economic growth depends on better environmental management, including of forest ecosystems, wetlands, and semi-arid and arid lands, which contain the key biodiversity habitats; and identifies deforestation and forest degradation as the main causes for the current decline in biodiversity in the country. One key biodiversity-related target of the KJAS is to maintain and safeguard habitat and biodiversity from encroachment and species loss. The KJAS is currently being evaluated by external consultants.

97. The first Joint Assistance Strategy in Zambia (JASZ) is an instrument developed by 16 DAC and multilateral providers to co-ordinate their development assistance and align their activities to the country's national development plans. The Strategy has been reviewed and updated with the introduction of successive national development plans. Among the key priorities identified by the JASZ are the sustainable management of fisheries, forests, land, renewable 
energy and wildlife (IIED, 2009). Additional priorities are: reforming and enhancing the capacity of key government institutions working on the environment; strengthening co-ordination mechanisms; addressing equity and transparency issues in the access and control of natural resources; capturing data on the environment and natural resources sector's contribution to the national economy and in poverty reduction; and assessing the impact of natural resource base degradation on sectors underpinning growth in the country, such as tourism and agriculture (Ministry of Foreign Affairs of Denmark, 2010).

98. The first evaluation of the JASZ concluded that the mechanism led to a more structured process to support the environment in Zambia (Ministry of Foreign Affairs of Denmark, 2010). Information sharing through the JASZ reduced duplication of activities and, where relevant, provided more co-ordinated support to the development of government systems. The dialogue architecture that emerged from the Strategy has made a considerable contribution to encouraging harmonisation. However, the co-operating partners identified generic drawbacks that significantly weakened the Strategy's ability to achieve its objectives (Ministry of Foreign Affairs of Denmark, 2010). For example, the Strategy neither contains specific targets nor does it define indicators against which progress can be measured. A work plan was developed in late 2007 and some elements of this have been implemented but there have been no subsequent work plans and no systematic processes to follow up on the commitments and actions agreed. Also, the government of Zambia was initially neither a signatory to the JASZ nor to the work plan, despite the success of the JASZ depending on government actions and the effective aid principles. Finally, there were doubts regarding the government's leadership and the capacity for the Ministry of Finance and National Planning to manage aid (Ministry of Foreign Affairs of Denmark, 2010). The government has since taken steps to develop a mechanism for taking an effective cross-sector strategic view on development co-operation issues. In important respects, too, existing consultative mechanisms are driven by co-operating partners and often do not respect governmental processes, an issue that would need to be explored in the future. A renewed JASZ II builds on the lessons learned from JASZ I but has not been evaluated yet (Cooperating Partners to the JASZ II, 2011).

99. A final co-ordination instrument is the Informal Donor Meeting (IDM) of the Mekong River Commission (MRC). This instrument groups a dozen DAC providers, including Australia, Denmark, European Union, Finland, Germany, Japan, Sweden, Switzerland, and the United States. The Meeting is helping strengthen relationships between the Commission and the provider community and has fostered transboundary dialogue among riparian countries and other stakeholders, notably in reaching consensus on conducting further study on sustainable management and development of the Mekong River, including the impacts of mainstream hydropower projects. Providers consider the IDM a solid co-ordination instrument, allowing them to "speak with one voice" and facilitating provider contact, information exchange and reporting, which in turn is also appreciated by the MRC (MRC, 2013).

\section{Gaps identified and possible future work}

100. Several avenues for future work have been identified in this section on both alignment and harmonisation. First, further work would be necessary to understand what drives the extent of alignment identified here, and how well provider priorities are integrated (or not) into partner arrangements (in particular the linkages between NBSAPs and National Development Plans). Another area requiring further study would be to consider how these alignment efforts could help achieve other development objectives, such as poverty reduction, in biodiversity-related development activities as more broadly enshrined by the Aichi Targets or the forthcoming Sustainable Development Goals. Additional work could explore the other dimensions of alignment, as well as study how bilateral ODA links with other sources of finance, such as domestic resources, multilateral lending and private sector flows. Second, on harmonisation, further work is necessary to understand whether and how providers formulate the harmonisation principle in their strategies, and how individual projects integrate harmonisation into their interventions. Why and how harmonisation is occurring on the ground is an area for future research, which could focus in particular on how providers jointly could support partner countries 
in reaching the Aichi Biodiversity Targets and, looking forward, on implementing the proposed biodiversity-related Sustainable Development Goals (and the goals where biodiversity has been streamlined), without compromising the need for alignment with national priorities. Finally, further research could usefully consider what makes some of the harmonisation approaches already in practice effective (or not) in the area of biodiversity.

\section{Endnotes Section V}

27. Alignment means that development co-operation providers align behind the objectives of developing country strategies and use local systems.

28. Harmonisation means that providers co-ordinate, simplify procedures and share information to avoid duplication) to their biodiversity-related interventions.

29. With the Global Partnership on Effective Development Co-operation, however, the principle of harmonisation is no longer monitored. 


\section{BIBLIOGRAPHY}

African Development Bank (AfDB) (2004), Revised Guidelines for Bank Group Operations Using Sector-wide Approaches (SWAps), Tunis: AfDB.

African Parks (2014), "Zakouma National Park, Chad", www.african-parks.org/Park 6 Zakouma+National+Park\%2C+Chad.html, last accessed 27 October 2014.

Agence Française du Développement (AFD) (2013), Biodiversity Cross-Sectoral Intervention Framework 2013-2016, http://www.afd.fr/webdav/shared/L AFD/L AFD s engage/documents/2013-08-28-CIT\%20BIODIVERSITY-VA.pdf, last accessed 4 July 2014.

AidData (2014), Tracking Chinese Development Finance to Africa, presentation online, http://aiddata.org/sites/default/files/tuff and china - dfid 02.25.14.pdf, 25 February 2014, accessed 5 June 2014.

The American Heritage $®$ Dictionary of the English Language, Fourth Edition copyright $\odot 2000$ by Houghton Mifflin Company. Updated in 2009. Published by Houghton Mifflin Company. All rights reserved.

Andam, K. S., et al. (2008), "Measuring the Effectiveness of Protected Area Networks in Reducing Deforestation", Proceedings of the National Academy of Sciences 105(42): 16089-94

Aplizar, F. and Bovarnick, A. (2013), Targeted Scenario Analysis - A New Approach to Capturing and Presenting Ecosystem Service Values for Decision Making, UNDP.

Armah, F.A. et al. (2013), "Management of natural resources in a conflicting environment in Ghana: unmasking a messy policy problem", Journal of Environmental Planning and Management, http://dx.doi.org/10.1080/09640568.2013.834247.

Australian Agency for International Development (AuSAID) (2012), Environment Management Guide for Australia's Aid Program 2012 - AusAID's Environment Management System, http://aid.dfat.gov.au/Publications/Pages/22971393 19179648 6600.aspx, last accessed 4 July 2014.

Axford, J. et al. (2008), "What constitutes success in Pacific Island community conserved areas?", Ecology and Society 13(2): 45.

Bandyopadhyay, S. et al. (2009), "Benefits to local communities from community conservancies in Namibia: an assessment", Development Southern Africa 26(5): 733-754.

Barrett, C., Travis, A. and Dasgupta, P. (2011), "On biodiversity conservation and poverty traps", PNAS, Vol. 108, No. 34, pp. 13907-13912.

Billé, R., Lapeyre, R., and Pirard, R. (2012), "Biodiversity conservation and poverty alleviation: a way out of the deadlock?", S.A.P.I.E.N.S, Vol.5, No.1.

Biodiversity Indicators Partnership (BIP), http://www.bipindicators.net/, last accessed 4 August 2014.

Birdsall, N. and Kharas, H. (2014), The Quality of Official Development Assistance (QuODA), Third Edition, Washington D.C.: The Brookings Institution.

Blom, B., Sunderland, T. and Murdiyarso, D. (2010), Getting REDD to work locally: lessons learned from integrated conservation and development projects, Environmental Science Policy, 13 (1): 164-172.

BMU (German Ministry for the Environment, Conservation and Nuclear Safety) and BMZ (German Federal Ministry for Economic Cooperation and Development) (2014), Committed to Biodiversity - Germany's International Cooperation to Implementing the Convention on Biological Diversity for Sustainable Development, published by Deutsche Gesellschaft fur Internationale Zusammenarbeit (GIZ) GmbH, Bonn and Eschborn.

BMU and BMZ (2012), Committed to Biodiversity - Germany's International Cooperation to Implementing the Convention on Biological Diversity for Sustainable Development, published by GIZ GmbH, Bonn and Eschborn. 
BMZ (2008), Strategies of the Federal Ministry for Economic Cooperation and Development: Biological Diversity, Strategy 166, Bonn: BMZ.

Bottrills, M., Hockings, M. and Possingham, H. (2011), In pursuit of knowledge: addressing barriers to effective conservation evaluation, Ecology and Society, 16(1): 14-31.

Bowler, D. et al. (2011), "Does Community Forest Management Provide Global Environmental Benefits and Improve Local Welfare?", Frontiers in Ecology and the Environment 10(1): 29-36.

Butchart, S.H.M. et al. (2010) "Global Biodiversity: Indicators of Recent Declines", Science, 328: 1164-68.

Cardinale et al. (2012), "Biodiversity loss and its impact on humanity", Nature, vol. 486 no. 59.

CBD (2014a), Global Biodiversity Outlook 4, https://s3-ap-northeast-1.amazonaws.com/ap1-www-docs/gbo4/gbo4-en.pdf, last accessed 24 October 2014

CBD (2014b), "High Level Panel on Global Assessment of Resources for Implementing the Strategic Plan for Biodiversity 20112020 - Draft Executive Summary", UNEP/CBD/WGRI/5/INF/8, 5 June 2014, http://www.cbd.int/doc/meetings/wgri/wgri05/information/wgri-05-inf-08-en.pdf, last accessed 7 July 2014.

CBD (2014c), "Strategy for Resource Mobilization: Review of Implementation", UNEP/CBD/WGRI/5/4, 5 May 2014 , http://www.cbd.int/doc/meetings/wgri/wgri-05/official/wgri-05-04-en.pdf, last accessed 8 July 2014.

CBD (2014d), Summary of the Global Monitoring Report on the Implementation of the Strategy for Resource Mobilisation, UNEP/CBD/WGRI/5/INF/4, 10 June 2014, http://www.cbd.int/doc/meetings/wgri/wgri-05/information/wgri-05-inf-04-en.pdf, last accessed 1 July 2014.

CBD (2014e), Strategy for Resource Mobilisation: Review of Goals 2, 5, 6, 7 and 8, UNEP/CBD/WGRI/INF/3, http://www.cbd.int/doc/meetings/wgri/wgri-05/information/wgri-05-inf-03-en.pdf, last accessed 1 July 2014.

CBD (2014f), Biodiversity for Poverty Eradication and Sustainable Development - Draft recommendation submitted by the chair of the Friends of the Chair Group, UNEP/CBD/WGRI/5/L.9, 20 June 2014, available at http://www.cbd.int/wgri5/in-session/, last accessed 10 July 2014.

CBD (2013), "Mainstreaming", presentation from the Global Workshop on Reviewing Progress and Building Capacity for the NBSAP Revision Process, 11-15 November 2013, Nairobi, https://www.cbd.int/doc/nbsap/nbsapcbw-global-01/nbsapnairobi-scbd-mainstreaming.pdf, accessed 15 January 2013.

CBD (2012a), State of Financing for Biodiversity: Draft Global Monitoring Report 2012 on the Strategy for Resource Mobilization under the Convention, UNEP/CBD/COP/11/INF/16, https://www.cbd.int/doc/meetings/cop/cop-11/information/cop-11-inf16-en.pdf, accessed 21 January 2014.

CBD (2012b), Report of the High-Level Panel on Global Assessment of Resources for Implementing the Strategic Plan for Biodiversity 2011-2020, UNEP/CBD/COP/11/INF/20, http://www.cbd.int/doc/meetings/cop/cop-11/information/cop-11-inf20-en.pdf, accessed 21 January 2014.

CBD (2012c), Review of Implementation of the Strategy for Resource Mobilisation, UNEP/CBD/COP/11/14/Add.1, http://www.cbd.int/doc/meetings/cop/cop-11/official/cop-11-14-add1-en.pdf, last accessed 27 March 2014.

CBD (2011) NBSAP training modules version 2.1 - Module 3. Mainstreaming biodiversity into national sectoral and cross-sectoral strategies, policies, plans and programs. Montreal, June 2011.

CBD (2010a), Global Biodiversity Outlook 3 (GBO 3), CBD, Montreal.

CBD (2010b), Strategic Plan for Biodiversity 2011-2020 and the Aichi Targets, CBD, Montreal.

CBD (2009a), Biodiversity, Development and Poverty Alleviation: Recognizing the Role of Biodiversity for Human Well-being, Secretariat of the Convention on Biological Diversity, Montreal. 
CBD (2009b), Connecting Biodiversity and Climate Change Mitigation and Adaptation, Key Messages from the Report of the Second Ad Hoc Technical Expert Group on Biodiversity and Climate Change, CBD, Montreal.

CBD (2006) Biodiversity in EIA and SEA; Background Document to CBD Decision VIII/28: Voluntary Guidelines on Biodiversity Inclusive Impact Assessment; Commission for Environmental Assessment, Netherlands.

CBD (2002b), Annex to the Hague Ministerial Declaration of the Conference of the Parties to the Convention on Biological Diversity, COP 6 Decision VI/21, URL: www.cbd.int/decision/cop/default.shtml?id=7195, accessed 15 January 2014

CBD (Convention on Biological Diversity) (1992), 'Text of Convention'. http://www.cbd.int/convention/text/default.shtml, accessed 21 January 2014.

CEPF (Critical Ecosystems Partnership Fund) (2012), "CEPF Achievements", CEPF, Arlington, VA, USA, http://www.cepf.net/Documents/CEPF Impact web.pdf, last accessed 18 March 2014.

Conservation Finance Alliance (CFA) (2008), Rapid Review of Conservation Trust Funds, Second Edition, Prepared for the CFA Working Group on Environmental Funds by Barry Spergel and Philippe Taïeb, May 2008, http://www.conservation.org/global/gcf/Documents/rapid review.pdf, last accessed 24 March 2014.

Conservation Strategy Fund (CSF) (2014), Biodiversity Understanding in Infrastructure and Landscape Development (BUILD), http://conservation-strategy.org/en/node/1031\#.U-EilPmSxHV, last accessed 5 August 2014.

Centre d'échanges d'informations du Bénin (2014), « Sensibilisation sur les gestes utiles pour la biodiversité et l'eau au Bénin », http://bj.chm-cbd.net/cooperation/coop/cooperation-bilaterale/partenariat-benin-belgique/cooperation-dgfrnirscnb/sensibilisation-sur-les-gestes-utiles-pour-la-biodivesite-et-l-eau-au-benin./, last accessed 2 July 2014.

Centre d'échanges d'informations du Niger (2014), « Projet Sensibilisation des décideurs politiques et acteurs de la biodiversité sur le site de Centre d'Echange d'Informations sur la Diversité Biologique (CHM Niger) », http://ne.chmcbd.net/cooperation/tech coop/projet-sensibilisation-des-decideurs-politiques-et-acteurs-de-la-biodiversite, last accessed 2 July 2014.

CFA (2014), http://conservationfinance.org/, last accessed 18 March 2014.

Conservation Strategy Fund (CSF) (2014a), "Economic Tools for Conservation and Infrastructure Planning in the Albertine Rift", http://conservation-strategy.org/en/course/economic-tools-conservation-and-infrastructure-planning-albertinerift\#.U7q8a mSxHU, last accessed 7 July 2014.

CSF (2014b), Biodiversity Understanding in Infrastructure and Landscape Development (BUILD), http://conservationstrategy.org/en/node/1031\#.U-EilPmSxHV, last accessed 5 August 2014.

Dalal-Clayton, D.B. and Bass, S. (2009) The Challenges of Environmental Mainstreaming. Environmental Governance Series, No.1. International Institute for Environment and Development, London, UK.

Davies, T.E. et al. (2013), "Missing the trees for the wood: Why we are failing to see success in pro-poor conservation", Animal Conservation, 21 November 2013.

Dempsey, J. and Campbell, R. (2006), "A Value-Chain Approach to Coffee Production: Linking Ethiopian Coffee Producers to International Markets", World Report, Spring 2006: Speciality Coffee; Improved Market Linkages and Increased Profits, http://www.acdivoca.org/site/Lookup/WRSpring06-Page5-7-ValueChainCoffee/\$file/WRSpring06-Page5-7ValueChainCoffee.pdf, last accessed 18 March 2014.

Development Initiatives (2013), Investments to End Poverty, Development Initiatives, Bristol, United Kingdom.

Diálogos Setoriais, União Europeia Brasil (n.d.), "Environmental Dimension of Sustainable Development", http://sectordialogues.org/en/acoes-apoiadas/763, last accessed 21 October 2014.

Drakenberg, O. S. Paulsen, J. Andersson, E. Dahlberg, K. Mattsson, E. Wikstrom (2009). "Greening Development Planning: A Review of Country Case Studies for Making the Economic Case for Improved Management of Environment and Natural Resources." Environment Working Paper No. 5. 26 January 2009. OECD Publishing, Paris. 
Doswald, N. et al. (2014), "Effectiveness of ecosystem-based approaches for adaptation: review of the evidence-base", Climate and Development, doi: 10.1080/17565529.2013.867247.

Elmqvist et al. (2010) 'Biodiversity, Ecosystems and Ecosystem Services', in Kumar, P. (ed.) (2010) The Economics of Ecosystems and Biodiversity Ecological and Economic Foundations. London/Washington, D. C.: Earthscan.

Equator Principles, http://www.equator-principles.com/index.php/about-ep/about-ep, last accessed 18 July 2014.

European Commission (2011), "Our life insurance, our natural capital: an EU biodiversity strategy to 2020", Communication from the Commission to the European Parliament, the Council, the Economic and Social Committee and the Committee of the Regions, COM(2011) 244 final, Brussels, 3 May 2011.

European Commission, OECD, United Nations and World Bank (2013), System of Environmental-Economic Accounting 2012 Experimental Ecosystem Accounting, http://unstats.un.org/unsd/envaccounting/eea white cover.pdf, last accessed 18 July 2014.

Esen, E. (2014), personal correspondence, 19 November 2014.

FAO (Food and Agriculture Organisation of the United Nations) (2012), Mainstreaming climate-smart agriculture into a broader landscape approach, background paper for the Second Global Conference on Agriculture, Food Security and Climate Change, www.fao.org/docrep/016/ap402e/ap402e.pdf, last accessed 14 November 2014.

FFEM (2014), Rapport Annuel 2013,

http://www.ffem.fr/webdav/site/ffem/shared/ELEMENTS COMMUNS/U ADMINISTRATEUR/5-

PUBLICATIONS/Rapport\%20annuel/2013/140627\%20RA2013\%20FFEM\%20BD-VF.pdf, last accessed 4 July 2014.

FFEM (Fonds Français pour l'Environnement Mondial) (2012), French Global Environment Facility Annual Report 2012, http://www.ffem.fr/webdav/site/ffem/shared/ELEMENTS COMMUNS/U ADMINISTRATEUR/5PUBLICATIONS/Rapport\%20annuel/2012/RA 2012 FFEM UK WEB.pdf, last accessed 18 March 2014.

Ferraro, P. and Pattanayak, S. (2006). "Money for Nothing? A call for Empirical Evaluation of Biodiversity Conservation Investments", PLos Biology 4(4): e105.

Ferraro, P. et al. (2012), "Forest Figures: Ecosystem Services Valuation and Policy Evaluation in Developing Countries", Review of Environmental Economics and Policy 6(1): 20-44.

Fisher, B. and Christopher, T. (2007) 'Poverty and biodiversity: Measuring the overlap of human poverty and the biodiversity hotspots', Ecological Economics, 62(1): 93-101.

Gardner, C. et al. (2013), "Protected areas for conservation and poverty alleviation: experiences from Madagascar", Journal of Applied Ecology, Vol. 50, pp. 1289-1294.

GEF (2012), Annual Report 2012, GEF, Washington D.C, available at http://www.thegef.org/gef/sites/thegef.org/files/publication/GEF-AR2012.pdf, last accessed 11 February 2014.

GEF (Global Environment Facility) (2010), Annual Report 2010, GEF, Washington D.C., available at http://www.thegef.org/gef/sites/thegef.org/files/publication/WBAnnualReportText.revised.pdf, last accessed 11 February 2014.

GIZ (Deutsche Gesellschaft für Internationale Zusammenarbeit) (2012), Integrating Ecosystem Services into Development Planning - A stepwise approach for practitioners based on the TEEB approach, GIZ and KfW, Bonn and Frankfurt am Main.

GIZ (2010) Biodiversity in German Development Cooperation, http://www2.gtz.de/dokumente/bib-2010/gtz2010-0421enbiodiversity-german-dc.pdf, last accessed 10 October 2014.

Government of Uganda (2013), Preparation of the Joint Water and Environment Sector Support Programme (2013-2018), Final Programme Document, April 2013, Kampala: Ministry of Water and Environment. 
GPPI (2009), ADA Fallstudie WiPas: Lieferkette zum nachhaltigen Kaffeeanbau in Tansania, Berlin: GPPI.

Grant, J.A., Balraj, D. and Mavropoulos-Vagelis, G. (2013), "Reflections on network governance in Africa's forestry sector", Natural Resources Forum, Vol. 37, pp.269-279.

Hannah, L. et al. (2013), "Global Climate Change Adaptation Priorities for Biodiversity and Food Security", PLOS ONE, Vol. 8, No. 8, e72590. doi: 10.1371/journal.pone.0072590.

Harvey, C.A. et al. (2013), "Climate-smart landscapes: opportunities and challenges for integrating adaptation and mitigation in tropical agriculture", Conservation Letters, 00(2013) 1-14.

Herkenrath, P. (2012), Promoting synergies within the cluster of biodiversity-related multilateral environmental agreements Summary report, UNEP World Conservation Monitoring Centre, April 2012.

Hildén, M. (2009), "Time horizons in evaluating environmental policies", New Directions for Evaluation 122: 9-18.

Hirsch et al. (2010), "Acknowledging Conservation trade-Offs and Embracing Complexity", Conservation Biology, Vol. 25, №. 2, pp. 259-264.

Hockings, M. et al. (2006), Evaluating effectiveness: a framework for assessing management effectiveness of protected areas, International Union for Conservation of Nature.

Honey-Rosés, J. et al. (2011), "A Spatially Explicit Estimate of Avoided Forest Loss", Conservation Biology 25(5): 1032-1043.

Huntley, B.J. and Redford, K.H. (2014). 'Mainstreaming biodiversity in Practice: a STAP advisory document'. Global Environment Facility, Washington, DC

IEG (2011), Regional Program Review of the Mesoamerican Biological Corridor, Washington: IEG.

IFC (International Finance Corporation) (2012), "Performance Standard 6 - Biodiversity Conservation and Sustainable management of Living Natural Resources", available at http://www.ifc.org/wps/wcm/connect/bff0a28049a790d6b835faa8c6a8312a/PS6 English 2012.pdf?MOD=AJPERES, last accessed 18 March 2015.

IIED (2008), "Public Environmental Expenditure Review (PEER)", Profiles of Tools and Tactics for Environmental Mainstreaming, www.unpei.org/sites/default/files/dmdocuments/Introduction to PEER IIED.pdf, last accessed 21 October 2014.

IIED and UNEP-WCMC (2014), "Developing a 'business case' for biodiversity - Tips and tasks for influencing government and the private sector", NBSAPs 2.0: Mainstreaming Biodiversity and Development, IIED and UNEP-WCMC, London and Cambridge.

IIED and UNEP-WCMC (2012), Biodiversity Mainstreaming: A rapid diagnostic tool, IIED (International Institute for Environment and Development) and UNEP-WCMC (World Conservation Monitoring Centre), London and Cambridge. Available online at: http://povertyandconservation.info/sites/default/files/Mainstreaming\%20DiagnosticsTool 1.pdf, accessed 15 January 2014.

IIED and UNEP-WCMC (2013a), "Biodiversity and Development Mainstreaming - A State of Knowledge Review: Discussion Paper", NBSAPs 2.0: Mainstreaming Biodiversity and Development, IIED and UNEP-WCMC, London and Cambridge.

IIED and UNEP-WCMC (2013b), "Maun Statement on Biodiversity and Development Mainstreaming", January 2013, NBSAPs 2.0: Mainstreaming Biodiversity and Development, IIED and UNEP-WCMC, London and Cambridge.

IIED and UNEP-WCMC (2013c), "Entebbe Statement on Biodiversity in Development Planning", August 2013, NBSAPs 2.0: Mainstreaming Biodiversity and Development, IIED and UNEP-WCMC, London and Cambridge.

IIED and UNEP-WCMC (2013d), Ten steps to biodiversity mainstreaming - Tips for NBSAPS 2.0 and beyond, IIED and UNEPWCMC, London and Cambridge. 
Ingram, J.C. et al. (2014), "Evidence of Payments for Ecosystem Services as a mechanism for supporting biodiversity conservation and rural livelihoods", Ecosystem Services, Vol. 7, pp.10-21.

International Energy Agency (2013), World Energy Outlook, OECD/IEA, Paris.

IPCC (Intergovernmental Panel on Climate Change) (2007), Contribution of Working Group II to the Fourth Assessment Report of the Intergovernmental Panel on Climate Change, 2007, in M. L. Parry et. al. (eds), Cambridge University Press, Cambridge and New York.

IUCN (2010), Discussion note to accompany IUCN's position paper on the Convention on Biological Diversity (CBD) Strategic Plan 2011-2020: Target 20, Information Paper, IUCN, Gland,http://cmsdata.iucn.org/downloads/cbd cop10 information paper target 20.pdf, accessed 4 February 2014.

IUCN (International Union for the Conservation of Nature) (2008), 2008 IUCN Red List of Threatened Species, IUCN, Gland. www.iucnredlist.org, accessed 21 January 2014.

James, A. (2013), "Saint Lucia's Experiences - Identifying Values of Biodiversity and Integrating them into the Revised NBSAP", presentation from the Global NBSAP Forum, Nairobi, Kenya, 10-16 November 2013

Japanese International Cooperation Agency (JICA) (2010a), Achieving Poverty Alleviation through Biodiversity Conservation JICA's Initiatives and Approach, http://www.jica.go.jp/english/our work/thematic issues/environment/pdf/position paper 01.pdf, last accessed 4 July 2014.

JICA (2010b), "Guidelines for Environmental and Social Considerations", http://www.jica.go.jp/english/our work/social environmental/guideline/pdf/guideline100326.pdf, last accessed 3 July 2014.

Jones, B. (2004), Principles, Processes and Products: Best practices in project design and implementation. Lessons learned from the Living in a Finite Environment Project (LIFE), Namibia 1993-2004, USAID Manuscript.

Joppa, L.N. et al. (2013), "Achieving the Convention on Biological Diversity's Goals for Plant Conservation", Science, 341, 1100, doi: $10.1126 /$ science.1241706.

Joppa, L. and A. Pfaff (2010), "Reassessing the forest impacts of protection: The challenge of non-random location and a corrective method", Annals of the New York Academy of Sciences 1185(2010): 135-149.

Joseph, L. N. et al. (2009), "Optimal allocation of resources among threatened species : a project prioritisation protocol", Conservation Biology 23: 328-338.

Joppa, L. et al. (2008), "On the protection of 'protected areas"', Proceedings of the National Academy of Sciences of the USA 105: 6673.

Kapos, V. et al. (2008), "Calibrating conservation: new tools for measuring success", Conservation Letters 1: 155-164.

Kareiva, P., Chang, A. and Marvier, M. (2008), "Development and Conservation Goals in World Bank Projects", Science, Vol. 321, No. 5896, pp. 1638-1639.

Karin Isaksson, Swedish Development Cooperation Agency (Sida), personal communication to submit examples of Sida's practice, 15 September 2014.

Kennedy, E. T. et al. (2009), "Issues of scale and monitoring status and trends in biodiversity", in M. Birnbaum and P. Mickwitz (Eds.), Environmental Program and Policy Evaluation: Addressing Methodological Challenges, New Directions for Evaluation 122(1): 41-51.

King, K. and Palmer, R. (2007), Skills Development and Poverty Reduction: A State of the Art Review, European Training Forum, Turin.

King, M. (2013), "Green growth and poverty reduction: Policy coherence for pro-poor green growth", OECD Development Cooperation Working Paper, December 2013. 
Lambini, C.K. and Nguyen, T.T (2014), "A comparative analysis of the effects of institutional property rights of forest livelihoods and forest conditions: Evidence from Ghana and Vietnam", Forest Policy and Economics, Vol. 38, Issue C, pp. 178-190.

MA (Millennium Ecosystem Assessment) (2005), Millennium Ecosystem Assessment - Ecosystems and Human Well-being: Synthesis, World Resources Institute, Washington, DC.

Mace, G.M., Norris, K. and Fitter, A.H. (2012), "Biodiversity and ecosystem services: a multi-layered relationship", Trends in Ecology and Evolution, January 2012, Vol. 27 No. 1.

Mangroves for the Future (2014), www.mangrovesforthefuture.org/, last accessed 24 October 2014.

Manzoor Rashid, A.Z.M. et al. (2013), "A journey towards shared governance: Status and prospects for collaborative management in the protected areas of Bangladesh", Journal of Forestry Research, Vol. 24, Issue 3, pp.599-506.

Margoluis, R. et al. (2009), "Using conceptual models as a planning and evaluation tool in conservation", Evaluation and Program Planning 32: 138-147.

McCarthy, D. et al. (2012), "Financial Costs of Meeting Global Biodiversity Conservation Targets: Current Spending and Unmet Needs", Science, Vo. 338, pp.946-949.

McShane, T. et al. (2011), "Hard choices: Making trade-offs between biodiversity conservation and human well-being", Biological Conservation, Vol. 144, pp. 966-972.

Mekong River Commission (MRC) (2013), Report: Informal Donor Meeting, $27-28$ June 2013, Phnom Penh, Cambodia. Available online at: http://www.mrcmekong.org/assets/Publications/governance/Report-IDM-2013-Complete-set-final.pdf

Meriam-Webster Dictionary (2014), Definition of "mainstream", http://www.merriam-webster.com/dictionary/mainstream, last accessed 4 July 2014.

Meta Management et al. (2007), Evaluation of Sector Approaches in Environment: Vietnam Case Study Report, Amsterdam: Meta Management.

Miller, D. (2014), "Explaining Global Patterns of International Aid for Linked Biodiversity Conservation and Development", World Development, Vol. 59, pp. 341-359.

Miller, D., Agrawal, A. and Roberts, J.T. (2013), "Biodiversity Governance, and the Allocation of International Aid for Conservation", Conservation Letters, Vol. 6, pp. 12-20.

Ministry of Foreign Affairs of Finland (2010), Evaluation of Finnish Support to Forestry and Biological Resources: Main Report, Helsinki: Ministry of Foreign Affairs of Finland.

Mohammed, A.J. and Inoue, M. (2014), "Linking outputs and outcomes from devolved forest governance using a Modified ActorPower-Accountability Framework: Case Study from Chilimo forest, Ethiopia", Forest Policy and Economics, Vol. 39, Issue C, pp.21-31.

Miteva, D. A. et al. (2012), "Evaluation of biodiversity policy instruments: what works and what doesn't?", Oxford Review of Economic Policy 28(1): 69-92.

Mueller, M. (2014), personal communication, 6 November 2014.

Munang, R., Andrews, J., Alverson, K., and Mebratu, D. (2014), "Harnessing Ecosystem-based Adaptation To Address the Social Dimensions of Climate Change", Environment: Science and Policy for Sustainable Development, 56:1, 18-24, doi: 10.1080/00139157.2014.861676.

wa Mutu, K. (2014), "Informed land-use decision making with the MARZAN Decision Support Tool", Africa Biodiversity Collaborative Group, 23 July 2014, www.abcg.org/news?article id=19, last accessed 18 March 2015.

Myers, N. et al. (2000), "Biodiversity hotspots for conservation priorities", Nature, Vol. 403, pp. 853-858. 
Norad (2011), Real-time Evaluation of Norway's International Climate and Forest Initiative, Contributions to a Global REDD+ Regime (2007-2010), Oslo: Norad.

OECD (Organisation for Economic Co-operation and Development) (forthcoming), A Stock-take of OECD DAC Members' Reporting Practices on Environment-related Official Development Finance and Reporting to the Rio Conventions, prepared for the OECD DAC Joint ENVIRONET and WP-STAT Task Team on the improvement of the Rio markers, environment and development finance statistics.

OECD (2014), Making Development Co-operation more Effective: 2014 Progress Report, Paris: OECD.

OECD (2013a), Development Co-operation Report 2013: Ending Poverty, OECD Publishing, Paris, http://dx.doi.org/10.1787/dcr2013-en.

OECD (2013b), Scaling-up Finance Mechanisms for Biodiversity, OECD Publishing, Paris, doi: 10.1787/9789264193833-en.

OECD (2013c), Putting Green Growth at the Heart of Development, OECD Publishing, Paris, http://dx.doi.org/10.1787/9789264181144-en.

OECD (2013d), Converged Statistical Reporting Directives for the Creditor Reporting System and the Annual DAC Questionnaire, DCD/DAC(2013)15/FINAL, OECD, Paris.

OECD (2013e), Measuring and Monitoring External Development Finance, OECD and Post 2015 Reflections - Element 11, Paper 1, http://www.oecd.org/dac/Monitoring\%20and\%20measuring\%20external\%20development\%20finance.pdf, accessed 28 August 2014.

OECD (2013f), Evaluating Development Activities: 12 Lessons from the OECD DAC, Paris: OECD.

OECD (2012a), OECD Environmental Outlook to 2050: The Consequences of Inaction, OECD Publishing, Paris, doi: 10.1787/9789264111318-en.

OECD (2012b), Greening Development: Enhancing Capacity for Environmental Management and Governance, OECD Publishing, http://dx.doi.org/10.1787/9789264167896-en.

OECD (2012c), Policy Framework for Policy Coherence for Development, OECD Office of the Secretary General, Unit for Policy Coherence for Development, Working Paper no. 1, 2012.

OECD (2011a), DAC Principles for Evaluation of Development Assistance, Paris: OECD.

OECD (2011b), Aid Effectiveness 2011: Progress in Implementing the Paris Declaration, Paris: OECD.

OECD (2010a), Paying for Biodiversity - Enhancing the Cost-Effectiveness of Payments for Ecosystem Services, OECD Publishing, Paris.

OECD (2010b), Policy Statement on Integrating Biodiversity and Associated Ecosystem Services into Development Co-operation, Development Assistance Committee, DAC Senior Level Meeting, 15 April, 2010, Paris.

OECD (2010c), Strategic Environmental Assessment and Ecosystem Services, DAC Network on Environment and Development Co-operation (ENVIRONET), November 2010, OECD Publishing, Paris.

OECD (2010d), OECD DAC Policy Statement on Integrating Biodiversity and associated ecosystem services into development cooperation, OECD, Paris.

OECD (2009a), Integrating Climate Change Adaptation into Development Co-operation - Policy Guidance, OECD Publishing, Paris.

OECD (2009b), Glossary of Key Terms in Evaluation and Results-based Management, Paris: OECD.

OECD (2008a), Natural Resources and Pro-Poor Growth: The Economics and Politics, DAC Guidelines and Reference Series, OECD Publishing, Paris. 
OECD (2008b), "Is it ODA?", Factsheet - November 2008, http://www.oecd.org/investment/stats/34086975.pdf, accessed 28 August 2014.

OECD (2008c), 2008 Survey Monitoring the Paris Declaration: Making Aid more Effective by 2010, OECD.

OECD (2007), Promoting Pro-Poor Growth: Policy Guidance for Donors, OECD, Paris.

OECD (2006a), Applying Strategic Environmental Assessment: Good Practice Guidance for Development Cooperation, DAC Guidelines and Reference Series, OECD, Paris.

OECD (2006b), Cost-Benefit Analysis and the Environment: Recent Developments, OECD, Paris.

OECD (2006c), Development Co-operation Report 2006: Preliminary Findings from the 2006 Baseline Survey on Monitoring the Paris Declaration, Paris: OECD.

OECD (2001) The DAC Guidelines: Poverty Reduction, OECD, Paris, http://www.oecd.org/development/povertyreduction/2672735.pdf, accessed 24 January 2014.

OECD DAC ENVIRONET (2012), Good Practice Guidance Note 4: How donors can support developing countries to generate greater value and welfare from natural capital, contribution by A. Ruhweza, UNDP, with contributions from DACENVIRONET Members. Draft, 21 November.

OECD DAC Statistics (2014), "Aid to Biodiversity", October 2014, http://www.oecd.org/dac/environment-development/Biodiversityrelated\%20aid\%20Flyer\%20-\%200ctober\%202014\%20FINAL.pdf, accessed 9 October 2014.

Overseas Development Institute (ODI) (2008), Evaluation of Sector-wide approach in environment: Colombia Case Study Report. Characteristics, opportunities, risks and recommendations for taking the experience forward, London: ODI.

Parker, C., Cranford, M., Oakes, N., Leggett, M., ed. (2012), "The Little Biodiversity Finance Book", Global Canopy Programme, Oxford.

Perrings, C. and Halkos, G. (2012), "Who cares about biodiversity? Optimal conservation and transboundary biodiversity externalities", Environmental Resource Economics, Vol 55, pp. 585-608.

Pirard, R., Billé, R. and Sembrés, T. (2010), "Questioning the theory of Payments for Ecosystem Services (PES) in light of emerging experience and plausible developments", Institut du Développement Durable et des Rélations Internationales (IDDRI) Working Paper No. 04/10, June 2010, Paris.

Prip, C., Gross, T., Johnston, S. and Vierros, M. (2010), Biodiversity Planning: an assessment of national biodiversity strategies and action plans", United Nations University Institute of Advanced Studies, Yokohoma.

Pullin, A. S. and T. M. Knight (2009), "Data credibility: a perspective from systematic reviews in environmental management", New Directions for Evaluation 122: 65-74.

REDD+ SES (2012), REDD + Social and Environmental Standards, Version 2, 10 September 2012, http://www.reddstandards.org/files/REDDSES Version 2/REDDSES Version 2 - 10 September 2012.pdf, last accessed 9 March 2015.

Redford, K. H. (2013), Mainstreaming Biodiversity Conservation. A Framing Paper for the Scientific and Technical Advisory Panel of the Global Environment Facility, Archipelago Consulting, Portland. Available at www.stapgef.org/stap/wpcontent/uploads/2013/09/Mainstreaming-Biodiversity-at-GEF-V.-May-13.pdf, accessed 15 January 2014.

Redpath, M. et al. (2013), "Understanding and managing conservation conflicts", Trends in Ecology and Evolution, Vol. 28, No. 2, pp. 100-109.

Rio Declaration on Environment and Development (1992), http://www.unep.org/Documents.multilingual/Default.asp?DocumentID=78\&ArticlelD=1163, last accessed 24 October 2014. 
Ruhweza, A. (2009), Using Trust Funds to Channel Payments for Biodiversity Conservation: Lessons Learned from the Mgahinga and Bwindi Impenetrable Forest Conservation Trust", case study prepared for the WGEAB Workshop on Innovative International Financing for Biodiversity Conservation and Sustainable Use, 2 July 2009, OECD, Paris, http://www.oecd.org/env/resources/43353354.pdf, last accessed 24 March 2014.

Roe, D. et al. (2013a) "Linking biodiversity conservation and poverty reduction: de-polarising the conservation-poverty debate", Conservation Letters, Vol. 6, Issue 3, pp. 162-171.

Roe, D. et al. (2013b), "Assessing the social impacts of conservation policies: rigour versus practicality", IIED Briefing October 2013.

Roe, D., et al. (2011), "Biodiversity and Poverty: Ten Frequently Asked Questions - Ten Policy Implications", Gatekeeper 150, IIED, London.

Roe, D. (2010a). "Linking Biodiversity Conservation and Poverty Alleviation: A State of Knowledge Review", CBD Technical Series 55, Secretariat of the CBD, Montreal. Available at www.cbd.int/doc/publications/cbd-ts-55-en.pdf

Roe, D. (2010b), "Whither Biodiversity in Development? The Integration of Biodiversity in International and National Poverty Reduction Policy", Biodiversity, 11, 1\&2, 13-18.

Royal Belgian Institute of Natural Sciences (RBINS) (2013), Building capacities for biodiversity for sustainable development and poverty reduction - Strategy 2014-2023, April 2013, Brussels, Belgium.

Salafsky, N. (2011), "Integrating development with conservation - A means to a conservation end, or a mean end to conservation?", Biological Conservation, Vol. 144, pp. 973-978.

Sandker, M., Ruiz-Perez, M. and Campbell, B.M. (2012), "Trade-Offs Between Biodiversity Conservation and Economic Development in Five Tropical Forest Landscapes", Environmental Management, Vol. 50, pp. 633-644.

Sayer, J. et al. (2013), "Ten principles for a landscape approach to reconciling agriculture, conservation, and other competing land uses", PNAS, Vol. 110, No. 21, pp. 8349-8356.

System for Environmental-Economic Accounting (SEEA) (n.d.), System of Environmental-Economic Accounting - Measurement Framework in Support of Sustainable Development and Green Economy Policy, http://unstats.un.org/unsd/envaccounting/Brochure.pdf, last accessed 14 November 2014.

Sida (Swedish International Development Co-operation Agency) (2004), "Sida's Environmental Management System", http://www.sida.se/contentassets/d98acab07fba4d3ea6608530ac757ac5/sidas-environmental-managementsystem 1297.pdf, last accessed 18 March 2015.

Smith, R. (2013), "Ecosystem Services and the Macroeconomy: A Review of Linkages and Evaluation of Analytical Tools", Ecosystem Services Economics (ESE) Working Paper Series 20, http:/lesevaluation.org/A\%20Review\%20of\%20Linkages\%20and\%20Evaluation\%20f\%20Analytical\%20Tools.pdf, last accessed 4 July 2014.

Smith, S., Bass, B. and Craeynest, L. (2008), "Curbing UK impacts on global biodiversity: an agenda for action", Sustainable Development Opinion, International Institute for Sustainable Development, May 2008, http://pubs.iied.org/pdfs/17036IIED.pdf, accessed 9 March 2015.

Smith, T. (2012), Revised draft of the Good Practice Guidance Note 2: Governance and Green Growth for Poverty Reduction, DAC ENVIRONET Task Team on Green Growth and Poverty Reduction, paper presented at the $5^{\text {th }}$ Meeting of DAC ENVIRONET, 21 November 2012, OECD Conference Centre, Paris.

Sobrevila, C. (2008), The Role of Indigenous Peoples in Biodiversity Conservation - The Natural but Often Forgotten Partners, The World Bank, Washington D.C.

Steffen, W. et al. (2011), "The Anthropocene: conceptual and historical perspectives", Philosophical Transactions of the Royal Society, 369, pp. 842-867. doi: 10.1098/rsta.2010.0327 
Stem, C. et al (2014), "Understanding Biodiversity - Development Integration Efforts and Opportunities", prepared for the United States Agency for International Development by Environmental Incentives, LLC, Foundations of Success and ICF International, March 2014.

Tayleur, J. (2015), personal correspondence, 9 March 2015.

TEEB (The Economics of Ecosystems and Biodiversity) (2010a), The Economics of Ecosystems and Biodiversity: Mainstreaming the Economics of Nature: A Synthesis of the Approach, Conclusions and Recommendations of TEEB, TEEB, United Nations Environment Programme, Geneva.

TEEB (2010b), TEEB for Local and Regional Policy Makers, TEEB, United Nations Environment Programme, Geneva.

TEEB (2009), "Rewarding Benefits Through Payments and Markets", The Economics of Ecosystems and Biodiversity for National and International Policy Makers, TEEB, UNEP, Geneva.

Thomas, J. (2014), "Workshop Report - Third International Workshop of the NBSAPs 2.0 Mainstreaming Biodiversity and Development project", http://pubs.iied.org/pdfs/G03827.pdf? , last accessed 28 October 2014.

Turner, W. et al. (2012), "Global Biodiversity Conservation and the Alleviation of Poverty, BioScience, Vol. 62, No. 1, pp. 85-92.

UN (United Nations) (2014), Millennium Development Goals Report 2014, http://www.un.org/millenniumgoals/2014\%20MDG\%20report/MDG\%202014\%20English\%20web.pdf, last accessed 19 November 2014.

UNGA (United Nations General Assembly) (2014), Outcome document of the high-level plenary meeting of the General Assembly known as the World Conference on Indigenous Peoples, A/RES/69/2, 25 September 2014.

UNDP (United Nations Development Programme) (2014), The Biodiversity Finance Initiative - An overview and key progress summary, information document, UNEP/CBD/WGRI/5/INF/13, 10 June 2014, http://www.cbd.int/doc/meetings/wgri/wgri05/information/wgri-05-inf-13-en.pdf, last accessed 1 July 2014.

UNDP (2013a), "Integrating Biodiversity into Development and Poverty Plans - An Overview", presentation from the Global Workshop on Reviewing Progress and Building Capacity for the NBSAP Revision Process, 11-15 November 2013, Nairobi, https://www.cbd.int/doc/nbsap/nbsapcbw-global-01/nbsap-nairobi-undp-02-en.pdf, last accessed 15 January 2014.

UNDP (2013b), "Transforming Biodiversity Finance: The Biodiversity Finance (BIOFIN) Workbook for assessing and mobilizing financial resources to achieve the Aichi Targets and to implement National Biodiversity Strategies and Action Plans", Version 3.0 Draft for Distribution, June 4, 2013.

UNDP (2012), The Future We Want: Biodiversity and Ecosystems-Driving Sustainable Development. United Nations Development Programme Biodiversity and Ecosystems Global Framework 2012-2020, New York.

UNDP and UNEP (2013), The Poverty and Environment Initiative, http://www.unpei.org/, last accessed 28 October 2014.

UNDP and UNEP (2009a), Mainstreaming Poverty-Environment Linkages into Development Planning: A Handbook for Practitioners, UNDP-UNEP Poverty Environment Initiative, http://www.unpei.org/sites/default/files/dmdocuments/PE|\%20Full\%20handbook.pdf, last accessed 4 July 2014.

UNDP and UNEP (2009b), Making the Economic Case: A Primer on the Economic Arguments for Mainstreaming PovertyEnvironment Linkages into Development Planning, UNDP-UNEP Poverty Environment Initiative, http://www.unpei.org/sites/default/files/PDF/primer-complete-LR.pdf, last accessed 4 July 2014.

UNEP (United Nations Environment Programme) (2014a), Integrating Ecosystem Services in Strategic Environmental Assessment: A guide for practitioners, A report of Proecoserv, Geneletti, D.

UNEP (2014b), Project for Ecosystem Services (ProEcoServ), http://www.proecoserv.orgl, last accessed 16 July 2014.

UNEP (2007), Global Environmental Outlook 4: Environment for Development, UNEP, Nairobi. 
UNEP-WCMC and IEEP (Institute for European Environmental Policy) (2013), "Incorporating Biodiversity and Ecosystem Services Values into NBSAPs - Guidance to Support NBSAP Practitioners", UNEP-WCMC and IEEP, available at http://www.unep-wcmc.org/guidance-for-incoporating-biodiversity-and-ecosystem-service-values-into-nbsaps 1026.html, last accessed 18 March 2014.

UNGA (United Nations General Assembly) (2012), "The Future We Want - Outcome Document", A/RES/66/288, 123rd Plenary Meeting, 27 July 2012, New York. Available at http://www.un.org/ga/search/view doc.asp?symbol=A/RES/66/288\&Lang=E, accessed 14 January 2014.

UN (United Nations) (2013), "Goal 7 - Ensure Environmental Sustainability: Fact Sheet 2013", United Nations Millennium Development Goals, available at http://www.un.org/millenniumgoals/pdf/Goal 7 fs.pdf, last accessed 7 February 2014.

UN (2010), "The Millennium Development Goals Report 2010", United Nations, available at http://www.un.org/millenniumgoals/pdf/MDG\%20Report\%202010\%20En\%20r15\%20-low\%20res\%2020100615\%20-.pdf, last accessed 19 May 2014.

USAID (United States Agency for International Development) (2014), "USAID's Biodiversity Policy", http://www.usaid.gov/sites/default/files/documents/1865/USAID\%20Biodiversity\%20Policy.pdf, last accessed 18 July 2014.

USAID (2013), "ADS Chapter 2014 - Environmental Procedures", The Automated Directives System (ADS), http://www.usaid.gov/sites/default/files/documents/1865/204.pdf, last accessed 18 March 2015.

Van Noordwijk, M. and Leimona, B. (2010), "Principles for Fairness and Efficiency in Enhancing Enviromental Services in Asia: Payments, Compensation, or Co-Investment?", Ecology and Society 15(4): 17.

Vaz, J. and Agama, A.L. (2013), "Seeking synergy between community and state-based governance for biodiversity conservation: The role of indigenous and community-conserved areas in Sabah, Malaysian Borneo", Asia Pacific Viewpoint, Vo. 54, Issue 2, August 2013.

Vincent, J. R. (2010), "Microeconomic Analysis of Innovative Environmental Programs in Developing Countries", Review of Environmental Economics and Policy 4(2): 221-33.

Waldron, A. et al. (2013), "Targeting global conservation funding to limit immediate biodiversity declines", PNAS, Vol. 110, No. 29, pp. 12144-12148.

Wealth Accounting and the Valuation of Ecosystem Services (WAVES) (2014), Philippines, https://www.wavespartnership.org/en/philippines, last accessed 24 October 2014.

Weber, J. et al. (2011), "Do ICDPs Work? An Empirical Evaluation of Forest-Based Microenterprises in the Brazilian Amazon", Land Economics 87(4): 645-681.

White (2009): International Initiative for Impact Evaluation Working Paper 3: "Theory-Based Impact Evaluation: Principles and Practice", June.

World Bank (2012), Expanding Financing for Biodiversity Conservation - Experiences from Latin America and the Caribbean, Environment \& Water Resources Occasional Paper Series, World Bank, Washington, http://www.worldbank.org/content/dam/Worldbank/document/LAC-Biodiversity-Finance.pdf, last accessed 25 March 2014.

World Bank (2006), Where is the wealth of nations? Measuring capital for the $21^{\text {st }}$ Century, World Bank: Washington DC.

World Bank (2004), Do Households Gain from Community-based Natural Resource Management? An Evaluation of Community Conservancies in Namibia, Washington DC: World Bank Group.

World Health Organisation (WHO) (2014), "Climate change and human health - biodiversity", http://www.who.int/globalchange/ecosystems/biodiversity/en/, last accessed 24 October 2014.

WRI (2008), Ecosystem Services - A Guide for Decision Makers, WRI, Washington DC. 
World Resources Institute (WRI) et al. (2007), Nature's Benefits in Kenya, An Atlas of Ecosystems and Human Well-Being. Washington, DC and Nairobi: World Resources Institute.

Wunder, S. and Borner, J. (2013), "Payments for Environmental Services: Conservation with Pro-Poor Benefits", in Roe et al. (eds), Biodiversity Conservation and Poverty Alleviation, Exploring the Evidence for a Link. Wiley Blackwell, in association with ZSL, Oxford.

Wunder, S., Engel, S. and Pagiola, S. (2008), "Taking stock: A comparative analysis of payments for environmental service programs in developed and developing countries", Ecological Economics, Vol. 65 pp. 834-852.

Wunder, S. (2005), "Payments for environmental services: some nuts and bolts", Occasional Paper No. 42, Bogor, CIFOR.

WWF (World Wildlife Fund) (2012), "Governments make good progress on marine, slow on finance at Hyderbad biodiversity meet", http://wwt.panda.org/?206503/Governmentsmakegoodprogressonmarineshow, last accessed 14 February 2014.

WWF (2008), The 2010 Biodiversity Target in EU Development Co-operation: "Halting the Loss of Biodiversity by 2020" A critical challenge for EU external development, Brussels: WWF.

\section{ANNEX 1. BIODIVERSITY-RELATED EVALUATIONS CONSULTED}

Austria: 2009 Evaluation of the project on "Sustainable coffee production and processing coupled with income diversification in Mbeya and Mbozi District in Tanzania."

Denmark: 2010 Evaluation of Programmatic Approaches to Support for the Environment in Africa (1996-2009).

Finland: 2010 Evaluation of Finnish Support to Forestry and Biological Resources (Main Report).

France: 2011 Evaluation of Projects to Support the Management of National Parcs in Morocco.

Norway: 2011 Real-time Evaluation of Norway's International Climate and Forest Initiative, Contributions to a Global REDD+ Regime (20072010).

Spain: 2007 Evaluation of the ARAUCARIA Programme for biodiversity conservation and sustainable development in Latin America.

Switzerland: 2009 Evaluation of SDC's contribution towards biodiversity: impact in the Andean region.

United States: Principles, Processes and Products: Best practices in project design and implementation. Lessons learned from the Living in a Finite Environment Project (LIFE), Namibia 1993-2004.

World Bank: 2011 Regional Program Review of the Mesoamerican Biological Corridor.

These evaluations are available online at the DAC Evaluation Resource Centre. For further information see http://www.oecd.org/derec. 


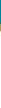

